Rehabilitation Research and Training Center for Economic Research on Employment Policy for Persons with Disabilities

\title{
The Economics of Policies and Programs Affecting the Employment of People with Disabilities
}

Prepared by:

Cornell University

The Lewin Group

Gina A. Livermore

David C. Stapleton

Mark W. Nowak

David C. Wittenburg

Elizabeth D. Eiseman 
For further information about this paper contact:

Gina Livermore, Ph.D., Vice President, The Lewin Group

3130 Fairview Park Drive, Suite 800, Falls Church, VA 22042

tel: (703) 269-5561 fax: (703)269-5503

e-mail: gina.livermore@lewin.com web:www.lewin.com

This paper is being distributed by Rehabilitation Research and Training Center for Economic Research on Employment Policy for Persons with Disabilities at Cornell University.

This center is funded to Cornell University, in collaboration with The Lewin Group (Falls Church, VA), by the U.S. Department of Education, National Institute on Disability and Rehabilitation Research (Grant No. H133в980038).

This research and training effort is an across college effort at Cornell University between the Program on Employment and Disability in the Extension Division of the School of Industrial and Labor Relations, and the Department of Policy Analysis and Management in the College of Human Ecology. The Lewin Group is an internationally recognized research and consulting firm specializing in health and human services policy and management.

The Co-Principal Investigators are:

Susanne M. Bruyère-Director, Program on Employment and Disability, ILR Extension, Cornell University

Richard V. Burkhauser-Sarah Gibson Blanding Professor and Chair, Department of Policy Analysis and Management, College of Human Ecology, Cornell University

David C. Stapleton-Senior Vice President and Director of Applied Economics with The Lewin Group 


\section{The Economics of Policies and Programs Affecting the Employment of People with Disabilities}

Prepared by:

\section{Cornell University \\ The Lewin Group}

Gina A. Livermore

David C. Stapleton

Mark W. Nowak

David C. Wittenburg

Elizabeth D. Eiseman

March 2000

For more information on the

Cornell RRTC contact:

Susanne Bruyère, Ph.D.

Project Director

Cornell University

106 ILR Extension Building

Ithaca, NY 14853-3901

Tel (607) 255-7727

Fax (607) 255-2763

TDD (607) 255-2891

emailssmb23@cornell.edu

web www.ilr.cornell.edu/rrtc
Send comments on paper to:

Gina Livermore, Ph.D.

Vice President

The Lewin Group

3130 Fairview Park Drive, Suite 800

Falls Church, VA 22042

Tel (703) 269-5561

Fax (703) 269-5503

email gina.livermore@lewin.com web www.lewin.com 


\section{The Economics of Policies ANd Programs Affecting the EMPLOYMENT OF PEOPLE WITH DISABILITIES}

\section{CONTENTS}

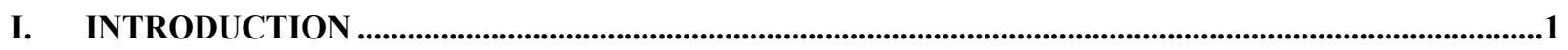

II. AN ECONOMIC MODEL OF LABOR FORCE PARTICIPATION …....................................................

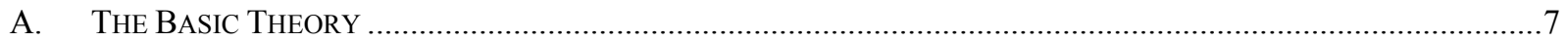

B. APPLYING THE BASIC THEORY TO PEOPLE WITH DiSABILITIES .............................................................

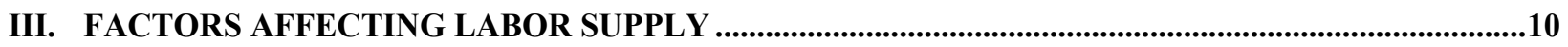

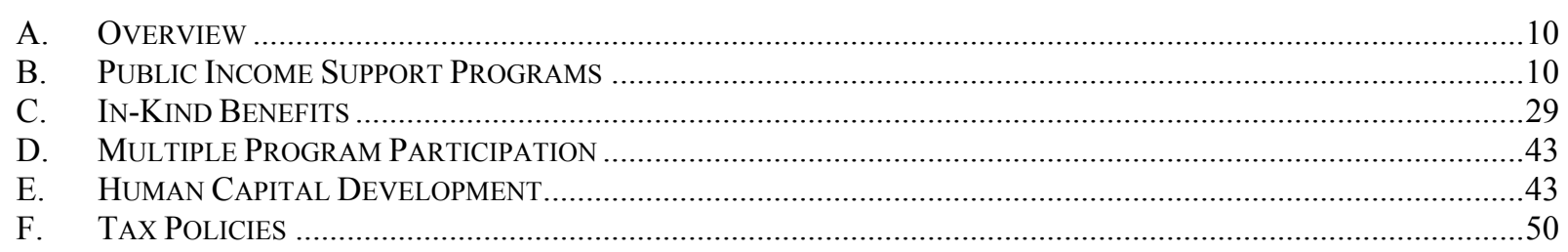

IV. FACTORS AFFECTING EMPLOYER DEMAND AND USE OF HUMAN RESOURCES .....................52

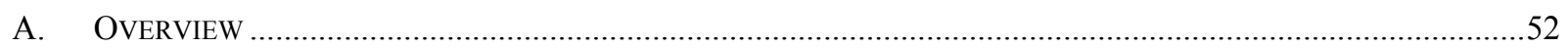

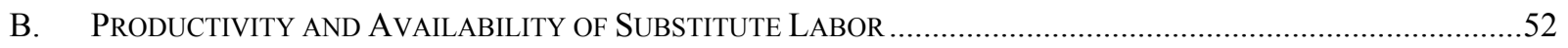

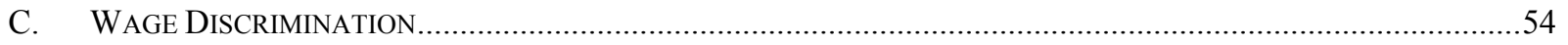

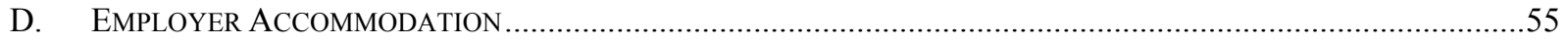

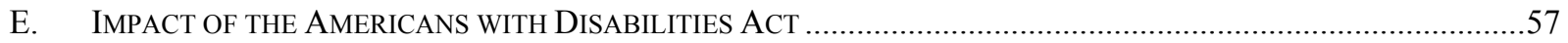

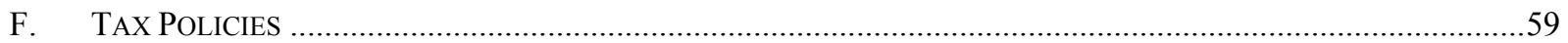

V. FACTORS AFFECTING JOB - EMPLOYEE MATCHING …...........................................................60

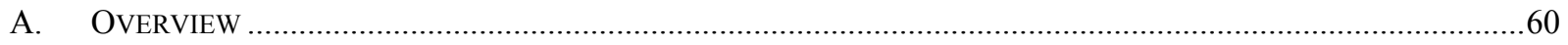

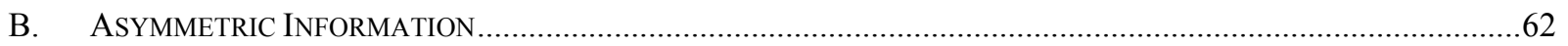

C. TRANSITIONAL InCOME ASSISTANCE AND INCOME SUPPORT PROGRAMS..................................................63

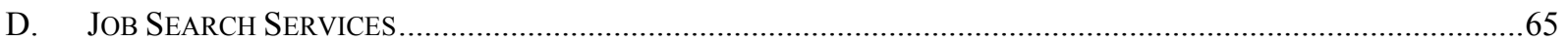

VI. RECENT POLICIES AND INITIATIVES DESIGNED TO PROMOTE THE EMPLOYMENT OF

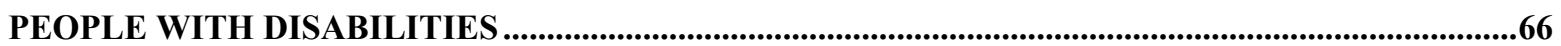

A. Presidential TaSk Force ON EMPloyment of AdUlts with Disabilities...............................................66

B. Department of Labor OfFice on Disability Policy, EValuation, and TeChNical Assistance ........67

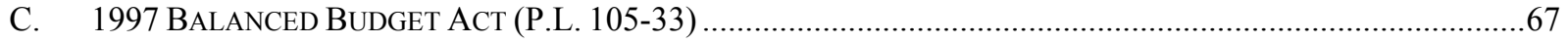

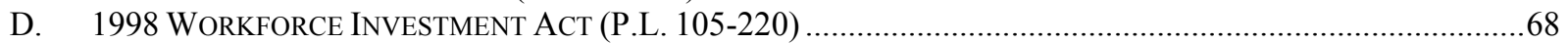

E. 1999 TICKET TO WORK AND WORK INCENTIVE IMPROVEMENT ACT (P.L. 106-170) .........................................70

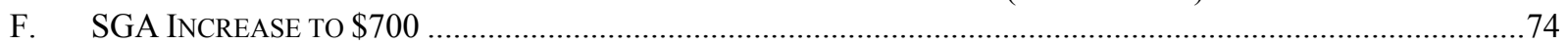

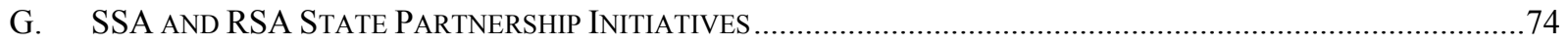

H. SSA DEMONSTRATION ON THE TREATMENT OF AFFECTIVE DISORDERS ….................................................74

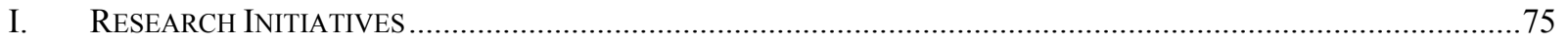

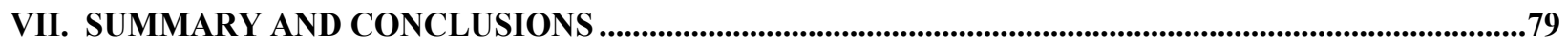

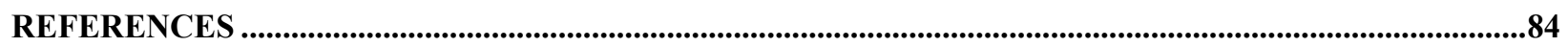




\section{Introduction}

Over the last several decades, there has been a movement toward the inclusion of people with disabilities in mainstream social institutions. The 1990 Americans with Disabilities Act (ADA), which supports the full participation of people with disabilities in society and mainstream institutions, illustrates the shift in attitudes toward people with disabilities. Rather than being perceived as having a social or medical problem, individuals with disabilities are increasingly viewed as people with challenges that can be solved if appropriate policies and supports are available for addressing them.

One important activity to which people with disabilities have sought greater access is competitive employment. Increased employment and better jobs for people with disabilities, as for all people, can lead to greater economic well-being, improved emotional and physical wellbeing, and greater self-sufficiency. Market work is the principal source of income in all modern societies and is key to financial independence. For many, employment and contributing to family and societal productivity is an important component of self-worth and self-esteem. For all of these reasons, people with disabilities, like most individuals, desire the opportunity to work. According to one study, among working-age people with disabilities who were not working, $72 \%$ indicated that they would prefer to work (Louis Harris, 1998).

People with minor or major disabilities represent a significant proportion of the U.S. workingage population. Based on the 1993 Survey of Income and Program Participation (SIPP), approximately 30 million (19\%) of men and women age 18 to 64 report some type of physical or mental limitation. For approximately $55 \%$ of these individuals (about $10 \%$ of those age 18 to 64), the limitations are severe (Stapleton et al., 1998).

Despite the potential benefits of employment and an apparent desire to work on the part of people with disabilities, the employment and earnings of people with disabilities, as a group, have remained low. People with disabilities are less likely to be employed than people without disabilities (Stoddard et al., 1998), and when employed, are likely to have less job experience than people without disabilities (Yelin and Katz, 1994b). In addition, individuals with disabilities might be more likely to encounter employment discrimination than persons without disabilities (Louis Harris, 1987). For these and other reasons, the incomes of persons with disabilities tend to be lower than the incomes of those without physical or mental impairments (Acemoglu and Angrist, 1998). Even during times of economic expansion, people with disabilities remain at a disadvantage relative to the general population. Between 1989 and 1997, while the median incomes (in 1998 dollars) of both men and women without disabilities increased, the median incomes of both men and women with disabilities declined (Burkhauser, Daly, and Houtenville, 1999).

Because people with disabilities have disproportionately low incomes, many rely heavily on two major income support programs - Social Security Disability Insurance (DI) and Supplemental Security Income (SSI). Over the last decade, the number of people with disabilities participating in these programs has been rising. During the period from 1990 to 1999 , the number of workers with disabilities receiving monthly DI payments increased from 3.01 million to 4.78 million, and benefits paid to these individuals increased from $\$ 1.77$ billion to $\$ 3.51$ billion monthly. During 
this same period, the number of persons receiving SSI payments rose from 4.81 million to 6.61 million, with State and Federal benefits totaling \$1.44 billion to \$2.34 billion (SSA, 1999a).

There is substantial interest in identifying and implementing policies and programs that will facilitate the commencement of and/or return to employment for persons with disabilities. In 1998, a Presidential Executive Order created the National Task Force on Employment of Adults with Disabilities (Task Force). The Task Force was established to create a coordinated and aggressive national policy to bring adults with disabilities into gainful employment at a rate that is as close as possible to that of the general population.

Both independently and in connection with the Task Force, a number of recent efforts and policies have been initiated to assist persons with disabilities to secure and retain employment. Many of these new policies and initiatives are modifications to existing programs and policies that have historically created disincentives for employment among people with disabilities. A myriad of programs and policies currently exists that creates, as well as reduces, barriers to employment for people with disabilities. The purpose of this paper is to describe the many factors that affect employment decisions, focusing on the public programs and government policies that influence the employment of people with disabilities. A second purpose of this paper is to assess the likely impact of important recent policies and initiatives on the work behavior of people with disabilities.

In describing the factors that affect the employment behavior of people with disabilities and assessing the likely effects of recent policies, we apply a general model of the labor market. Specifically, we:

- Describe an economic model of the employment decisions of people with disabilities (labor supply) and the hiring decisions of employers (labor demand) with respect to job candidates with disabilities;

- In the context of the economic model, briefly describe the major factors affecting work behavior and employment decisions, what is known about the importance of each factor, and the existing public programs and policies of relevance to each factor;

- Describe recent policies and new initiatives designed to promote employment and their potential effect on the employment of people with disabilities; and

- Discuss several key public policy issues identified in our review of programs and policies affecting the employment of people with disabilities.

There are numerous public programs and policies that are likely to affect the labor supply of and demand for people with disabilities, both positively and negatively. In Exhibit 1, we provide an overview of the specific government programs and policies that are described in this review. 


\section{Exhibit 1}

Public Programs and Policies Affecting the Employment of People with Disabilities

PROGRAM / POLICY / INITIATIVE DESCRIPTION

TARGET POPULATION

Labor Supply

Public Income Support Programs

Social Security Disability Insurance (DI)

Program to insure workers against loss of income because of disability. Payments are based on individuals' lifetime average earnings covered by Social Security.

Supplemental Security Income (SSI)

Means-tested program to provide monthly cash income to people age 65 and older and those under 65 who are blind and disabled.

Workers' Compensation

Cash payments, rehabilitation services, and medical benefits provided by employers to workers who suffer work-related injuries or diseases.

Programs including disability compensation payments and veterans pensions that provide

Veterans Administration Programs payments to people aged 65 or older or under 65 and disabled who served in the military.

Temporary Assistance for Needy Families Program that provides time-limited cash benefits to needy families with children.

\section{In-Kind Benefits}

Medicare

Public health insurance program for individuals age 65 and over and persons with disabilities participating in the DI program. The program provides both hospital coverage (Part A) and supplementary medical insurance (Part B)

Medicaid

Federal-State matching entitlement program that provides medical assistance primarily to low-income and otherwise needy individuals, including persons with disabilities. Eligibility might be linked to SSI or TANF.

Provides grants to states that may be used to provide AT devices to individuals as well as to increase public awareness of available AT.

Assistive Technology Act of 1998

Increase the food purchasing power of low-income households by subsidizing food purchases

Food Stamps

through coupons that can be used like cash at the grocery store.

Low-Income Home Energy Assistance

Program (LIHEAP)

Makes grants available to states and other jurisdictions to assist eligible households to meet the costs of home energy.

Combines the Section 8 Voucher and Section 8 Certificate programs, providing housing

The Housing Choice Voucher Program assistance payments to participating owners on behalf of eligible tenants.

Supportive Housing for Persons with

Disabilities

Provides interest-free capital advances to nonprofit organizations to build, rehabilitate, or purchase rental housing to be used as supportive housing for persons with disabilities.

Disabled adults with sufficient DI-

covered earnings history.

People age 65 and older, blind,

and people with disabilities of any

age with limited income.

People who suffer work-related injuries and diseases.

Veterans of military service who

are over 65 or disabled.

Low-income families with children.

People age 65 and older, DI

beneficiaries, and former

beneficiaries who are working.

Low-income children and pregnant

women, adults in families with

dependent children, people with

disabilities, and the elderly.

Disabled people in need of AT devices.

Low-income households.

Low-income households.

Low-income households.

Persons with physical or menta

disabilities. 
Exhibit 1-continued

Public Programs and Policies Affecting the Employment of People with Disabilities

\begin{tabular}{|c|c|c|}
\hline PROGRAM / POLICY / INITIATIVE & DESCRIPTION & TARGET POPULATION \\
\hline \multicolumn{3}{|l|}{ Labor Supply } \\
\hline \multicolumn{3}{|l|}{ Human Capital Development } \\
\hline Individuals with Disabilities Education Act & $\begin{array}{l}\text { Requires states to provide free and appropriate public education for students with disabilities } \\
\text { at the elementary and secondary level. }\end{array}$ & $\begin{array}{l}\text { Children and young adults with } \\
\text { disabilities. }\end{array}$ \\
\hline State Vocational Rehabilitation & $\begin{array}{l}\text { A Federal-State program intended to help people with physical and mental impairments to } \\
\text { work by providing services including medical and therapeutic services, counseling, education, } \\
\text { training, and job placement assistance. }\end{array}$ & $\begin{array}{l}\text { Adults with physical or mental } \\
\text { impairments who are able to } \\
\text { benefit from VR services. }\end{array}$ \\
\hline Veteran Vocational Rehabilitation & A program similar to the state VR program that provides services exclusively to veterans. & $\begin{array}{l}\text { Veterans with service-related } \\
\text { disabilities. }\end{array}$ \\
\hline $\begin{array}{l}\text { State Workforce Development Systems } \\
\text { (Workforce Investment Act of 1998) }\end{array}$ & $\begin{array}{l}\text { Program mandated by the Workforce Investment Act of } 1998 \text { that requires states to integrate } \\
\text { job training, adult education and literacy, and VR programs into a one-stop delivery system. }\end{array}$ & $\begin{array}{l}\text { All adults, youth who meet state- } \\
\text { determined criteria. }\end{array}$ \\
\hline Independent Living Programs & $\begin{array}{l}\text { Provides grants to states and nonprofit organizations to establish and support centers for } \\
\text { independent living, which provide independent living skills training, peer counseling, } \\
\text { community outreach, and employment services. }\end{array}$ & People with significant disabilities. \\
\hline Projects with Industry Program & $\begin{array}{l}\text { Program that facilitates job placement for people with disabilities emphasizing job training in } \\
\text { work settings. Encourages partnerships among business, industry, labor, and the } \\
\text { rehabilitation community. }\end{array}$ & Adults with disabilities. \\
\hline \multicolumn{3}{|l|}{ Tax Policies } \\
\hline $\begin{array}{l}\text { Income Exemption of Flexible Healthcare } \\
\text { Spending Accounts }\end{array}$ & $\begin{array}{l}\text { A benefit that employers might offer and that allows employees to exclude up to } \$ 3,600 \text { per } \\
\text { year of their healthcare expenses from their taxable income. }\end{array}$ & $\begin{array}{l}\text { All employees of firms that offer the } \\
\text { benefit. }\end{array}$ \\
\hline Itemized Deduction of IRWEs & $\begin{array}{l}\text { Allows people with disabilities who work to deduct the cost of impairment-related work } \\
\text { expenses (IRWE) from their taxable income. }\end{array}$ & $\begin{array}{l}\text { Persons with physical or mental } \\
\text { disabilities that limit ability to work. }\end{array}$ \\
\hline Earned Income Tax Credit & $\begin{array}{l}\text { Supplements the earnings of low-income workers by providing them with a refundable income } \\
\text { tax credit. }\end{array}$ & Low-income individuals. \\
\hline \multicolumn{3}{|l|}{ Labor Demand } \\
\hline Americans with Disabilities Act of 1990 & $\begin{array}{l}\text { Prohibits job-related discrimination against people with disabilities and requires employers to } \\
\text { provide "reasonable accommodations" which might include personal assistance services or } \\
\text { AT devices. }\end{array}$ & All people with disabilities. \\
\hline \multicolumn{3}{|c|}{ m } \\
\hline Section 190 Tax Deduction & $\begin{array}{l}\text { Allows businesses to deduct expenses related to removing impediments to persons with } \\
\text { disabilities from their place of business. }\end{array}$ & All businesses. \\
\hline Section 44 Tax Credit & $\begin{array}{l}\text { Tax credit intended to help cover the expenses incurred by small businesses to provide } \\
\text { access to people with disabilities. }\end{array}$ & Small businesses. \\
\hline Work Opportunity Tax Credit & $\begin{array}{l}\text { Provides employers a tax credit equal to } 35 \% \text { of the wages of certain groups, including } \\
\text { people with disabilities. }\end{array}$ & $\begin{array}{l}\text { Employers of targeted groups } \\
\text { including people with disabilities. }\end{array}$ \\
\hline
\end{tabular}


Exhibit 1-continued

Public Programs and Policies Affecting the Employment of People with Disabilities

PROGRAM / POLICY / INITIATIVE DESCRIPTION

TARGET POPULATION

Job - Employee Matching

Americans with Disabilities Act

See above.

Unemployment Insurance

Temporary Assistance for Needy Families

Social Security Disability Insurance

Supplemental Security Income

Workforce Investment Act

\begin{tabular}{l|l} 
Project ABLE & disabilities.
\end{tabular}

Provides temporary benefits to workers, based on their earnings before unemployment, who have recently lost their jobs.

See above.

See above.

See above.

See above.

nk established specifically to match jobs to appropriately qualified people with

disabilities.

Recent Policies and Initiatives to Promote the Employment of People with Disabilities

Task Force on Employment of Adults with $\quad$ Task force instituted to create a coordinated national policy to increase the employment of

Disabilities

Department of Labor Office on Disability people with disabilities.

Policy, Evaluation and Technical

Assistance

Office charged with increasing the employment rate of people with disabilities. The Office will

be headed by an assistant secretary and will absorb the President's Committee on the

Employment of People with Disabilities.

Balanced Budget Act of 1997

Gives states the option of allowing people with disabilities with incomes of up to $250 \%$ of the

Federal poverty guideline to buy-in to Medicaid if they are not otherwise eligible.

This recently passed Act is intended to decrease disincentives to work related to the SSI and

DI programs. Provisions include the Ticket to Work program, which provides vouchers for

rehabilitation and employment services, expanded Medicaid and extended Medicare

eligibility, improved work incentives outreach to disseminate accurate information to

Ticket to Work and Work Incentives

Improvement Act of 1999

beneficiaries, a demonstration to study the effect of changing the DI benefits schedule, and

the elimination of other work disincentives.

The change in the definition of substantial gainful activity from $\$ 500$ to $\$ 700$ is intended to

SGA Increase to $\$ 700$

facilitate meaningful work among beneficiaries by reducing the chance that return-to-work efforts will cause the immediate loss of cash benefits.

Grants to states to improve coordination of services and programming for people with

disabilities preparing to enter (or reenter) the workforce.

SSA and RSA State Partnership Initiatives

Demonstration project to study the effectiveness of providing improved access to quality

SSA Affective Disorders Demonstration

treatment for affective disorders to DI beneficiaries who receive DI because of affective disorders.

SSA National Study of Health and Activity

SSA-sponsored study to better understand the relationship between disability and work,

family, community, and access to healthcare. Approximately 10,000 people with impairments

will be interviewed.

See above.

Recently unemployed workers

See above.

See above.

See above.

See above.

Adults with disabilities who are

"job-ready."

All people with disabilities.

All people with disabilities.

Low-income workers with

disabilities.

Primarily DI and SSI beneficiaries with disabilities and other low-

income people with disabilities.

SSI and DI beneficiaries.

Adults with disabilities (primarily SSI and DI recipients).

DI beneficiaries with a primary diagnosis of affective disorder.

All people with disabilities. 
Exhibit 1-continued

Public Programs and Policies Affecting the Employment of People with Disabilities

PROGRAM/ POLICY/INITIATIVE DESCRIPTION

TARGET POPULATION

\section{Recent Policies and Initiatives to Promote the Employment of People with Disabilities}

NIDRR Rehabilitation Research and

Training Centers on Employment

The National Institute of Disability Rehabilitation and Research sponsors a number of research and training centers that conduct research and training in areas related to improving the employment outcomes of people with disabilities.

SSA will fund an institute to conduct research on how different factors affect the employment,

SSA Disability Research Institute rehabilitation, and disability program participation behavior of people with disabilities.

ASPE Study of Employment Supports This study will collect qualitative data about the supports and other factors that contribute to

Used by Working People with Disabilities employment of successfully employed people with disabilities.

A service of the President's Committee on Employment of People with Disabilities, JAN is a

toll-free information and referral service that provides information on job accommodation,

The Job Accommodation Network (JAN)

employers' responsibilities under the ADA, and on technical assistance, funding, education,

All people with disabilities (the

specific population focused on varies by center).

All people with disabilities.

People with disabilities who are

successfully employed.

All interested persons and employers. 


\section{An Economic Model of Labor Force Participation}

\section{A. The Basic Theory}

In studying and describing work behavior among persons with disabilities - that is, the factors that promote and discourage labor force participation - it is useful to define a framework in which these factors can be organized, analyzed, and evaluated as to their ability to be addressed by public policy. In this paper, we present a discussion of the policies and programs affecting the employment of people with disabilities from an economic perspective. That perspective emphasizes the role of individuals making choices between various alternatives as key to understanding behaviors such as labor force participation. A well-developed theory of the labor market exists in the economics literature. It is this theory that forms the conceptual framework and perspective we use to present information on various factors that act as either barriers to or incentives for work among persons with disabilities and to discuss the likely impacts of policies and initiatives designed to promote the employment of people with disabilities. The economic theory of the labor market can be broken into three major components: factors affecting labor supply, factors affecting labor demand, and factors affecting the process of matching jobs to workers.

The economic theory of labor markets posits that the amount of labor individuals are willing to supply (i.e., the number of hours an individual is willing to work) will depend on their preferences and an hours/earnings tradeoff. Individuals must choose how to allocate their limited time between (market) work activities and all other activities. Non-work activities are euphemistically called "leisure" but include all forms of unpaid work and self-care. Market work is necessary to obtain earnings, which are used to purchase goods and services. Therefore, the allocation of hours to market work and other activities represents a choice based on the individual's preferences and the tradeoff between the consumption of goods and services and the consumption of leisure.

Economic theory also posits that the amount of labor firms demand will depend on the demand for the firm's product, the productivity of labor (and other inputs), the wage rate and other costs firms must incur to hire labor, and the costs associated with other inputs that are substitutes or complements to labor. The textbook profit-maximizing firm will demand the amount of labor at which the value of the additional output produced by the last worker hired is just equal to the cost of hiring that worker.

Finally, economic theory provides a framework for analyzing job and employee search behavior. Individuals vary in their abilities, education, work experiences, and demographic characteristics, and jobs vary in their skill and knowledge requirements. Economists often describe the labor market as a matching process in which workers with varying characteristics are matched with appropriate jobs. The economic framework for this process is useful for understanding how environmental factors affect an individual's job search (and ultimately, employment). According to job search theory, individuals entering the job market are constrained by their available resources to accept an offer of employment within a specified timeframe. Initial assets available and access to income during the search period will determine resource availability. While searching, individuals must weigh the risk of continuing to search for a job offering their 
"reservation wage" (the wage that must be received to accept an offer of employment) against the risk of exhausting their resources and being forced to accept the next offer of employment. Other factors also affect the matching process, such as employer perceptions of the qualifications of potential employees, potential employee perceptions of job characteristics, and the amount and nature of other information available to both parties in making their respective employment decisions.

\section{B. Applying the Basic Theory to People with Disabilities}

The economic view of how individuals decide how much labor to supply and how firms decide how much labor to demand is simple, but it forms a basic framework in which predictions can be made, hypotheses can be tested, and policies can be analyzed. This basic framework might also be modified and enhanced with details specific to the issues under study - in this case, to the labor market for people with disabilities.

For people with disabilities, the tradeoff between work and leisure is likely to be influenced by the availability of other sources of income in the absence of work (disability benefits or spousal earnings, for example); availability of health insurance, which is often contingent on employment or public program participation; and the wage rate. Wage rates for people with disabilities might be affected by the disability itself, because impairment can reduce productivity, influence employer perceptions of productivity, and/or be a source of discrimination by employers.

To participate in the labor market, people with disabilities might also be required to incur additional expenses, such as the costs of rehabilitation, special transportation, equipment, or personal assistance services. All else being equal, these additional work-related expenses will make labor force participation less attractive or even render the net gains to working negative, unless paid by a third party.

In addition, the labor/leisure tradeoff and decision to work for persons with disabilities might be affected if disability reduces the number of hours available for work and leisure. Disability has been characterized as a condition that "steals time" (Oi, 1991). Persons with disabilities might require more time for personal care or medical care activities and, thus, have less time available for work. Assistance that helps reduce the time required for non-work activities, such as housework, might increase the time available for work and, hence, increase labor force participation.

The labor supply of persons with disabilities is also determined by individual preferences, which are themselves likely to be influenced in a variety of ways by the presence of a physical or mental impairment. For example, impairments often steal time by reducing life expectancy. Other things remaining constant, it seems likely that the shorter an individual's life expectancy, the less the individual will want to work today.

The demand for workers with disabilities by firms will depend on the productivity of these workers (both perceived and actual) and the costs firms must incur (or believe they must incur) to hire them. If workers with disabilities require special accommodations to work, the costs of these accommodations will be taken into account when deciding whether or not to hire workers 
with disabilities. In theory, if firms do not believe that a worker's compensation plus the costs of accommodations and support for developing the worker's capabilities will be entirely offset by the worker's productivity, accommodation will not occur and workers with disabilities will not be hired. For people with disabilities, employer access to accurate information plays a particularly critical role in the employment process. Employers who lack good information about productivity or costs of accommodations can make inefficient, or even discriminatory, employment decisions.

Economic theory predicts that, in a competitive labor market, if the government imposes labor regulations or a benefit mandate on employers, workers will bear the burden through lower wages and employment in the long run. Regulations, including the 1990 Americans with Disabilities Act (ADA), might reduce the ability of employers to shift costs onto workers, but if the cost of a regulation to employers is high, enforcement of the regulation is likely to be difficult.

Institutional policies and practices associated with the labor market will also affect the demand for workers with disabilities. A forty-hour workweek, wage scales that do not adjust for productivity, and other occupational rigidities might reduce the likelihood that persons with disabilities are hired. Some regulations might have a positive impact on employment and wages by reducing or eliminating such rigidities.

In addition to the principal players in this labor market (individuals and firms), third parties might have a direct or indirect interest in whether or not those with disabilities participate in the labor force and might create incentives accordingly. For example, public and private disability insurers might encourage their beneficiaries to return to work to reduce payments to these individuals. Healthcare providers might encourage individuals with disabilities to apply for Supplemental Security Income (SSI) so that their services will be reimbursed by Medicaid, and states might also encourage persons with disabilities to apply for Federal SSI benefits to reduce State and local support for these individuals; such encouragement might reduce the likelihood that persons with disabilities will participate in the labor force. Families and peers represent other third parties also likely to influence the employment decisions and outcomes of those with disabilities.

In the search for employment, persons with disabilities are likely to face higher costs than persons without disabilities, which might decrease the likelihood that a person with a disability will be matched with an appropriate job and might also reduce the likelihood that the individual will enter the job market. Higher search costs might partly be related to the physical characteristics of the disability, which could make communicating and interviewing with employers more expensive. In addition, an individual with a disability requiring expensive care technologies has greater resource needs during the search process than a person without disabilities who is otherwise identical. This might significantly reduce the amount of time that the individual is able to search before accepting a job, resulting in a job of lower quality than for the individual who has the resources to search for a longer period. If, however, the individual has significant support from other sources during the search process, search costs are lower and the need to accept an offer at any given wage is reduced - potentially to the point where no offer is ever accepted. This could be true even if the support during the search period were not contingent on work. 


\section{Factors Affecting Labor Supply}

\section{A. Overview}

Economists generally view the supply of labor and the demand for leisure as two sides of the same coin: for each hour of labor supplied, an individual has one fewer hour of leisure to consume. It is possible, then, to model labor supply decisions as leisure demand decisions. An individual's demand for leisure will be determined by three factors: the opportunity cost of leisure (i.e., the wages lost by not working), the individual's level of wealth (including income from work and non-work sources), and the individual's preferences.

Other things being equal, the higher the opportunity cost of leisure (i.e., the higher a person's compensation), the more hours a person will work. The lower the opportunity cost of leisure, the fewer hours a person will work. A low opportunity cost of leisure can result from a low wage level or from receipt of non-work-related income, such as income from assets, public income support, or spousal earnings. The effect of non-work income on the opportunity cost of leisure is especially large if the income is contingent on not working, as in the case of income support programs. Public in-kind goods and services that depend on income (and, indirectly, work effort because most income is derived from earnings), such as healthcare and food stamps, also lower the opportunity cost of work by providing goods and services in the absence of adequate earnings that would otherwise be purchased with earnings. Each person's individual preferences for work and leisure will have some effect on the decision to supply labor. Preferences are considered fixed by economists and are unaffected (at least in the short term) by changes in wages or wealth.

The supply of labor among people with disabilities is affected by availability of public income support programs, availability of in-kind support programs, access to programs that develop human capital, and tax policies that affect wages and income.

\section{B. Public Income Support Programs}

Public income and in-kind support programs create work disincentives to individuals with disabilities whenever eligibility or the level of benefits is tied to the individual's earnings, directly or indirectly. Below, we discuss several public income support programs used by people with disabilities: the Social Security Disability Insurance (DI) program; the Supplemental Security Income (SSI) program; Workers' Compensation; the Veterans Administration programs; Temporary Assistance for Needy Families (TANF) ${ }^{1}$; Food Stamps; and energy and housing assistance. For each program, we provide a brief description of the program and its potential impact on the labor supply of persons with disabilities, and then note any evidence regarding its effects on the employment and earnings of people with disabilities.

\footnotetext{
${ }^{1}$ Formerly the Aid to Families with Dependent Children (AFDC) program.
} 


\section{Social Security Disability Insurance}

The Federal DI program was created to insure workers against loss of income because of a disabling physical or mental health condition. Disability determinations are generally made by State agencies that are funded to perform this function by the Social Security Administration (SSA). The payment amount for a worker is based on his or her lifetime average earnings covered by Social Security. DI benefits replace a portion of the worker's prior earnings. DI benefits are designed to be "progressive;" that is, the proportion of earnings that DI replaces is higher for lower-wage workers than for higher-wage workers. ${ }^{2}$ As of October 1999, 4.85 million workers with disabilities received DI benefits. The average monthly benefit for a worker with a disability is $\$ 775$ (SSA, 1999a). A person must have worked and paid Social Security taxes (FICA) for enough years to be covered by DI. ${ }^{3}$ If DI recipients qualify for other Federal, State, or local government disability or Workers' Compensation programs, DI benefits will be reduced if total benefits exceed $80 \%$ of average earnings before the onset of disability. However, meanstested benefits are exempt (Burkhauser and Wittenburg, 1996).

Disability under the DI program is defined as the inability to engage in substantial gainful activity (SGA) because of physical or mental impairment. SGA is currently defined as the equivalent of working at job that pays $\$ 700$ a month. The physical or mental impairment must be medically determinable and expected to last for not fewer than 12 months or to result in death. To receive DI benefits, an applicant must first demonstrate that he or she has been earning below the SGA threshold for at least five consecutive months. ${ }^{4}$ This, along with proof of an impairment and consistent and recent work history, allows an individual to become eligible for benefits (Committee on Ways and Means, 1998). Medicare coverage begins for DI beneficiaries after they have been on the DI rolls for 24 months.

Since eligibility for DI is contingent on the inability to work, the strict guidelines create work disincentives for individuals wishing to become eligible for DI and discourage the efforts of those already receiving DI to return to work. The loss of Medicare benefits for those on the rolls longer than 24 months adds to the disincentive. To counter this effect, several "work incentive" programs have been added to the DI program over the years (SSA, 1999e). The primary work incentive programs are:

- A Trial Work Period of at least nine months that permits beneficiaries to test their ability to work without affecting their disability benefits.

\footnotetext{
${ }^{2}$ Benefits are calculated identically to retirement benefits and are based on the worker's average indexed monthly earnings (AIME).

${ }^{3}$ An individual must have worked in employment subject to Social Security contributions for about one-fourth of the time elapsing after age 21 and up to the year of disability. In addition, he or she must have recent covered work equivalent to five of the preceding 10 years. A worker who has worked in employment subject to Social Security contributions for 10 years or more is fully insured for life (Ways and Means, 1998).

${ }^{4}$ Under current regulations, in most cases if a person is earning more than $\$ 700$ a month (net of impairment-related work expenses), he or she will be considered to be engaging in SGA. The SGA earnings guideline was increased from $\$ 500$ to $\$ 700$ on July 1, 1999.
} 
- An Extended Period of Eligibility (EPE) and Medicare Coverage, which allows beneficiaries to work and earn as much as they want over the course of a consecutive 36month period without jeopardizing their eligibility for benefits. DI cash benefits are reduced to zero when earnings reach the SGA level, but during the EPE, beneficiaries can receive DI benefits in any month in which their earnings are below the SGA level and receive at least 39 months of Medicare coverage after the end of the trial work period. The extended period of Medicare coverage has been lengthened by an additional four and one-half years with the enactment of the 1999 Ticket to Work and Work Incentives Improvement Act (WIIA), which goes into effect on October 1, 2000 (discussed further in Section VI).

- Impairment-Related Work Expenses, which allow the costs of certain impairment-related items and services that a person needs to work to be excluded from earnings in the DI benefit and eligibility calculation.

\section{a. Impact of DI on the Employment of People with Disabilities}

From an economic perspective, the availability of DI income unambiguously decreases the incentive to work by lowering the opportunity cost of leisure. The disincentives to work are manifested in several ways:

- Initial eligibility for benefits contingent on five months of no substantial work activity;

- High wage replacement rates of benefits for some individuals; and

- Continued eligibility for benefits contingent on no substantial work activity.

Unemployed individuals wanting to become eligible for DI are discouraged from seeking employment, primarily because receipt of DI is contingent on having earnings below the SGA threshold for a minimum of five months. Because a single month of earnings above the SGA threshold resets the five-month waiting period, there is a high cost to individuals not yet on the DI rolls who "try out" employment, through the delay in receipt of DI benefits should their work attempt fail. This cost associated with the application for DI encourages jobless individuals with disabilities to choose a path-disability benefits or work-and to stay on the chosen path (Burkhauser and Daly, 1995). A person who wants to work, for example, might still choose the path to DI benefits because he or she might be unsure about his or her ability to work indefinitely because of the impairment. Even if work is attractive in the short term, he or she might choose to stay out of the labor force because of a fear of failing to qualify for future benefits.

The rate at which DI replaces earnings also affects the extent to which the receipt of DI serves as a disincentive to work. ${ }^{5}$ As described previously, prior work history and earnings determine the level of DI benefits. Lower-wage workers receive smaller benefits than higher-wage workers, but the replacement rate for lower-wage workers is higher than for higher-wage workers (Exhibit 2).

\footnotetext{
${ }^{5}$ The DI replacement rate is the extent to which DI benefits replace earned income. For example, if a DI beneficiary receiving $\$ 600$ a month in benefits previously earned $\$ 1,000$ in wages, the DI replacement rate for that individual would be $60 \%(600 / 1000)$.
} 


\section{Exhibit 2}

Social Security Disabled Worker Benefit Wage Replacement Rates, 1995

\begin{tabular}{|c|c|c|}
\hline \multirow{2}{*}{ Prior Annual Earnings } & \multicolumn{2}{c|}{$\begin{array}{c}\text { Monthly Disability Benefit } \\
\text { Amount }\end{array}$} \\
\hline$\$ 10,000$ & $\$ 507$ & $61 \%$ \\
\hline$\$ 15,000$ & $\$ 636$ & $51 \%$ \\
\hline$\$ 20,000$ & $\$ 766$ & $46 \%$ \\
\hline$\$ 25,000$ & $\$ 896$ & $43 \%$ \\
\hline$\$ 30,000$ & $\$ 1,026$ & $41 \%$ \\
\hline$\$ 40,000$ & $\$ 1,170$ & $35 \%$ \\
\hline$\$ 60,000$ & $\$ 1,332$ & $26 \%$ \\
\hline
\end{tabular}

Source: National Academy of Social Insurance, 1996b, Table 2-1. The figures are from SSA data (Office of the Actuary).

Some have argued that the receipt of DI benefits does not serve as a disincentive to work because of the low absolute amount for low-wage workers and the low replacement rate for higher-wage workers. The relevant replacement rate, however, for assessing the incentive effect of DI is the rate at which DI benefits replace future, not prior, earnings. This is because the relevant choice for the worker with a disability is between receiving benefits or returning to work at a future wage, not at the previous wage (which might or might not be equivalent).

In Exhibit 3, we illustrate this concept. The second column contains the replacement rate (from Exhibit 2) for a worker earning $\$ 25,000$ a year (pre-disability earnings). The first column contains values for potential post-disability earnings as a percentage of pre-disability earnings. For example, the first row represents post-disability earnings of $\$ 7,500(30 \%$ of $\$ 25,000)$. The third column contains the replacement rate of potential post-disability earnings. In the first row, this figure is equal to $\$ 10,752$ (annual benefits available to an individual with previous annual earnings of \$25,000 (see Exhibit 2)) divided by \$7,500 (earnings from column one), or 143\%. In every case in which the post-disability earnings for a worker are smaller than his or her predisability earnings, the post-disability earnings replacement rate is higher than the pre-disability earnings replacement rate. We see that the work incentive associated with post-disability replacement rates is potentially different from the work incentive associated with pre-disability replacement rates. 


\section{Exhibit 3}

\section{Hypothetical Replacement Rates for Pre-Disability and Post-Disability Earnings for a Worker with Pre-Disability Earnings of \$25,000 in 1994-1995}

\begin{tabular}{|c|c|c|}
$\begin{array}{c}\text { Potential Post- } \\
\begin{array}{c}\text { Disability Earnings as } \\
\text { a Percentage of Pre- } \\
\text { Disability Earnings }\end{array}\end{array}$ & $\begin{array}{c}\text { Pre- } \\
\text { Disability } \\
\text { Earnings }\end{array}$ & $\begin{array}{c}\text { Potential Post- } \\
\text { Disability Earnings }\end{array}$ \\
\hline $30 \%$ & $43 \%$ & $143 \%$ \\
\hline $40 \%$ & $43 \%$ & $108 \%$ \\
\hline $50 \%$ & $43 \%$ & $86 \%$ \\
\hline $60 \%$ & $43 \%$ & $72 \%$ \\
\hline $70 \%$ & $43 \%$ & $61 \%$ \\
\hline $80 \%$ & $43 \%$ & $54 \%$ \\
\hline $90 \%$ & $43 \%$ & $48 \%$ \\
\hline $100 \%$ & $43 \%$ & $43 \%$ \\
\hline
\end{tabular}

It seems likely that DI beneficiaries who would like to return to work are often discouraged from doing so by the earnings restrictions associated with eligibility. Because earnings above SGA result in the termination of benefits after the EPE, the loss of DI benefits (including non-cash benefits like Medicare) can substantially offset the gains from working. For individuals who are unable to obtain sufficient earnings (such as those who are able to work part-time but not fulltime), the lost benefits might well outweigh the financial gains from working, especially if the individual must bear other significant costs associated with returning to work, such as transportation, childcare, or assistive technology (AT) costs.

Finally, SSA has historically used work activity as one of several criteria for initiating a continuing disability review (CDR). With some exceptions, CDRs are supposed to be conducted at least every three years to determine if there has been a change in the beneficiary's status that would render him or her no longer eligible for DI benefits. CDRs can happen more or less frequently for specific beneficiaries depending on the health condition causing disability and other factors such as work. The triggering of CDRs by work activity created a disincentive to work among beneficiaries who feared that scrutiny by SSA would jeopardize their continued eligibility for benefits. A recent policy change has, however, eliminated this work disincentive. A WIIA provision stipulates that work activity cannot be used to trigger the review process or to end medical eligibility.

The work disincentives created by the DI program apply only to earnings above the SGA level. Below $\$ 700$ a month, a beneficiary can retain his or her earnings without affecting his or her DI benefit level, and, therefore, has an opportunity to increase total income through work. Once the trial work period and the EPE expire, a beneficiary who earns more than the SGA level is no longer eligible for cash benefits. Thus, the SGA level represents a "cliff," where earnings beyond 
this level will result in a significant drop in total income. This creates a substantial incentive for DI beneficiaries to work up to the SGA level itself, but no higher. ${ }^{6}$

The DI work incentive provisions described previously are designed to reduce some of the work disincentives associated with the receipt of DI. The trial work period reduces the cost of entering the labor force and encourages beneficiaries to try out employment without a loss in benefits. Although the anticipated short-term effect of the trial work period is to increase short-term employment, in theory the provision could result in increases in long-term employment, as well, because successful employment in the short term could lead to a long-term success.

The EPE also reduces the risk and cost of returning to work by providing benefits in those months that earnings fall below the SGA level. The provision is likely to be effective in moving persons with disabilities into work only if the circumstances that it provides for-periods of variable and low earnings - eventually lead to long-term gainful employment. There is some incentive, however, for individuals to engage in short-term employment under the EPE and to cease employment activities before the EPE expires.

The Impairment-Related Work Expenses (IRWE) and Extended Period of Medicare Eligibility are intended to reduce the costs a person with a disability faces in returning to work, thereby increasing the net benefits from working. The availability of IRWE deductions, however, might have only a small impact on the employment of people with disabilities, for two reasons. First, the provision affects only those for whom total earnings, when reduced by the amount of their work-related expenses, are still below SGA. Individuals with earnings (minus IRWEs) above the SGA, the population most likely to leave the DI rolls for work, are not affected by the policy. Second, the size of the incentive created by the presence of an IRWE is proportional to the size of the IRWE; most IRWEs, however, are small. ${ }^{7}$

Healthcare, in contrast, can be prohibitively expensive for many individuals with disabilities. For those individuals unable to hold a job that offers healthcare benefits, Medicare coverage is a significant incentive to participate in the DI program. The Extended Period of Medicare Eligibility allows a person with a disability to return to work for up to four years without losing access to healthcare coverage under Medicare, which can remove a substantial disincentive to work, particularly for persons with impairments associated with high healthcare costs. The extent to which this provision will encourage work activity depends, in part, on the timeframe in which the individuals with disabilities view their employment opportunities and the risk preferences of those individuals. If most individuals returning to work believe that they will be able to find work that provides health insurance within the four-year timeframe and if they have a reasonably high tolerance for risk, this provision is likely to increase employment. However, if most beneficiaries believe they will likely be without private health insurance at the end of the term of

\footnotetext{
${ }^{6}$ Economists refer to the loss of benefits at earnings above the SGA threshold as a "tax" on earnings, because earnings above the SGA threshold result in a loss in benefits, reducing total income.

${ }^{7}$ IRWE data on SSI recipients show that in September 1999, 93 percent of IRWE deductions were for expenses totaling less than $\$ 200$. IRWE deductions of $\$ 1,000$ or more were taken by only 0.2 percent of SSI recipients (SSA, 1999b). Although we have found no data specific to DI beneficiaries, we can think of few reasons why the distribution of IRWE deduction might be substantially different for DI beneficiaries.
} 
extended eligibility and if they are risk averse regarding long-term loss of health insurance coverage, the likely impact on employment will be small.

Although the DI work incentive provisions described above are designed to reduce the work disincentives associated with the receipt of DI, none directly addresses the disincentives associated with the total loss of cash benefits when earnings exceed SGA beyond the EPE. Provisions of the WIIA require SSA to test, via demonstration, specific policies that will directly address the earnings cliff faced by DI beneficiaries who desire to increase their work and earnings levels (described further in Section VI).

Although the work incentive programs do reduce the return-to-work disincentives for beneficiaries that are associated with the basic features of the DI program, they might at the same time encourage workers with disabilities who are not DI beneficiaries to leave the labor force and apply for benefits ("induced demand"). Thus, for instance, a worker with high medical costs and limited health insurance might find it attractive to leave work and seek DI benefits as a way to obtain eligibility for Medicare. In theory, the individual could return to work after the 24month Medicare waiting period is over and maintain Medicare eligibility for nine and one-half years. Concerns about induced demand for DI and Medicare are a major reason that the numerous proposals to reduce the disincentive associated with the earnings cliff have not been enacted into law.

One important feature of the DI program that often is overlooked in considering its work incentive effects is the program's interaction with private disability insurance (PDI). Forty-three percent of full-time workers in medium and large establishments and $22 \%$ of full-time workers in small establishments are covered by employer-provided private disability insurance (Bureau of Labor Statistics, 1996, 1997).

Most PDI policies are "wrapped around" DI. That is, long-term PDI beneficiaries are required to apply for DI, and DI benefits they receive are offset, dollar for dollar, by reductions in the PDI benefit. PDI benefits generally are more substantial than DI benefits, usually requiring only that the worker is unable to perform his or her past work (rather than any work), and typically replace $60 \%$ of lost earnings.

For DI beneficiaries who also receive PDI benefits, the DI replacement rate is irrelevant to the work incentives they face. The relevant replacement rate is the PDI benefit as a percentage of post-disability earnings. To illustrate, consider again the worker earning $\$ 25,000$. That worker's DI replacement rate for pre-disability earnings was $43 \%$ from $1994-95$, but $61 \%$ of postdisability earnings if disability reduced the worker's earning capacity by $30 \%$. If the same worker were covered by a PDI policy with a $60 \%$ replacement rate, the replacement rate for postdisability earnings would be $86 \%$.

Although DI income benefits are not relevant to work disincentives for those who also are PDI beneficiaries, the DI program contributes indirectly to the disincentives associated with PDI benefits because it, in effect, subsidizes PDI. That is, insurers can offer a given level of PDI replacement earnings at a premium that is substantially lower than what it would be if PDI were not wrapped around DI. 
Less information is available about the relationship between PDI and private health insurance benefits. Workers might lose their employer-provided health benefits when they become longterm PDI beneficiaries but have the option under Federal law to extend those benefits for 18 months by paying the full premium themselves (COBRA benefits). Some might also receive benefits similar to early retiree health benefits. These benefits might also discourage return to work.

Other features of PDI or related disability management (DM) programs encourage, rather than discourage, return to work. DM programs promote return to work through incentives or services. These include aggressive early intervention to prevent loss of work capacity as well as early support for rehabilitation and return to work. Some PDI policies, for instance, increase the amount of the monthly disability benefit for beneficiaries who enroll in vocational rehabilitation programs.

Although the Federal government clearly subsidizes PDI income replacement benefits via DI, as discussed above, the Federal government's role in supporting the return-to-work efforts associated with PDI and DM is less clear, but perhaps substantial. Presumably such programs take advantage of government-supported rehabilitation and other services available to those with disabilities when cost-effective to do so, but we have no information on how extensively these programs use government-supported services. Many have argued that prevention and early intervention are keys to reducing job loss from disability and that employers and their employees are in the best position to take timely action. Hence, public policies that promote such actions are of considerable interest.

\section{b. Evidence}

Several studies have investigated the relationship between DI benefits and the decision to withdraw from the labor force. Most have involved an analysis of the relationship between the DI replacement rate (a ratio of average DI awards to average earnings) and the labor force participation rate or number of disability applications. In general, these studies have supported the theoretically logical supposition that an increase in the level of disability benefits available is associated with an increase in disability applications (Lando, Coate, and Kraus, 1979) and a decrease in labor force participation (Parsons, 1980; Haveman and Wolfe, 1984; Haveman, Wolfe, and Warlick, 1987; Kreider, 1994). These studies vary widely, however, in their findings on the size of these effects.

At one extreme, Parsons (1980) found that a $1.0 \%$ increase in the replacement rate increases the percentage of men age 48-62 who are not in the labor force by $0.62 \%$. Several other studies, however, suggest that the effect of the same increase is no more than a $0.03 \%$ reduction in male labor force participation. (Haveman and Wolfe, 1984; Haveman, Wolfe, and Warlick, 1987; Kreider, 1994). Examining data from Canada following a change in some provincial disability benefit levels, Gruber (1999) estimated that a 1.0\% increase in the replacement rate reduced labor force participation of men age $45-59$ by $0.28 \%$ to $0.36 \%$. These findings stand in contrast to Bound (1989), who, using data from 1972 and 1978 SSA surveys of people with disabilities, found that only about $45 \%$ of men age $45-64$ whose disability application had been rejected worked in the year before the survey. For this reason, Bound argues that in the absence of DI many recipients would continue to remain out of the labor force and concludes that the DI 
program is responsible for only a small fraction of the decline in the labor force participation of older men.

A significant shortcoming of all the empirical work on replacement rates is that translation of programmatic replacement rates on pre-disability earnings into actual replacement rates for postdisability earnings is problematic. Post-disability earnings potential is not observed, and PDI and other benefits also contingent on earnings are seldom known. The effect of a change in an actual replacement rate on work might be considerably greater than the effect of an equal change in a program's replacement rate because other programs (e.g., PDI) mitigate the impact of the latter on the former. Put differently, the findings described above might substantially understate the importance of financial incentives to work effort by people with disabilities.

Empirical research also suggests that the work incentives built into the DI program are ineffective in returning recipients to work. Typically, not more than one in 500 DI beneficiaries leaves a disability program to return to work (GAO, 1997). Perhaps the most compelling evidence of the failure or inadequacy of the existing work incentives is that many of those who did return to work were actually unaware of the incentives and believed that SSA was unresponsive to their desire to return to work (Hennessey and Muller, 1994; GAO, 1998).

Building on the preliminary analysis presented in the authors' 1994 article, Hennessey and Muller (1995) explore the effect of the three major DI work incentives (trial work period, extended period of eligibility, and extended Medicare coverage) and the receipt of vocational rehabilitation (VR) on the decision to return to work. They find that receipt of VR and knowledge of the trial work period increase the tendency of a DI beneficiary to return to work. Dykcacz's (1998) finding that former recipients who receive VR are less likely to return to the DI rolls support this result. In contrast, Hennessey and Muller found that knowledge of extended Medicare coverage actually reduces effort to pursue employment. Although this result is unexpected and counterintuitive, Hennessey and Muller postulate that beneficiaries might see the combination of the EPE, where the person receives no cash benefits, and the extended Medicare coverage as events leading to termination from the program. The authors hypothesize that the fear of future financial insecurity created by the potential loss of the EPE/Medicare safety net might, in practice, override work incentives these benefits might create. The results of this study should be interpreted with caution, however. The authors had no access to information about beneficiary health status, which is likely to substantially influence a decision to return to work, independent of beneficiary knowledge about work incentives.

\section{Supplemental Security Income}

The Federal SSI program provides basic monthly income to people age 65 and older and to the blind and people with disabilities of any age who have limited income. Administered by SSA this means-tested program replaced the former Federal-State programs of Old-Age Assistance (OAA), Aid to the Blind (AB), and Aid to the Permanently and Totally Disabled (APTD) in 50 states and the District of Columbia (SSA, 1998a). As of January 2000, individuals eligible for SSI can receive a maximum monthly Federal cash payment of $\$ 512$ (\$769 for a couple if both members are eligible) (Federal Register, 1999). Legislation that created the SSI program allows individual states to supplement the Federal payment. Some of these supplements are mandatory 
under the maintenance-of-effort provisions of the original SSI legislation, although others are voluntary. Beneficiaries turning 18 years of age are subject to disability re-determination.

In September 1999, there were 342,680 SSI disability recipients working. This represented 6.4\% of the total SSI disabled caseload (SSA, 1999b). Included in this count are 70,580 Section 1619(b) participants who were not receiving an SSI payment but who had special SSI status for Medicaid eligibility purposes. Approximately $83 \%$ of these workers had amounts of earned income below the SGA level of $\$ 700$ per month; $28 \%$ earned $\$ 65$ or less (SSA, 1999b).

Aside from a \$65 labor earnings disregard, plus possible other disregards described below, an SSI recipient loses $\$ .50$ in benefits for every dollar earned. Thus, SSI recipients face an implicit $50 \%$ tax rate on all labor earnings up to more than twice the maximum SSI benefit in that state, at which point the SSI benefit is zero (referred to as the "break even point"). Unlike DI beneficiaries, SSI recipients do not face an earnings cliff that causes a tax rate of more than $100 \%$ on earnings in a certain range.

As with DI beneficiaries, many SSI disability recipients would like to work but are afraid they will lose their SSI cash benefits and Medicaid coverage if they do (National Academy of Social Insurance, 1996a). In contrast to the DI program, SSI has been structured to provide stronger work incentives. As long as a person's disability remains, the work incentives do not allow work activity to stop SSI medical coverage. Even if a person cannot receive SSI cash benefits because of the amount of his or her earnings, eligibility for Medicaid can continue indefinitely under some circumstances. The primary SSI work incentive provisions include:

- Section 1619(a) of the Social Security Act of 1980, which provides continued Medicaid coverage and reduced SSI payments to recipients who earn more than the SGA amount (\$700 a month) but whose overall income is below their state's SSI break-even point;

- Section 1619(b) of the Social Security Act of 1980, which provides continued Medicaid coverage and SSI eligibility but with no monthly payments to recipients whose income, after certain disregards, exceeds the state's break-even point by the mean of Medicaid spending for SSI disability recipients in the state. The 1619(b) income limit varies substantially across states because of variation in Medicaid spending and State SSI supplements. In many states it is high. In 1996, the threshold was above $250 \%$ of the poverty line for individuals in 21 states (Stapleton et al., 1998);

- Plans for Achieving Self-Support (PASS), which allows a recipient to set aside income and/or resources, for such things as education, vocational training, or starting a business, and not have the income and/or resources included in the SSI income and resource eligibility tests;

- Impairment-Related Work Expenses, which allows exclusion of the cost of the impairment-related items and services that the recipient needs to work when considering SGA in the eligibility determination process; 
- Blind Work Expenses (BWE), which allows expenses attributed to working to be deducted from earnings for purposes of eligibility determination and countable income of blind SSI recipients. The expenses need not be impairment related; ${ }^{8}$ and

- Student Earned Income (SEI), which allows a student under age 22 who regularly attends school to exclude up to $\$ 400$ of earned income a month.

\section{a. Impact of SSI on the Employment of People with Disabilities}

There are a number of similarities between the incentives created by the SSI program and those created by the DI program discussed above. Like the DI program, the SSI program unambiguously decreases the incentive to work. SSI benefits are taxed at a lower rate than DI benefits, however (rather than the total loss of benefits occurring under DI when SGA has been attained, SSI benefits are reduced by $\$ .50$ for every dollar earned above the eligibility threshold); there is no SSI earnings cliff. The continued Medicaid eligibility available under Section 1619(b) also reduces the major work disincentive created by the fear of losing health insurance coverage, at least up to the 1619(b) income threshold. At this point there is a Medicaid earnings cliff. BWE reduce the costs of working and therefore encourage work, but only for a small subset of the SSI population. Likewise, the SEI exclusion creates an incentive to work and attend school but only for the small subset of recipients who both meet the age restriction and are enrolled in school.

PASS, in theory, creates an incentive for SSI recipients to earn and invest in training or business development to increase earnings in the long run. There is reason to believe that a program that allows higher earnings for purposes of investment in training would have an impact on short- and long-run employment. However, the success of such a program depends on recipients' having a strong desire to return to work as well as the ability to earn enough in the short run to make the funding of training or development in this way worthwhile - requirements that might be difficult to meet for the majority of SSI recipients.

A 1996 General Accounting Office (GAO) study of PASS found that the program was small but growing, with about 10,300 participants (or 1\% of the SSI population) in December 1994, a number that had increased more than five-fold in the five years before the study. Three-quarters of these participants also were receiving DI payments, and $40 \%$ had income that exceeded the income eligibility threshold for Federal SSI payments, meaning that PASS allowed them to qualify for SSI (GAO, 1996c).

There might well be a significant number of other SSI recipients who qualify for SSI only because of their use of PASS or other work incentive disregards, especially IRWEs. This means that some individuals who otherwise might be ineligible for Medicaid (through section 1619[b], for example) can qualify via use of these work incentives. Thus, some persons with disabilities who highly value Medicaid eligibility might have a strong incentive to use the SSI work incentive programs for reasons other than work. This includes some DI beneficiaries who have

\footnotetext{
${ }^{8}$ These expenses can include payroll taxes, income taxes, union dues, transportation, visual and sensory aids, and translation of material into Braille.
} 
Medicare coverage because Medicare doesn't pay for outpatient drugs or for many other services that some people with disabilities need.

More generally, it is possible that the SSI work incentive programs, like the DI work incentive programs, induce at least some demand for SSI. The fact that almost all SSI recipients obtain Medicaid benefits immediately on award of SSI and continue to be eligible for Medicaid as long as they have earnings below the 1619(b) limit seems likely to make this an attractive way to obtain health benefits for some people with disabilities. Induced demand for SSI seems especially likely in the states where the 1619(b) threshold is high.

\section{b. Evidence}

Yelowitz (1998) is one of the few studies to specifically examine the value of SSI benefits and their effect on the program participation of people with disabilities. The study finds only marginally significant evidence indicating that increasing the SSI benefit increases program participation. Yelowitz concludes that, although the size of the cash benefit might increase the probability of participation, it cannot explain recent growth in participation.

In contrast to return-to-work research on DI beneficiaries, relatively little has been written on SSI recipients who leave the program and return to work. Several studies have examined the work activity and earnings of SSI recipients while they were participating in the SSI program. One finding of these studies is that a relatively high percentage of SSI recipients work while on the rolls, especially when compared with DI beneficiaries. For example, one study finds that nearly one-quarter of SSI recipients who entered the program after 1976 and had spent at least one full calendar year in benefit status had earnings in at least one year while on the rolls (Muller, Scott, and Bye, 1996). This figure compares to an estimated employment rate of 10\% among DI beneficiaries. There are several possible explanations for this difference in work participation rates. One is that there are differences between the two populations that make SSI recipients more inclined to work regardless of program rules. Another is that the SSI means test and the low level of SSI benefits make work more critical for SSI recipients than for DI recipients as a way of meeting basic needs. A third is that implicit tax rates on earnings are lower for SSI, although this does not explain why DI recipients are less likely to work below the SGA threshold. A final one is that the SSI work incentive programs induce greater demand for SSI than do the DI work incentive programs.

The findings of several studies have suggested that, although many SSI recipients do at some point participate in 1619(a) or 1619(b), this employment tends to be sporadic. Rupp and Scott (1998) find no evidence that the introduction of the 1619 provisions in 1980 corresponded with a significant increase in income-related suspensions, suggesting that the 1619 provisions have not led to increases in earnings sufficient in both level and duration to result in benefit suspensions. This conclusion is consistent with the finding presented in Stapleton et al. (1998) that some SSI recipients actually restrain their earnings to stay below the cut-off threshold for the section 1619 work incentive program. Stapleton et al. (1998) also found that the portion of 1990 SSI recipients with earnings in that year who participated in 1619(b) for at least one month between 1990 and $1996(44 \%)$ was substantially higher than the percentage that participated for at least one month during 1990 alone $(26 \%)$. 
A 1996 GAO report on PASS suggested that its impact on employment of people with disabilities was minimal. Those participating in the PASS program were more likely to work than other SSI recipients and often had earnings high enough to reduce their SSI payments, but the majority had also worked prior to participating in PASS. The report pointed out that a number of internal control weaknesses compromised the integrity of the PASS program, including minimal or nonexistent program participation requirements, such as no penalties for willful noncompliance and no limits on the number of PASSes a person may have approved; broad and nonstandardized PASS guidance and compliance reviews leading to inconsistent program administration; and a lack of SSA policy to guide their PASS preparers. The provisions of PASS create an incentive to apply for and stay on PASS, to secure receipt of SSI and/or Medicaid. GAO was unable to determine the degree to which this might occur because data were not available on the length of PASSes or the number of PASSes per recipient. However, in interviews with regional and field office staff, some staff said they believed that, unless prohibited from doing so, PASS program participants might stay out of work indefinitely and continue to receive Medicaid and SSI (GAO, 1996c).

\section{Workers' Compensation}

There is a workers' compensation (WC) act for each of the 50 states and the District of Columbia as well as two Federal programs covering Federal employees and shipping employees working on navigable waters. States began passing WC acts as early as 1911, and by 1920, all but seven states had enacted some form of WC legislation. The last state to pass a WC law was Mississippi in 1948. In 1970, the Occupational Safety and Health Act (OSHA) created the National Commission on State Workmen's Compensation Laws, to study workers' compensation systems across the country and to recommend improvements designed to enhance worker protections. The Commission published 19 recommendations essential to ensuring minimum protection for workers, and states have adopted these recommendations to various degrees since their publication. In 1972, states on average complied with 7 of the 19 essential recommendations. Today, compliance levels range from 7.25 in Mississippi to 18.75 in New Hampshire (Illinois Industrial Commission, 2000).

Although the specifics of the acts differ, most have similar basic features. WC provides cash benefits, medical care, and rehabilitation services for workers who suffer work-related injuries and diseases. Benefits are extended also to dependents of workers whose deaths resulted from the same type of injury or illness. WC programs vary widely among the states with regard to the number of weeks for which benefits may be paid and the amount of benefits payable. Despite the role of the states in WC, the program is largely administered and funded by employers. Costs are determined by the hazards of the industry and the method used to ensure eligibility (SSA, 1998d).

Benefits provided under workers' compensation include periodic cash payments and medical services to the worker during a period of disablement and death and funeral benefits to the worker's survivors. Cash benefits for temporary total disability, permanent total disability, and death of a worker usually are calculated as a percentage of weekly earnings at the time of accident or death—most commonly $66.67 \%$ (SSA, 1998d). 
People receiving WC who might improve via medical treatment will have benefits provided to them temporarily for the duration of the disability. Three-quarters of all compensatory claims for WC benefits and one-quarter of all cash benefits involve temporary disability (National Academy of Social Insurance, 1994). If the injury appears to be permanent and totally disabling, the majority of programs provide for the payment of weekly benefits for life or the entire period of disability. However, some programs reduce the benefits after a specified period. Still, if the worker's permanent disability is determined to be only partial (i.e., the loss of a body part or hearing or injury to the head, back, or nervous system) and unlikely to impede his or her work ability, permanent partial disability benefits are payable because of the specified injury and the potential for reduction in earning capacity (SSA, 1998d).

Work disincentives are associated with WC benefits for varying reasons. For instance, WC payments are discontinued for beneficiaries with temporary and permanent disabilities when they return to work. Because workers with permanent partial benefits usually receive payments equal to two-thirds of their demonstrated wage loss, there is a relatively small incentive to increase earnings unless the increase significantly exceeds the demonstrated loss of wages. Even more of a disincentive exists for workers qualified to receive WC and DI payments simultaneously. Combined income benefits can be as high as $80 \%$ of the former average earnings of a worker with disabilities, as calculated by the SSA (Burkhauser and Wittenburg, 1996).

The literature on WC programs finds conclusive evidence of a negative effect of WC benefits on work effort (see, for example, Butler and Worall, 1985; Johnson and Ondrich, 1990; Kreuger, 1990; Meyer, Viscusi, and Durbin, 1991; and Currington, 1993). The strength of the estimated effect depends on the nature of the program and the methodology used to estimate it. We have not found a study that carefully reviews all of the WC literature and examines the relationships between the findings, the nature of the program, and the methodology. The findings of the studies reviewed for this report suggest that the substantial increases in generosity of WC that occurred following Federal legislation in 1972 might have contributed significantly to the decline in labor force participation of older men, but we have not identified studies that have attempted to estimate the magnitude of this effect.

\section{U.S. Department of Veterans Affairs Programs ${ }^{9}$}

Men and women discharged from active military service under other than dishonorable conditions are eligible to receive benefits distributed by the U.S. Department of Veterans Affairs (VA). ${ }^{10}$ Disability compensation (i.e., monetary benefits) is available to those veterans who have experienced, or who have had aggravated, a disabling injury or disease during active military service. The amount received through disability compensation depends on the severity of the disability(ies) and the number of dependents. If the veteran's service-connected disabilities are evaluated at $30 \%$ or more, the veteran is entitled to additional allowances for dependents. Even though the benefits are untaxed at the Federal or State levels, military retirement pay, disability

\footnotetext{
${ }^{9}$ This section is based on information found in the U.S. Department of Veterans Affairs (1998).

${ }^{10}$ Active military service means full-time service as a member of the Army, Navy, Air Force, Marines, or Coast Guard or as a commissioned officer of the Public Health Service, the Environmental Services Administration, or the National Oceanic and Atmospheric Administration.
} 
severance pay, and separation incentives known as Special Separation Benefits (SSB) and Voluntary Separation Incentives (VSI) affect the amount of benefits received by a veteran with disabilities.

Veterans who have non-service related disabilities, or who are age 65 or older, are eligible to receive a veteran's pension. Qualified low-income veterans with disabilities with 90 days or more of active military service, one day of which occurred during a period of war, can be monetarily supported through the pension program. Payments are made to this population of veterans with disabilities to bring their total income, including other retirement or Social Security income, to a level set by Congress. Benefits from the pension program are not payable to those possessing assets that allow them to maintain an adequate standard of living.

In addition to military disability benefits, veterans are also entitled to Social Security retirement, disability, and survivor benefits. When calculating Average Indexed Monthly Earnings (AIME) for determining Social Security benefits, veterans are credited $\$ 300$ for each calendar quarter as an allowance for basic living expenses. Veterans eligible for both military and Social Security disability may select the higher of the two amounts, but not both. Social Security disability benefits are unreduced by the amount of service-connected disability compensation received from the VA (National Underwriter Company, 1994).

Because veterans' disability compensation is paid regardless of work activity, there are no real incentives or disincentives to acquire employment. The veterans pension program, however, is means tested and might discourage work because of its asset guidelines. We are aware of no studies that have evaluated the impact of the VA disability compensation programs on employment.

\section{Temporary Assistance for Needy Families}

The TANF program, which replaced the Aid to Families with Dependent Children (AFDC) program, was established in 1996 with the passage of the Personal Responsibility Work Opportunity Reconciliation Act (PRWORA). Before PRWORA, the AFDC program provided cash benefits to needy families with children when a parent was absent from the home, incapacitated, deceased, or unemployed. Each state determined eligibility requirements and benefit levels (within Federal guidelines). A combination of State and Federal funds was used to finance the program, with Federal funds covering between $50 \%$ and $80 \%$ of benefit costs and $50 \%$ of administrative costs. In all states, AFDC recipients were automatically eligible for Medicaid insurance coverage. In 1988, the passage of the Family Support Act established the Job Opportunity and Basic Skills (JOBS) program. JOBS provided education, training, and job placement for AFDC recipients; and it defined target groups who were to be given priority in participating in the JOBS program and set quotas for participation. (Committee on Ways and Means, 1998).

Under PRWORA, Congress eliminated AFDC's open-ended entitlement and replaced it with TANF's State Block Grants. Although states still have flexibility to determine eligibility requirements and benefit levels under TANF, those benefits are subject to Federal time limits and work requirements. The Federal time limit is five years, though states can choose a shorter limit. In general, states must place adult TANF recipients in work no later than their twenty- 
fourth month of assistance. TANF recipients who do not satisfy the work requirements are subject to either reduced benefits or benefit termination, and states whose caseloads do not meet certain participation requirements are subject to financial penalties.

Finally, unlike under AFDC, TANF recipients are not automatically eligible for Medicaid but must qualify for Medicaid separately. To determine Medicaid eligibility, states may not use a standard more restrictive than the July 1996 AFDC income and resource standard eligibility criteria. States have the flexibility to lower this standard to those in effect in May 1988. States may also raise the standard annually but by no more than the percentage point increase in the Consumer Price Index (CPI). The median monthly cash benefit for a family of four receiving TANF assistance in 1998 was $\$ 463$ (Committee on Ways and Means, 1998).

Although TANF was not designed primarily to serve people with disabilities, we discuss the program here because a large percentage of those receiving benefits from TANF (and AFDC) have disabilities, although estimates vary widely depending on the definition of disability used. One source estimated that approximately $50 \%$ of adult AFDC recipients have disabilities or have a child with a disability (National Council on Disability, 1997). Another study found that, among female welfare recipients, $10 \%$ to $19 \%$ have a physical disability (Johnson and Meckstoth, 1998). A study of California TANF recipients found that almost $40 \%$ of the recipient households had some member with a disability (Brady, Meyers, and Luks, 1998). Finally, an analysis of data from the March 1989 Current Population Survey found that prevalence of disability among mothers age 18 to 60 was more than twice as high among AFDC recipients (11\%) than among non-recipients (5\%) (Wolfe and Hill, 1993).

The prevalence of mental health disabilities among welfare recipients is substantial and might be relevant to the fact that the number and proportion of individuals applying for DI and SSI on the basis of a mental impairment are increasing (Stapleton and Livermore, 1996). Estimates of the prevalence of mental health disorders among the welfare population - that is, the presence of a mental health impairment that might or might not constitute a disability-vary widely. Among three studies conducted by the Urban Institute (1996a, 1996b, 1997) evaluating the prevalence of mental disorders in the AFDC population, the low estimate was 11.1\% of the AFDC population reporting depression between three and five days per week (from the National Longitudinal Survey of Youth). The high estimate was $42.0 \%$ of mothers in a Georgia demonstration reporting high levels of depressive symptoms.

Although many of TANF's work incentive and work requirement provisions vary by state, the law establishes two minimum requirements:

- Forty percent of a state's TANF caseload must participate in work activities. States are given the flexibility to determine, within Federal guidelines, what qualifies as work activities. The work requirement will increase to $50 \%$ in 2002 .

- TANF recipients can receive no more than 60 cumulative months of benefits over their lifetime. States are permitted to continue assistance past this time limit for up to $20 \%$ of their monthly average caseload. Many states have adopted shorter lifetime benefit limits. 
Under AFDC, the JOBS program categorically exempted welfare recipients defined as "ill or incapacitated" or "caring for an ill or incapacitated household member." may require all recipients, including those with disabilities, to participate in welfare-to-work program activities. As of October 1998, 30 states had opted to create new work requirements for TANF recipients with disabilities. Eighteen states were continuing to use the same rules established under JOBS (Thompson et al., 1998). ${ }^{12}$

Some states have adopted, to varying degrees, "diversion" efforts in the application process. Under these efforts, states provide applicants one-time payments or referral to other programs and services, such as SSI or job search services to avoid TANF enrollment. Little is known about the states' various application processes or their effect on people with disabilities.

Finally, before welfare reform, people with disabilities were eligible for unlimited assistance as long as they met the income requirements and had a dependent child living in the household. The introduction of time limits under TANF now subjects these individuals in most states to time limits, although polices vary by state. Individuals with disabilities are 1) subject to time limits in 26 states; 2) exempt from time limits in 16 states; and 3) subject to time limits if required to participate in welfare-to-work services in 8 states. Because the experience under welfare reform is still new, many of the states that impose time limits on their recipients with disabilities expect to revisit their policies (Thompson et. al., 1998).

\section{b. Impact of TANF on the Employment of People with Disabilities}

As do DI and SSI, TANF unambiguously decreases the incentive to work by lowering the opportunity cost of leisure. However, a number of program characteristics specific to TANF produce incentive effects that are not present in either DI or SSI. First, unlike DI and SSI, TANF recipients must engage in work or work-related activities (such as job training). Second, TANF receipt is limited to 60 months over the course of a lifetime. These provisions make TANF substantially less attractive than either SSI or DI relative to employment. In addition, under TANF, recipients are not automatically eligible for Medicaid (as was the case under AFDC). This "de-linking" of TANF from Medicaid eliminates the incentive present under AFDC to apply for welfare to become eligible for public health insurance, which might be particularly important for people with disabilities. In sum, although TANF receipt serves as a disincentive to employment because it reduces the opportunity cost of leisure, both the work requirement and time limit provisions under TANF are likely to simultaneously discourage new applications to TANF and to encourage shifting from TANF to SSI.

Although most TANF recipients face important barriers to employment (e.g., low education and/or skill levels, lack of job experience, need for childcare), those with disabilities face additional challenges (e.g., special work-related expenses such as rehabilitation or special transportation, need for work accommodations, and discrimination in hiring). People with mental

\footnotetext{
${ }^{11}$ Individuals considered "ill or incapacitated" under the JOBS program, faced issues ranging from short-term illnesses to permanent disabilities. Many of the most severely disabled individuals traditionally have been referred to the SSI program (Thompson et al., 1998).

${ }^{12}$ States using JOBS criteria are California, Alaska, New Mexico, Nebraska, Kansas, Texas, Minnesota, Tennessee, Louisiana, Mississippi, Virginia, Pennsylvania, Vermont, Connecticut, Maryland, Delaware, and Massachusetts.
} 
impairments might face the additional barrier of stigma that is associated with their disorder, which might contribute to a reluctance to seek employment. These challenges make them among the least likely recipients to find and maintain employment.

States have been implementing important changes under TANF, primarily aimed at improving the skills and employability of recipients given the now temporary nature of the income assistance provided. State welfare agencies, however, have limited experience in moving people with disabilities into work, principally because most people with disabilities were exempt from JOBS participation under AFDC. Because little is known about the needs of people with disabilities when returning to work, many of the strategies being employed might not be tailored to, or particularly effective in, addressing the needs of recipients with disabilities. If this is the case, people with disabilities represent a potentially large group of recipients whose TANF payments will be terminated because of the expiration of the time limit for benefit receipt. Given the prevalence statistics cited above, it is possible that the size of this group will exceed the $20 \%$ caseload exemption, and over time, as only the "hard core" unemployable cases remain on the TANF rolls, the percentage of the caseload with disabilities is likely to increase.

\section{c. Evidence}

The labor supply effects of welfare have been examined in numerous studies, most of which rely on data analyzed under AFDC. The general finding is that the program does have a significant negative impact on labor supply, although the estimates of this effect vary greatly from study to study (Danziger et al., 1981). In short, the presence of welfare is expected to decrease the attractiveness of work. A set of studies designed to measure the labor supply impact of welfare receipt studied how benefit levels affected exit rates from the AFDC program. These studies show a significant negative relationship between benefit levels and the probability of leaving AFDC. ${ }^{13}$

There are few studies that examine specifically the impact of welfare on the labor supply of people with disabilities. One such study, conducted using 1984 Survey pf Income and Program Participation (SIPP) data, evaluates the effects of then-proposed welfare reforms on the likelihood of employment of single mothers (Wolfe and Hill, 1995). The authors use a model to simulate policy changes designed to affect the labor force participation of single mothers. The policies considered include a wage subsidy, a decrease in AFDC benefits, and the provision of health insurance independent of AFDC participation. Among their results were the findings that decreasing AFDC benefits by 50\% would increase employment among health-compromised AFDC recipients by 8.2 percentage points compared to an increase of 14.3 percentage points among healthy recipients. ${ }^{14}$ With respect to the impact of a $50 \%$ wage subsidy, ${ }^{15}$ the labor force participation of health-compromised recipients would increase by 19.3 percentage points compared to a 32.1 percentage point increase among healthy recipients.

\footnotetext{
${ }^{13}$ Moffit (1992) provides an extensive review of studies that examine the employment effects of the AFDC program.

${ }^{14}$ In this study, "health compromised" refers to those mothers with difficulty performing one or more activities of daily living (ADL) or who report poor or fair health.

${ }^{15}$ The wage subsidy in these policy simulations is phased out at an hourly wage rate of $\$ 7.00$.
} 
Thus, the findings suggest that the employment of AFDC recipients with disabilities is less responsive than that of recipients without disabilities to strategies that create work incentives by changing AFDC benefits or increasing wage earnings. The findings also indicate that the provision of health insurance independent of AFDC participation might reduce the work disincentives associated with the program for both recipients with and without disabilities. Simulations under a plan where all persons working 15 or more hours per week are covered by health insurance indicate that the labor force participation of AFDC recipients would increase by approximately 20 percentage points. ${ }^{16}$

Although little is known about the success of ongoing State efforts under TANF to provide employment services to people with disabilities, findings from studies examining the success of people with disabilities in the JOBS program are instructive.

Two studies of the JOBS program provide some evidence that AFDC recipients with disabilities might either perceive or encounter barriers to participating in the program. A survey of JOBS enrollees conducted at seven sites found that nearly one in five enrollees believed he or she was unable to engage in education or training activities because of a health or emotional problem. The percentage who reported his or her health as a barrier to participation was much higher among respondents who had been on the AFDC rolls for two years or more compared with those receiving benefits for fewer than two years-22\% versus 14\% (Manpower Demonstration Research Corporation, 1994).

As part of another study of JOBS programs, AFDC and JOBS administrators were interviewed to obtain information on AFDC recipients with disabilities. Nearly all interviewees mentioned that clients with functional impairments experienced difficulty in finding and retaining employment. Many also stated that full-time JOBS participation might be difficult or impossible for participants with disabilities (Office of the Inspector General, 1992). ${ }^{17}$

Several studies have examined the interaction between AFDC/TANF and SSI. Using administrative data from California, Brady, Meyers, and Luks (1998) found that recipients with disabilities had a significantly higher probability of leaving AFDC/TANF for SSI than those without disabilities. The General Accounting Office (1997) found that approximately 12\% of households in Iowa, Massachusetts, and Wisconsin that lost AFDC benefits subsequently began receiving SSI. Finally, Stapleton et al. (2000) found a large increase in the number of former AFDC recipients applying for SSI from 1990 through 1996 at the national level. They estimated that the number of first applications filed on behalf of young female and child AFDC recipients from 1990 to 1996 was equivalent to $57.5 \%$ and $140.0 \%$ of the respective mean caseload sizes of young female and child SSI recipients in the early 1990s. They noted that the replacement of

\footnotetext{
${ }^{16}$ Two other studies (Moffit and Wolfe, 1992, and Yelowitz, 1994) also found the provision of Medicaid to have a significant negative effect on the labor force participation of AFDC recipients. Two other studies, however, did not find a strong relationship between Medicaid and work effort among AFDC recipients (Winkler, 1990, and Blank, 1988).

${ }^{17}$ The Federal regulations for the JOBS program require that states average 20 hours per week of participation in JOBS activities per enrollee.
} 
AFDC with TANF in 1996 would likely increase SSI participation as TANF recipients with disabilities sought SSI benefits to avoid TANF work requirements and time limits.

\section{In-Kind Benefits}

In-kind benefits consists of goods and services provided free of charge. Examples of public inkind benefits include food stamps, housing subsidies, and health insurance. Within an economic framework, in-kind benefits function as income because absent the benfit, recipients would need to purchase the goods or services on their own. Of particular importance to people with disabilities are health-related benefits, including public health insurance, assistive devices and technologies, and personal assistance services.

\section{Public Health Insurance}

Health insurance coverage is especially important for many people with disabilities because their need for medical services can be much greater than that of people without physical or mental impairments. Because of their medical conditions, however, people with disabilities often have difficulty obtaining affordable private health insurance. Those who are able to obtain private health insurance frequently face restrictions concerning the types of services their insurance will cover (Friedland and Evans, 1996). A 1998 survey of 1,000 Americans with disabilities age 16 and older revealed that although $90 \%$ of adults with disabilities are covered by health insurance, $32 \%$ reported that their health insurance did not cover a special need related to their disability (e.g., certain therapies, equipment, or medicine). Moreover, 20\% of adults with disabilities had been unable to get medical care that they needed on at least one occasion during the past year, compared to $11 \%$ of adults without a disability. Similarly, $18 \%$ of adults with disabilities indicated that they were unable to obtain insurance because of a disability or preexisting health condition (Louis Harris and Associates, 1998).

\section{a. Medicare, Medicaid, and the Link to Income Support Programs}

Medicare provides health insurance coverage for individuals age 65 and over as well as for persons with disabilities participating in the DI program. The program provides both hospital coverage (Part A) and supplementary medical insurance (Part B). Although nearly all persons age 65 and over are automatically eligible for Part A, individuals receiving DI benefits become eligible for Medicare coverage only after a 24-month waiting period. On returning to work, a former DI recipient can continue to receive Medicare benefits for up to four years, a period that will be extended to eight and one-half years in October 2000 when the healthcare provisions of the WIIA go into effect. Approximately 4.5 million persons with disabilities are estimated to have received Medicare benefits during fiscal 1996, with an average annual benefit of $\$ 4,741$ (Health Care Financing Administration, 1998).

Medicaid is a Federal-State matching entitlement program that provides medical assistance primarily to low-income and otherwise needy individuals, including persons with disabilities. In most states, persons receiving SSI are also eligible to receive Medicaid; in a few, a small share of SSI recipients is ineligible because the Medicaid means test is more restrictive. As discussed previously, SSI recipients who return to work and lose their SSI payments as a result of employment earnings might, in some cases, continue to receive Medicaid under section 1619(b) 
of the Social Security Act. In 1995, 5.8 million individuals with disabilities received Medicaid benefits totaling $\$ 49$ billion-approximately $\$ 8,448$ per recipient (Committee on Ways and Means, 1998). Two pieces of Federal legislation have recently given states the option of delinking Medicaid receipt from SSI participation. Section 4733 of the 1997 Balanced Budget Act allows states to extend Medicaid eligibility to working individuals with disabilities even if they have never received SSI benefits. Those buying must meet all SSI eligibility criteria other than the earned income requirements and have family income (after certain deductions) below $250 \%$ of the poverty level. ${ }^{18}$ States can require Medicaid recipients to pay for their benefits, under a sliding scale. In 21 states, however, this income limit was lower than the 1619(b) income threshold. The WIIA expanded this option by allowing states to eliminate all income and asset restrictions on the Medicaid Buy-in for persons with disabilities.

\section{b. Impact of Health Insurance on the Employment of People with Disabilities}

The availability of health insurance has the potential to affect the employment decisions of people with disabilities. High potential healthcare costs combined with an inability to obtain private health insurance might influence a person's decision to exit the labor force and apply for DI and/or SSI to obtain medical benefits through Medicare and/or Medicaid. Likewise, DI and SSI disability program participants face a strong disincentive to leave these programs and return to work because their receipt of public health insurance is largely contingent on disability program participation. A survey of 1,200 leaders of major disability constituencies conducted by the President's Committee on Employment of People with Disabilities identified the fear of losing Medicaid or Medicare as the greatest barrier to the employment of SSI and DI program participants (GAO, 1996a).

Policymakers and advocates for people with disabilities have generally agreed that the Medicare and Medicaid programs create substantial work disincentives for people with disabilities because of the programs' links to DI and SSI, where eligibility is contingent on insubstantial work activity. In recent years, the disability community as well as Federal and State policymakers have developed a variety of options for de-linking health insurance benefits from disability benefits by extending Medicare and Medicaid coverage to working people with disabilities. This was the motivation behind several of the provisions of the WIIA, including the extension of Medicare benefits for an additional four and a half years for former DI recipients and the State option to eliminate income and asset restrictions on the Medicaid Buy-in.

Although many suggest that de-linking health insurance from DI and SSI would unambiguously increase employment of people with disabilities, the issue is complex. The effect on an individual will depend on a variety of factors, including:

- the means of de-linking;

\footnotetext{
${ }^{18}$ As of January 2000, Oregon, Minnesota, Mississippi, and South Carolina were the only states that had extended Medicaid eligibility to working individuals with disabilities, with Wisconsin and Alaska planning to implement such a program.
} 
- the availability of insurance from other sources;

- the variation in benefits provided by various types of insurance;

- the individual's current employment or disability program participation status;

- the individual's eligibility for other programs that provide medical assistance (e.g., TANF, veterans benefits, general assistance);

- the individual's healthcare needs; and

- the individual's other characteristics, such as age, skills, work experience, and education.

Benefit variation by type of health insurance is likely to be particularly important for some people with disabilities. Medicaid, which was designed as a last resort for people with disabilities and other vulnerable groups, can provide the most comprehensive benefits, including long-term care, pharmaceutical, personal assistance services, and assistive device coverage but often has severe limits on payments that can result in restricted access to providers. In contrast, private health insurance and Medicare often do not provide coverage for services that some people with disabilities use intensively (for example, Medicare does not cover prescription drugs) but generally reimburse at higher rates than Medicaid for covered services. Further, Medicare does not cover most physician and outpatient services unless the beneficiary pays the premium for Part B coverage. ${ }^{19}$

When considering the effect of public health insurance on the employment of people with disabilities, it is useful to differentiate between the decision to seek (or increase) employment and the decision to leave (or decrease) employment.

The Decision to Seek Employment: The potential loss of public health insurance might well discourage DI and SSI program participants from seeking employment or increasing their earnings to a level that would jeopardize their public health insurance. It is this group of individuals who are most often considered in discussions of health insurance access and the employment of people with disabilities. Public health insurance also likely serves as a disincentive to work for non-workers with disabilities who are not DI or SSI recipients and are not privately insured. One incentive for a non-employed individual with a disability to obtain employment, for instance, is to receive employer-provided insurance or generate income to pay for healthcare directly. Public health insurance coverage reduces this incentive. The number of non-working people with disabilities for whom employment is a realistic route to insurance or health services is probably small, however. For those who are privately insured (e.g., as a spouse or dependent), public health insurance has little effect on the incentive to work unless the public insurance covers important services that are not covered by private insurers. Public coverage of such additional services would reduce the incentive to work because in the absence of insurance coverage the individual might view earnings from work as a means to obtain those services.

\footnotetext{
19 Individuals who meet certain earnings requirements are eligible to participate in the Qualified Medicare Beneficiary Program (QMB), in which Medicare premiums are paid by state Medicaid programs. We discuss evidence regarding the effects of this program below.
} 
The Decision to Leave Employment: Many workers with new or progressive impairments have little choice but to leave their jobs because of their health status. Others have a choice, and health insurance might be critical to that choice. Among these workers, it is helpful to distinguish between those in jobs with employer-provided health insurance and jobs without such insurance.

If the individual has health insurance through his or her employer and experiences a change in circumstances that causes him or her to consider leaving employment, the effect of public health insurance eligibility will depend, in part, on the continued availability of private insurance as the individual leaves employment. Insured workers who leave jobs might obtain coverage immediately in several ways: through paying premiums to continue employer coverage for up to 18 months $\left(\mathrm{COBRA}^{20}\right.$ continuation coverage); through the employer's disability or workers' compensation plan; through retiree health benefits; through a spouse's employer; from the VA; and through Medicaid if they meet the SSI means and disability tests or qualify by other means. Medicare can be obtained only after 29 months (five months of no SGA before applying, plus the 24-month waiting period for Medicare once eligible for DI) and only if the worker is DI eligible.

Medicare presumably would have little effect on the decision to leave employment of an insured worker who could obtain post-job insurance in some other way but could have a substantial effect if other options were unavailable. Medicaid would have similar effects, except that coverage of certain services by Medicaid might be an attractive reason to leave work for an individual who would otherwise have to pay for these services out of pocket. Public provision of these same services to those who continue employment would presumably reduce the incentive to leave work, but even so, providing these services would remove an important incentive to work.

The situation is different for workers with disabilities who are not insured. Faced with high healthcare costs, some such workers - particularly those with low earnings - might decide to leave work to obtain eligibility for public health insurance via DI and/or SSI. If, instead, the same worker could obtain public health insurance and continue to work, he or she might choose continued employment. Thus, uninsured workers with disabilities would be more likely to continue working if they could do so and obtain public health insurance. Note that the 29-month waiting period for Medicare eligibility under DI reduces this incentive considerably for those who would be eligible for DI only.

\section{c. Evidence}

A substantial amount of anecdotal evidence exists on the importance of health insurance in the employment and program participation decision of people with disabilities. In addition to the study cited above, another survey found that $79 \%$ of SSI applicants rated continued medical coverage as a major work incentive (GAO, 1996a). A survey of 359 chronic dialysis patients reported that $79 \%$ of non-employed and $78 \%$ of employed respondents viewed the loss of health insurance as a barrier to employment (Medical Education Institute, undated).

\footnotetext{
${ }^{20}$ The Consolidated Omnibus Reconciliation Act, passed in 1986.
} 
Despite this growing body of anecdotal evidence, policymakers and analysts are reluctant to rely on it because people's statements about the factors behind their own behavior often are inconsistent with their actual responses to changes in those factors. Further, people with disabilities often report multiple reasons for limiting employment, and removal of one of the reported deterrents will not remove the others.

No studies have been conducted to determine the extent to which Medicare and Medicaid availability and the high costs of private health insurance might induce individuals with disabilities to leave the labor force to obtain health insurance coverage. Several studies, however, have examined the relationship between availability of health insurance and labor force participation in other populations:

- Three studies have found evidence supporting the hypothesis that expansions of Medicaid benefits to coverage of former AFDC and other low-income families (without the link to AFDC program participation) increase labor force participation by mothers and decrease AFDC program participation (Moffitt and Wolfe, 1992; Yelowitz, 1995; and Wolfe and Hill, 1995).

- A study of the effect of the Qualified Medicare Beneficiary (QMB) program ${ }^{21}$ on SSI participation by the elderly found that SSI participation would have been $25 \%$ to $40 \%$ higher in 1992 than it actually was if there had been no QMB program (Yelowitz, 1996).

One recent study has demonstrated a relationship between section 1619(b) income thresholds (for purposes of eligibility) and the earnings levels of working SSI recipients that suggests the importance of health insurance. As previously discussed, section 1619 of the Social Security Act allows SSI disability recipients who work to receive Medicaid and remain SSI eligible but with reduced or zero payments, even if their earnings exceed the SGA level, provided their medical condition does not improve and their "chargeable income" (income after certain reductions) remains below the 1619(b) income threshold. Although recognizing the work incentive created by section 1619, GAO (1996a) suggests the effectiveness of this incentive is limited. GAO (1996a) argues that SSI recipients who lose their Medicaid benefits because their earnings exceed the threshold amount are apt to be uninsurable or face prohibitively high insurance premiums. Thus, SSI recipients who can work have a strong incentive to work up to the section 1619(b) threshold, but a much weaker, if any, incentive to work beyond the threshold.

Using SSA administrative data on SSI recipients who had reported earned income in 1990, Stapleton et al. (1998) examined whether some SSI recipients restrain earnings and employment to stay below the threshold. Controlling for other factors, the authors assess whether increases in the earnings of some SSI recipients are associated with recent increases in the 1619(b) threshold. The authors find strong evidence that some SSI recipients who work substantially increase their earnings as the threshold increases. This suggests that they restrain their employment earnings to stay below the 1619(b) threshold. The study found little evidence of an effect of threshold

\footnotetext{
${ }^{21}$ The Qualified Medicare Beneficiary (QMB) program, implemented in 1986, is available to Medicare beneficiaries with incomes at or below $100 \%$ of the Federal poverty level. Under the QMB program, Medicare premiums, deductibles, and coinsurance of QMB beneficiaries are paid by state Medicaid programs (OMB, 1999).
} 
increases on either the likelihood of employment or SSI participation. Significant effects were limited to impacts on the earnings levels of SSI recipients who were already working. The authors state that it appears recipients generally make marginal adjustments to their earnings in response to 1619(b) threshold changes and tend not to make wholesale changes to their SSI participation or employment status. Although the main reason for restraining earnings seems likely to be retention of Medicaid benefits, there is a second benefit of doing so-retaining automatic reinstatement of SSI payments should earnings fall.

\section{Assistive Devices and Technologies}

The Assistive Technology Act of 1998 defines an AT device as "any item, piece of equipment, or product system, whether acquired commercially, modified, or customized, that is used to increase, maintain, or improve functional capabilities of individuals with disabilities." Most AT devices are designed to help persons with physical or sensory impairments, although some assistive devices assist workers with mental impairments by helping these workers process information or by simplifying necessary work routines, such as using a magnetic scanning card to eliminate the need to manually clock in and out by computer (DeWitt, 1991; President's Committee on Mental Retardation, 1998).

In theory, access to AT should increase the labor force participation of people with disabilities by decreasing the barriers that prevent such individuals from working. These barriers might include difficulty completing work-related tasks, difficulty in traveling to and from work, and the increased time and effort necessary for persons with disabilities to complete non-work activities like housework and personal care. Devices such as specialized computer equipment allow people with disabilities to function more efficiently on the job. Other AT devices, like wheelchair lifts, make traveling easier for people with disabilities, allowing them to commute to and from work. Computers and the Internet have increased the opportunities for telecommuting. In addition, AT that is not used directly for work might make it easier and less time consuming to complete nonwork activities, allowing more time for work-related activities. ${ }^{22}$

A number of public policies exist regarding the provision of AT to persons with disabilities. These can be categorized as relating to either 1) public accessibility or 2) individual use of AT devices. Public accessibility policies promote or require increased access to buildings, services, or information for persons with a disability (or persons with a specific type of disability) through the use of AT. Policies regarding individual use of AT devices are intended to increase such use through either funding or promotion mechanisms.

\section{a. Policies Related to Public Accessibility}

Many potential physical barriers exist that might make it difficult or impossible for people who have disabilities to work. For instance, without accessible buildings and public transportation, a person who has an AT device such as a wheelchair will still face significant obstacles to working. The passage of the American with Disabilities Act (ADA) in 1990 requires that public

\footnotetext{
${ }^{22}$ This point is often overlooked for people with disabilities, but at the same time economists often cite advances in household technologies and the reduced time necessary to perform household tasks as a major explanation of the increased labor force participation of married women.
} 
transportation and "public accommodations" 23 be accessible to people with disabilities. All new buildings and renovations must comply with accessibility criteria, and existing architectural barriers must be removed (if the removal is readily achievable).

The Telecommunications Act of 1996 also promotes accessibility for people with disabilities. This act requires that manufacturers and providers of telecommunications equipment and services make the equipment and services they provide usable by people with disabilities or compatible with AT devices commonly used by people with disabilities (such as audio amplifiers and ring signal lights). Mandating that all telecommunications equipment be made this way ensures that people with disabilities will have equal access to telephones and other devices (manufactured subsequent to the Act). In addition, the Act decreases the expense and difficulty an employer likely would incur in providing an employee with a disability access to a telephone.

In addition to difficulties with physical accessibility, people with disabilities might also have difficulty gaining access to information. The Workforce Investment Act of 1998 requires that Federal departments and agencies use electronic and information technology that individuals with disabilities can access or provide information by an alternative means if providing access would impose an undue burden on the agency.

\section{b. Policies Related to Individual AT Devices}

Individual AT devices have the potential to make it possible for some people with disabilities to work. A number of government policies exist to improve access to AT for people with disabilities. Some policies provide funding for AT devices, while others are intended to promote awareness of AT or increase the level of coordination between the systems that provide AT.

Policies Related to AT Funding: One of the most important barriers preventing people with disabilities from using AT is lack of funding. Data from a national survey on the use of AT, the 1990 National Health Interview Survey on Assistive Devices (NHIS-AD), indicates that $48 \%$ of all AT devices were funded solely out of pocket by individuals, while another $18 \%$ were funded through a combination of out-of-pocket and other payment sources. The cost for some types of AT can be large, especially given the relatively low income of many workers and potential workers with disabilities (NCD, 1993). Tabulations from the 1990 NHIS-AD show that $22 \%$ of respondents age 18 to 64 who indicated a need for AT either did not use an AT device or needed additional devices (Adler, 1995). These data also indicate that more than $60 \%$ of people with unmet AT needs cite lack of affordability as the reason for their unmet needs (LaPlante, Hendershot, and Moss, 1994). ${ }^{24}$

A variety of government programs provide funding for AT. Medicaid, Medicare, and State VR programs all provide direct funding for some AT. Medicare provides coverage for durable medical equipment (DME) to people who have received DI for two years or more or are over age

\footnotetext{
23 "Public accommodations" include a wide variety of businesses and public gathering places such as restaurants, hotels, theatres, stores, museums, schools, and service establishments.

${ }^{24}$ People with unmet needs include those who use AT but indicate that they require additional AT and those who indicate that they need to, but do not, use AT.
} 
65. Medicare beneficiaries seeking coverage for DME must receive a certificate of medical need from a physician to be eligible. State Medicaid programs have the option of providing AT services, including prosthetic devices; speech, hearing, and language disorder services and devices; and eyeglasses. Most states provide these services, but some states restrict these services to the categorically needy only (those who are eligible for Medicaid through SSI) and exclude Medicaid recipients who are medically needy but do not take part in these programs. State VR programs are another potential source of funding for AT. In fiscal year 1991, $\$ 1.6$ billion in Federal funds provided benefits to 945,000 people served by VR programs, which was approximately $5 \%$ to $7 \%$ of individuals who were eligible. The Assistive Technology Act of 1998 provides continuity grants for AT to states that have received fewer than 10 years of funding under the Technology-Related Assistance for Individuals with Disabilities Act of 1988. This act allows states the option of using grant money to increase funding for AT through statefinanced systems.

Employers are another potential source of funding for AT for people with disabilities who work. The 1990 ADA requires employers of 15 or more workers to provide "reasonable accommodations" to current or potential workers with disabilities. These accommodations might include the provision of special devices or the modification of existing equipment to enable people with disabilities to work. As an employer mandate, the ADA devotes no Federal, State, or local funds directly to the provision of AT. However, indirect funding is available through small business tax credits for up to $50 \%$ of the cost of accommodations; eligible businesses are those with 30 or fewer employees and less than $\$ 1$ million in gross receipts.

DI and SSI do not provide direct funding for AT, but certain program features intended to encourage beneficiaries to return to work can help defray the cost of AT. IRWEs can be deducted from income when determining initial program eligibility and when testing earnings against the SGA standard. IRWEs include the expenses of purchasing, using, and maintaining AT for use on the job or the commute to work. The cost of AT might also be included in a beneficiary's PASS program, and those funds are not counted toward SGA or earnings under the SSI work incentive programs.

Policies Related to AT Information Dissemination: Information about AT availability generally is limited, meaning that many workers with disabilities remain unaware of products now available that could suit their needs. One focus-group study of working-age people with disabilities asked the interviewees for a "wish list" of AT yet unavailable. In many cases, the researchers informed participants that the desired items were available, including some at low cost (Ward, 1992).

The Assistive Technology Act of 1998 requires that states receiving grants promote greater public awareness of available AT. Many state programs have developed directories of AT resources and information about available funding (Seelman, 1998). The Center for Rehabilitation Technology at the Georgia Institute of Technology, through a grant from the National Institute on Disability and Rehabilitation Research (NIDRR), is developing an Internet site designed to provide information on a wide range of disability-related resources, including links to public and private AT resources and public and private programs of excellence. 
Policies Addressing the Fragmentation of AT Services: There is no national policy that determines who may or may not receive AT. Instead, there are a number of systems (including the special education and rehabilitation systems and public health insurance) that meet some of the AT needs of the special populations they serve. Often, AT devices purchased by the education system or the rehabilitation system are owned by the respective system, not by the user. Hence, when a person moves between systems (for example, when a student moves from one state to another or graduates from high school), he or she likely will lose access to an AT device he or she is already successfully using and must begin the process of eligibility determination and service planning again (Seelman, 1998). For individuals transitioning into the workforce, the loss of AT might serve as a substantial obstacle to successful employment.

Several policies have attempted to address the problem of coordination of services. The 1997 amendments to the Individuals with Disabilities Education Act and the Vocational Rehabilitation Act make transition planning a required service in both special education programs and State vocational rehabilitation agencies, respectively. As a part of transition planning, it is possible to arrange for the transfer of ownership of AT devices between the school system the student is leaving and the VR system he or she are entering. However, Mendelsohn and Goodman (1999) report that school districts might not have the authority to transfer ownership of AT devices, and this has prevented many administrators from allowing such transfers to take place. The Office of Special Education and Rehabilitative Services (OSERS) in the Department of Education recently issued a statement clarifying its policy on transition and expressly permitted schools to transfer ownership of AT devices to the State rehabilitation agency serving the former students (Mendelsohn and Goodman, 1999).

\section{b. Impact of AT-Related Policies on the Employment of People with Disabilities}

The policies described above have a number of potential implications for the employment of people with disabilities. State VR programs that provide information about and funding for AT devices mean that more people will have access to AT devices that could help them work. Increased access to public buildings and to telecommunications equipment is likely to make it easier for people with disabilities to enter and remain in the labor force. However, these policies also could create disincentives or other barriers to employment. For example, reliance on AT devices could actually discourage people with disabilities from returning to work. Access to devices purchased with the help of Medicare or Medicaid might be lost if a person loses eligibility for this coverage because of return to work. Because they do not own their AT devices themselves, potential clients of the VR system might also be concerned about losing access to AT after successful completion of the VR program, which could discourage them from accessing AT and employment-related services through the VR system.

Because AT devices, AT users, the circumstances under which AT devices are needed (i.e., for performing specific functions of daily living, for specific work-related functions, or both), and the means by which funding for these devices is obtained are so diverse, it is difficult to generalize about the likely impact on employment of public policies designed to improve access to AT in the same way we have for public assistance and health insurance programs. This might be one reason for the lack of empirical evidence on the effect of AT on employment. 
Although it is a logical assumption that, all else being equal, access to appropriate AT increases the ability of some people with disabilities to work, we have found little empirical evidence of the effect of AT on the employment of people with disabilities. We are aware of one study showing how the use of computers played an important role for many people with spinal cord injuries (SCI) who were working. Krueger and Kruse (1995) showed that individuals who used computers at work before they were injured were more likely to have been employed since their injuries than those who had never used a computer (before their injury) and were more likely to be employed at the time of the study. Those who became re-employed after injury were much more likely to use computers at work after their injury than they were before. Holding other characteristics constant, the authors found that SCI individuals with computer skills had higher weekly and quarterly earnings, longer work hours, and a quicker return to work following injury than SCI individuals without computer skills (Krueger and Kruse, 1995). The results of this study suggest that developing computer skills and the use of computers might be an especially effective AT for people with physical disabilities. However, a recent study found that although employed people with disabilities are more likely to have access to a computer at home and to use the Internet than their unemployed counterparts, they were considerably less likely to have access to a computer or use the Internet than employed people without disabilities (Kaye, 2000).

\section{Personal Assistance Services}

Personal Assistance Services (PAS) can be characterized as help from another person to accomplish the basic activities of daily living (ADL), including mobility, eating, dressing, bathing, toileting, and the instrumental activities of daily living (IADL), such as cleaning, preparing meals, and shopping. Other PAS might include assistance with communication, transportation, and completing job-related tasks.

Only a small minority of employed individuals with disabilities use personal assistance for ADLs or IADLs. Using data from the 1991/1992 SIPP, McNeil (1993) estimated that about $0.7 \%$ of all workers with disabilities, $5.4 \%$ of all people with disabilities, and more than $25 \%$ of people with severe disabilities needed personal assistance with an ADL and/or an IADL. Among workingage adults with ADL assistance needs, more than $80 \%$ are not in the workforce (Kennedy, 1998). The vast majority of people who receive assistance with an ADL receive it from a family member (83\%), most often a spouse or daughter. According to the 1991/1992 SIPP, only $9.2 \%$ of people receiving personal assistance use paid providers as the primary source (Kennedy, LaPlante, and Kaye, 1997).

PAS can affect the ability of people with disabilities to participate in the labor force in two ways: It can be used directly to help the person with a disability to meet job requirements, and it can be used to help individuals with disabilities to work by giving them more time. Disabilities increase the time needed to perform many everyday tasks, leaving less time available for activities like working. With the help of a personal assistant to complete some of these tasks, a person with a disability could have more time available to engage in employment-related activities.

\section{a. Impact of PAS on the Employment of People with Disabilities}

The employment incentives facing an individual needing PAS depend greatly on the funding sources available to the individual. PAS is primarily financed through public programs and by 
recipients' own resources. Few public PAS programs cover work-related PAS or competitively employed PAS users, and private insurance programs do not cover PAS (Litvak, 1991b and 1991c). This suggests that the cost of PAS is a key determinant of whether competitively employed individuals can gain access to PAS and, ultimately, whether PAS users can afford to work. The discussion of the incentives and their impact on employment is divided into those privately funded PAS created and those public PAS programs created.

Incentives Associated with the Private Funding of PAS: There are two possible private sources of PAS funding for workers with disabilities: the individual and his or her employer. Employer funding of PAS is likely to make work more attractive to the person with disabilities, but the cost of providing PAS, like the cost of any employer accommodation, increases the cost of hiring a worker with disabilities. It is likely, therefore, to have an impact on employer demand for such workers (discussed further in Section IV). In the absence of employer- or publiclyfunded PAS, the need for PAS might be a barrier to work. Some individuals might need assistance with tasks specifically related to work, such as help on the job or help with transportation to and from work. For these people, the costs of PAS will rise with work activity, thereby reducing the net gains from working and making work less attractive. Others might need PAS regardless of whether they are working but might need assistance for more hours a day or with more varied tasks if they work. For those who need PAS virtually full-time regardless of work activity, PAS is not a work-related cost. These individuals are likely to have the most severe disabilities and probably are the least likely to have the ability to work regardless of their circumstances. Therefore, unless some other party funds PAS or the earnings obtained through work substantially offset the costs of PAS, individuals with disabilities needing PAS to work will not have a strong incentive to seek employment.

The Federal tax code provides limited subsidies to individuals who bear the costs of their own PAS at work (Litvak, 1994). Under Section 67(d) of the internal revenue code, impairmentrelated work expenses, including attendant care services at or in connection with the place of work, are tax deductible without regard to the threshold levels that ordinarily apply to the deduction for employee business expenses. Although this deduction might offset some of the costs of PAS, it provides greater relief for upper income workers (via their higher marginal tax rates), who are already more likely able to afford PAS, and less relief to people with disabilities who have low or middle income.

Incentives Associated with the Public Funding of PAS: Publicly-financed programs that deliver PAS typically are designed and implemented at the State level, so there is a good deal of variation, and it is difficult to examine specific programs. A recurrent theme in the literature related to the public financing of PAS, however, is the restrictions that some programs place on participants and how these restrictions act as disincentives to employment. Features of public PAS programs that create access problems for workers with PAS needs, and often act as disincentives for employment, generally fall into two categories: eligibility criteria and service limitations.

Eligibility restrictions might be based on income and resources, age, documented need for services, functional limitations, risk of institutionalization, presence or absence of a caregiver, or whether the disability is physical or mental, and often are imposed by the funding sources that support PAS programs. These funding sources, which include Medicaid, Social Service Block 
Grants (Title XX), Title III of the Older Americans Act, State funds, VA Aid and Attendants Allowance, and Medicare, often have eligibility criteria related to age and income that preclude much of the working-age population (Litvak, undated; Litvak, 1991c; Kennedy, 1993; WID and Rutgers University, undated; Egley, 1994; Litvak and Kennedy, 1991). Income-based eligibility requirements might be particularly restrictive for PAS users who are competitively employed and might induce some users to restrict work and earnings to remain eligible for PAS.

For people with disabilities who need PAS to work, service limitations in their PAS delivery might make working unfeasible. These restrictions include limits on the types of services and number of hours, times when services are available, and types of caregivers available through these programs.

A study by Kimmich and Godfrey (1991) found that PAS users cited as barriers to employment both eligibility restrictions and service limitations. Enrollees of 10 public PAS programs noted the need for transportation $(22 \%)$, the need for personal assistance on the job complicated by the limited hours of paid assistance and agency rules (22\%), and fear of losing benefits (18\%) as important barriers.

Some states have attempted to minimize the extent to which their public PAS program eligibility requirements function as work disincentives, usually by having no income limit, setting the income limit high enough that most working people are covered, or allowing a state-subsidized buy-in arrangement for programs subsidized by Federal sources (Litvak, 1991a; Litvak, 1991c; Kennedy, 1993; Kimmich and Godfrey, 1991; Degener, 1992). Also, some states, such as Massachusetts and Pennsylvania, provide work-oriented PAS programs, which structure their service limitations to minimize work disincentives. These programs generally allow recipients to employ their own assistants, encourage people to obtain management training through local Independent Living Programs, and allow service 24 hours a day (Litvak, 1991a). Work-oriented PAS programs tend to be small (fewer than 100 recipients) and usually are administered by State VR agencies using State funds.

In recent years, four states have introduced acts that provide funding for PAS for people with disabilities, usually by reallocating funds from nursing home expenditures (Vermont's Personal Assistance Services Act of 1996, the Ohio Community Assistance Services Act of 1996, Georgia's Long Term Care Choice Act of 1997, and the Community Attendant Services Act of Texas of 1997). Although these laws do not specifically target employed people with disabilities, they all share common features that might make it easier for users to become employed. These features include the chance for those whose income is more than $225 \%$ of the poverty level to "buy in" to the program; eligibility based on functional need rather than diagnosis; and service provision in a variety of environments, including work and school (ADAPT, 1998). Similar legislation, the Medicaid Community Attendant Services Act (MiCASA), was introduced in Congress in 1998 but was not passed.

\section{c. Evidence}

Several studies have investigated the relationship between access to PAS, employment, and productivity. A study by Louis Harris \& Associates (1994) reported that 93\% of full-time workers with disabilities did not attribute their employment status to having an interpreter or 
personal care attendant but that nearly one-quarter of people with disabilities who were not working full-time reported that they needed the help of a personal assistant to get to work or maintain full-time employment. This suggests that although PAS might not be the deciding factor determining which people with disabilities work in many instances, the lack of availability of these services might be keeping many out of the workforce. The study is limited, however, in that it addresses only attitudes and beliefs and does not examine the actual effect of PAS use on workforce participation.

Several studies have focused on consumer-directed PAS and its effect on productivity and employment using data from a longitudinal evaluation of these services conducted in Virginia. In one such study comparing the productivity of people receiving consumer-directed PAS to the productivity of individuals still on a waiting list for the program, the authors found that, with controls for health status, level of disability, age, and sex, those receiving PAS demonstrated significantly higher levels of productivity. Productivity was measured using the occupation subscale of the Craig Handicap Assessment and Reporting Technique (CHART), which is based on the number of hours per week spent in paid work, school, active homemaking, home maintenance, volunteer work, recreation, and self-improvement activities (Richmond et al., 1997).

Using data from a different wave of the same evaluation, a study focused on people with spinal cord injuries (who made up 29\% of all participants in the PAS program studied) found that those receiving PAS were more than twice as likely to be employed than those on the waiting list and had significantly higher levels of productivity, suggesting that PAS might be particularly helpful for people with spinal cord injuries in seeking and maintaining employment (Adams and Beatty, 1998). Results of both of these Virginia studies were limited, however, by small sample sizes. Their findings might also be affected by the fact that approximately half of those on the waiting list (the comparison group) received some type of PAS outside of the consumer-directed program studied, which might have led to underestimates of the impact of PAS on productivity and employment.

\section{Other In-Kind Benefits}

Employment decisions of people with disabilities can be influenced by the receipt of in-kind benefits from other programs available to low-income individuals, regardless of disability status.

\section{a. Food Stamps}

Food stamps are designed to increase the food purchasing power of low-income households by subsidizing food purchases through coupons that can be used like cash at the grocery store. To qualify for food stamps, a household's gross income must be less than $130 \%$ of the federal poverty guideline based on household size. In addition, the household's income net of deductions (which include a standard deduction, $\$ 134$ in 1997, a deduction of $20 \%$ of earned income, and deductions for some dependent care, medical and housing costs, and child support payments) must be below $100 \%$ of the Federal poverty guideline. A household is exempt from these income requirements if all members of the household receive AFDC/TANF, general assistance, or SSI.

Food stamp recipients also must pass an asset test, having less than $\$ 2,000$ in countable assets (including cash, assets that can easily be converted to cash, and non-liquid resources). Vehicles 
used to transport a person with a disability do not count as assets, nor do family homes, tools of a trade, or business property used to earn income. There also is a work requirement for most food stamp recipients without dependents, but the requirement does not apply to people with disabilities. When eligibility is established, the food stamp benefit amount is determined by the difference between the calculated necessary food expenses for a household of a given size (as defined by the Thrifty Food Plan) and 30\% of net household income. Benefits are reduced by 30 cents for each dollar of additional net household income.

In fiscal year 1997, 2.1 million households having members with disabilities received food stamps, representing $22 \%$ of all food stamp households. These households received an average monthly benefit of \$104 (Cody and Castner, 1999).

In theory, the Food Stamp program creates a disincentive to work, because food stamps increase the income available for other purchases and decrease the need for work. However, a small work incentive is built into the calculation used to determine benefit levels. The program counts all income from SSI and DI toward eligibility and excludes $20 \%$ of earned income toward eligibility, making work slightly more attractive than receipt of DI or SSI benefits when expected earnings are small. The small size of the average food stamp benefit, however, would result in a small marginal difference in benefit size. For this reason, the disincentive effect of the food stamp program would likely outweigh its incentive effect on employment.

\section{b. Energy and Housing Assistance}

The Low-Income Home Energy Assistance Program (LIHEAP) makes grants available to states and other jurisdictions to help eligible households meet the costs of home energy. Although eligibility requirements vary by state, generally households are eligible for assistance if total household income does not exceed $150 \%$ of the Federal poverty guideline or if a member of the household receives SSI, TANF, food stamps or certain means-tested veterans benefits (Administration for Children and Families, undated).

The Housing Choice Voucher program, which combines the Section 8 Voucher and Section 8 Certificate programs, provides housing assistance payments to participating owners on behalf of eligible tenants. Housing assistance payments are generally the difference between the local payment standard and $30 \%$ of the family's adjusted income. Typically, a family pays a minimum of $10 \%$ of gross income.

A program specifically for people with disabilities, Supportive Housing for Persons with Disabilities, provides interest-free capital advances to nonprofit organizations that build, rehabilitate, or purchase rental housing to be used as supportive housing for persons with disabilities. The advance is interest free and does not have to be repaid as long as the housing remains available for low-income persons with disabilities for at least 40 years (Catalog of Federal Domestic Assistance, undated).

The Independent Living program provides services to individuals with disabilities to maximize their independence and productivity. Formula grants are awarded to states to provide independent living services and to support centers for independent living. The Centers for Independent Living (CIL) program provides funds to nonprofit organizations that establish such centers and provide independent living services to people with significant disabilities. Such 
services include independent living skills training, peer counseling, community outreach, and employment services. The CIL program supports approximately 250 CILs nationally, with at least one CIL in each state. Approximately 100,000 individuals nationally receive direct services from a CIL (Catalog of Federal Domestic Assistance, undated).

The work disincentives created by these programs apply only to earnings above the level at which benefits are terminated. Below the eligible earnings ceiling, a recipient can retain his or her earnings without affecting benefits, thereby allowing recipients to increase total income through work. When a recipient has earnings above the eligibility ceiling, he or she is no longer eligible for in-kind benefits. Thus, the eligibility level represents a cliff, where earnings beyond this level result in a significant drop in total income. This creates a strong incentive for recipients to work up to the earnings level itself, but no higher.

\section{Multiple Program Participation}

Among working-age persons with disabilities who receive government transfers, a substantial percent receive benefits from more than one program. For instance, data from the 1990 SIPP show that, among the approximately $13 \%$ of the working-age population with disabilities receiving SSI payments, about one in four were also receiving DI. In addition, all were eligible for Medicaid and 29\% were eligible for Medicare (Burkhauser and Wittenburg, 1996). In 1997, of the 4.5 million workers under age 65 receiving DI benefits, about 16\% (707,310) also were receiving SSI (SSA, 1998a). Where work disincentives associated with individual programs exist, participation in multiple programs can compound these disincentives, making work even less attractive.

For example, all SSI and DI recipients are eventually eligible to receive either Medicare or Medicaid. When beneficiaries of these two programs attempt to work or increase their earnings from employment, they will face three work disincentives: 1) They will be subject to implicit taxes in the form of reduced cash benefits from these programs and other transfer programs in which they participate (e.g., Food Stamps); 2) they will be subject to the regular assortment of Federal, State, and local taxes; and 3) they will be subject to the potential loss of their public health insurance and other public in-kind benefits (such as food stamps and PAS).

Thus, the implicit net tax on labor earnings-assessed participants in multiple public programs serving individuals with disabilities can be prohibitive, reaching as high as $74 \%$ according to one study (Burkhauser and Wittenburg, 1996). Using 1990 data, the authors estimate that the combined value of monthly DI and Medicare insurance for a single working-age male with a disability and with no labor income was $\$ 1,083$. The consequence of earning $\$ 1$ more than the SGA threshold (then $\$ 500$ ) for this worker was the loss of $\$ 1,083$ in benefits. To reach the same net income level he would have received while earning $\$ 500$, he would have to make $\$ 1,918$ in pre-tax labor earnings. Given these findings, it is not surprising, then, that few DI recipients return to work.

\section{E. Human Capital Development}

The lifetime investments that a person makes in his or her abilities and skills, which economists generally refer to as human capital, will have a major affect on their employment decisions. 
People can accumulate a larger stock of human capital by making (human capital) investments that enhance their skills and abilities, such as formal education and training. Individuals with more human capital will be able to command a higher wage rate in the labor market. For example, on average, high school graduates earn higher wages relative to those who drop out of school (Haveman and Wolfe, 1995).

Individuals make human capital investment decisions based on the costs associated with developing a particular skill set and the expected benefit of the future returns to the investment through (presumably) higher wages and increased job satisfaction. ${ }^{25}$ For example, when making a determination about attending college, an individual must weigh the opportunity costs of attending college (e.g., tuition, time, lost wages) against the future benefits of a college degree (e.g., higher paying future job).

Disability onset can have a major effect on a person's stock of human capital. For some, the onset of the disability might completely limit their ability to work or perform certain activities. For example, a hand injury might end the human capital development of a pianist. For others, disability onset might have limited effects. A severe hand injury might have no impact on a singer's career.

The timing of the disability onset strongly influences human capital development. An individual who experiences onset as a child likely will make different types of human capital investments throughout his or her life than an individual who experiences onset as an adult.

It is important to note that participation in several of the government transfer programs described above (particularly SSI) can also have a major effect on a person's human capital investment decisions. $^{26}$

\section{Education Programs and Policies}

Empirical evidence suggests that youth with disabilities develop less human capital relative to other groups. In comparison to other youth, youth with disabilities are significantly less likely to graduate from high school or college, become employed, or enroll in post-secondary education (Horn, 1999; Wagner, et al., 1996). Hence, it is important to identify programs that influence human capital development of youth with disabilities because these programs likely will have a major effect on later adult outcomes.

\footnotetext{
${ }^{25}$ Future benefits are "discounted" by the interest rate and by the individual's preferences for current consumption.

${ }^{26}$ There are several potential effects of program participation on human capital decisions. First, some individuals might plan to stay in these programs permanently and, hence, choose to invest less in human capital because of smaller perceived gains in the labor market. For example, child SSI recipients might choose to avoid work-like activities for fear of losing benefits as an adult. Second, the eligibility requirements that place restrictions on work in many of these programs will distort an individual's labor market decision. Consequently, some participants might not gain valuable labor force experience that aids in their human capital development. Third, stakeholders (e.g., family members) might influence program participants to pursue activities that will ensure their eligibility for the programs. For example, parents of SSI children might not encourage their child to enter the labor force in fear that the child could permanently lose important income and health supports. Fourth, SSI benefits can help finance an individual's education.
} 
Under the Individuals with Disabilities Education Act (IDEA), states are required to provide free appropriate public education for students with disabilities at the elementary and secondary levels. The Department of Education (2000) defines a child with a disability as any child "(i) with mental retardation, hearing impairments (including deafness), speech or language impairments, visual impairments (including blindness), serious emotional disturbance (hereinafter referred to as 'emotional disturbance'), orthopedic impairments, autism, traumatic brain injury, other health impairments, or specific learning disabilities; and (ii) who, by reason thereof, needs special education and related services."

Schools are required to create Individual Education Programs (IEP) to help youth with disabilities obtain important services at no extra cost to their families. IEPs provide a central guide to available services and a plan for post-secondary transitions from school to work for all youth with disabilities during secondary school. Examples of IEP services include physical therapy, personal counseling, speech therapy, life skills, and reader and interpreter services. Students may receive special education services from schools at no addition costs to their families. Services are provided in the classrooms, home, hospitals, institutions, and other settings.

The Department of Education Office of Special Education (OSEP) provides grants to assist states in providing services. In 1998, the activities included three formula grant programs, totaling more than $\$ 4.5$ billion for special education services (Department of Education OSEP, 1998). ${ }^{27}$

Previous studies find that special education programs and vocational classes can affect other school activities and future career decisions. In a study of the effect of special education programs on academic achievement, Hanushek, Kain, and Rivkin (1998) found initial evidence that such programs do raise their level of achievement in other core courses, such as math. Blackorby and Wagner (1996) found that a concentration of courses in one vocational area and taking unrelated survey courses increased the probability of competitive employment by youth in special education programs.

Youths with disabilities might also receive support from other support systems while in school. Some service systems, such as Mental Retardation (i.e., Mental Retardation/Developmental Disabilities system), serve youth with specific limitations, although others (e.g., transfer program, training services, assistive devices) ${ }^{28}$ provide services based on need.

Wittenburg et al. (2000) note that the interaction of these school-based services with other outside services has important implications for post-school transition decisions (including employment) of youth with disabilities. They also point out that there is a potentially large disconnect for some youth with disabilities between the services provided in school and the services available to them immediately following school. For example, although youth with

\footnotetext{
${ }^{27}$ The remaining activities were funded under discretionary grant programs that provided grants on a competitive basis to universities, state and local educational agencies, and other private and public profit and nonprofit organizations to conduct research, training, technical assistance, and evaluation aimed at supporting the implementation of IDEA.

${ }^{28}$ We provide a more detailed description of these training services below.
} 
mental retardation can continue to access the Mental Retardation/Developmental Disability program after they leave school, youth with other disabilities, such as learning disabilities, cannot necessarily access the same universal system of services.

\section{Vocational Rehabilitation Programs}

Two public programs that provide VR services are the Federal-State VR system and VR services provided by the VA.

\section{a. State VR}

VR is a nationwide Federal-State program that provides medical, therapeutic, counseling, education, training, work-related placement assistance, and other services. ${ }^{29}$ The VR system is intended to cover everything that a person needs to overcome a barrier to employment. People are eligible for VR services if they 1) have a physical or mental impairment that results in a substantial barrier to employment, 2) are able to benefit from VR services in terms of employment, and 3) require VR services to prepare for, enter, engage in, or retain employment (U.S. Department of Education, 1996b).

Social Security disability beneficiaries represent $65 \%$ to $75 \%$ of those served by the VR system. Historically, VR has had minimal success in assisting SSA beneficiaries to both obtain employment and exiting the benefit rolls. In the past, SSA referred these individuals to VR after a determination that the individual was an appropriate candidate. Relatively few DI or SSI beneficiaries, however, were referred; many of those referred were never accepted for services; and only a small fraction of those accepted obtained sufficient employment to enable them to leave the disability rolls.

Recently, a number of reforms have been initiated to increase access to and the effectiveness of the VR program. The most recent reauthorization of the VR program in 1998 loosened eligibility requirements for SSI and DI beneficiaries, promoted collaboration with One-Stop Career Centers and other programs funded through the Workforce Improvement Act, and provided for the awarding of competitive one-time, time-limited grants, contracts or cooperative agreements to eligible entities to establish self-employment projects for individuals with disabilities. Beginning in April 1999, DI and SSI disability recipients have the option of self referring to rehabilitation services (SSA, 1999d). The WIIA established a Ticket to Work program (described in Section V) to increase service capacity and promote competition among public and private service providers.

State VR agencies provide services to individuals with disabilities through field counselors, who work from offices located throughout each state. States provide a comprehensive array of VR services, including assessment of client eligibility and rehabilitation needs, counseling, vocational and other training services, guidance and work-related placement services, and

\footnotetext{
${ }^{29}$ In addition to the basic VR services program, the VR system includes a number of special programs that provide more than $\$ 100$ million in additional grant funds to enhance services for specific populations including services for: migratory agricultural and seasonal farmworkers with disabilities, American Indians with disabilities, people who are blind or blind-deaf, and other groups with severe disabilities (Stapleton et al., 1999b).
} 
rehabilitation technology services. VR agencies contract with community-based organizations to provide many of these services. Rehabilitation services are provided based on economic need, except for diagnostic, counseling, and placement services. Other services, such as medical therapies and educational services, might require some cost sharing by the client. The SSA pays for vocational rehabilitation services provided to DI and SSI beneficiaries contingent on the beneficiary's return to work for at least nine continuous months at a substantial earnings level.

VR programs are required to give priority to people with severe disabilities. Because of limited resources, individuals with less severe disabilities might be forced to wait for services or might leave VR without receiving services. The Rehabilitation Act of 1992 stipulated, however, that all individuals with disabilities are presumed to benefit from VR services, unless the agency can show evidence to the contrary. This change has resulted in a decrease in the number of applicants determined to be ineligible for services because of a severe disability and has increased the acceptance rate for applicants from 57\% in 1992 to $72 \%$ in 1996 (O'Shaughnessy and Butler, 1998).

On average, consumers receive services for approximately two years. Most receive some form of training. Clients are considered to be rehabilitated if, after receiving VR services, they maintain a rehabilitation objective - usually employment - for at least 60 days. In fiscal year 1995, 25\% received personal or vocational adjustment training, $17 \%$ attended business or vocational classes, $16 \%$ attended college, and $8 \%$ received on-the-job training (Kaye, 1998).

The VR program received Federal funding of $\$ 2.2$ billion for fiscal year 1998 (O'Shaughnessy and Butler, 1998), matched by approximately $\$ 645$ million in State and local funds (Kaye, 1998). In fiscal year 1995, the program served more than 1.25 million individuals with disabilities, of whom 209,500 were considered to have been rehabilitated (O'Shaughnessy and Butler, 1998). The number of rehabilitated clients represents $46 \%$ of all people exiting the VR system and $60 \%$ of those exiting after receiving services. On average, VR spent about $\$ 13,000$ per rehabilitated client. The majority (76\%) of people rehabilitated in 1995 were those with severe disabilities (Kaye, 1998).

There are concerns that the $60 \%$ success rate of those receiving services might reflect the fact that only selective portions of the population with disabilities are receiving the services. GAO (1993) estimated that VR served only between five percent and seven percent of the total eligible population. Further, GAO found that gains in employment and earnings faded by about two years after case closure, and the proportion of consumers who were working steadily declined. ${ }^{30}$ Some have also raised the concern that the VR system does not adequately address the needs of people with certain health conditions. For example, the National Alliance for the Mentally Ill (NAMI) concluded that VR has failed as a source of vocational rehabilitation services for the mentally ill population (Noble et al., undated). Although there are some limitations of this study, it raises concern that not all people with disabilities receive the same access to VR. ${ }^{31}$

\footnotetext{
${ }^{30}$ Participants, however, did fare better than program dropouts on all measure of work and earnings, even after statistical analyses controlled for some pre-program differences between the groups.

${ }^{31}$ Several of the reasons cited for this failure were specific to the mentally ill population. For example, NAMI pointed out that there was a lack of counselor training about the characteristics of individuals with severe mental
} 
The Longitudinal Study of the Vocational Rehabilitation Service Program, initiated in the fall of 1992, has examined characteristics of those taking advantage of VR. Interim findings show that at least $75 \%$ of all VR customers have disabilities classified as severe and that nearly half received some form of financial assistance during VR, including 16\% who received SSI and 12\% who received DI. Ninety-two percent of VR customers had some amount of employment experience before applying for VR services, and 25\% were working at the time they applied. Of those with employment histories, $87 \%$ were most recently employed in the competitive labor market, with a mean wage of $\$ 7.43$ per hour and a median wage of $\$ 5.85$. Approximately $35 \%$ received health insurance through their employer, substantially less than the national norm of 52\% (Hayward and Tashjian, 1996).

The study also provides information on the employment outcomes of those who became employed after leaving VR services. Of those who obtained a competitive job through VR services, the mean wage was $\$ 7.35$ an hour, but $60 \%$ made $\$ 7.00$ an hour or less and held jobs that were less likely to provide medical benefits. Those with relatively more education earned higher salaries, and those with low reading and mathematics achievement earned lower hourly wages. The study also found that $85 \%$ of those who had achieved a competitive job through VR were still working, $64 \%$ in the job they had obtained through VR. Over the course of the year, average hourly wages increased to $\$ 7.94$ (median of \$6.67), and nearly half reported receipt of medical benefits. More than 50\% reported satisfaction with their earnings, benefits, and opportunity for advancement, and $88 \%$ were satisfied with their sense of belonging to the workplace. (Hayward, 1998.)

\section{b. Veteran Vocational Rehabilitation Programs}

The VA provides separate VR services to veterans. VA VR services are available to veterans who incurred a service-connected disability during or after 1940. Veterans with disabilities are eligible for program services if their disability reduces their earning capacity by $20 \%$ or more, and VA determines that they have an employment handicap (GAO, 1996b). The services provided by veteran VR programs are similar to those provided by State VR agencies.

Veteran VR programs have had limited success in placing clients in employment, particularly when compared with State VR programs. ${ }^{32}$ GAO (1996b) reported that during the previous five years, VA "rehabilitated" only $8 \%$ of the 74,000 veterans who were eligible for vocational

illness and their service needs. However, a number of other problems cited in the study might be viewed as general weaknesses of the program, particularly in serving more severely disabled populations. The study pointed to the system of performance standards that rewards counselors for placing clients quickly into employment and at low cost, creating a disincentive to serving people with more long-term needs, and the disproportionate amount of resources put into determining client eligibility as serious problems. It also pointed out that the time-limited nature of VR services, which is not well suited to individuals with many psychiatric disabilities or other disabilities that tend to be episodic in nature.

${ }^{32}$ In the face of these and other criticisms, the VA has taken steps to address what it considers to be the causes of some of these problems (Thompson et al., 1998). Efforts have included investigating the high dropout rate among vocational rehabilitation program participants, improving communications with veterans and other stakeholders about the purposes of the program, and examining the effectiveness of contracting with non-government service providers. 
rehabilitation program services (GAO, 1996b). By comparison, State VR agencies rehabilitated $37 \%$ of their eligible population, most of whom had severe disabilities. The VA vocational rehabilitation program also spent significantly more $(\$ 20,000)$ than the State VR agencies $(\$ 3,000)$ on successful participants, in part because the VA program includes veteran living expenses. In the face of this and other criticism, VA has taken steps to address what it considers to be the causes of some of these problems. Efforts have included investigating the high dropout rate among vocational rehabilitation program participants, improving communications with veterans and other stakeholders about the purposes of the program, and examining the effectiveness of contracting with non-government service providers.

\section{Training Programs}

People with disabilities who do not immediately contact the VR, SSI, or TANF systems might access work and other support services through the State Workforce Development system or the Projects with Industry Program.

\section{a. State Workforce Development Systems}

The Workforce Investment Act of 1998 (WIA) organized Federal statutes governing the job training, adult education and literacy, and VR programs into a one-stop delivery system. ${ }^{33}$ (Section VI describes the WIA in more detail.) Under this system, states are required to develop workforce development plans that describe how the state will meet the needs of major customer groups, including individuals with disabilities, and show how the plans will ensure nondiscrimination and equal opportunity. Title IV of the WIA specifically targets people with disabilities with amendments to the Rehabilitation Act. In this section, State and local boards are required to 1) link the State vocational rehabilitation systems to the developing State workforce investment systems, 2) streamline the current State vocational rehabilitation systems, and 3) improve delivery of services by providing more consumer choice, facilitating self-employment for individuals with disabilities, ensuring certain core services are available to all eligible individuals, and improving the clients' dispute resolution process.

The WIA mandates that one-stop systems be readily accessible to all Americans. Some of the partners in this system include employment services, adult education, post-secondary vocational education, VR, Welfare-to-Work, and Community Services Block Grant. All adults are eligible for core services and youth enrolled in school are eligible for certain services if they meet certain State criteria for employment, income, and/or disability. In many states, these systems are directly linked to VR and/or TANF services.

\section{b. Projects with Industry Program}

The Projects with Industry program (PWI), created as part of the Rehabilitation Act of 1973, creates partnerships among business, industry, labor, and the rehabilitation community to assist in providing employment opportunities for people with disabilities. The U.S. Department of

\footnotetext{
${ }^{33}$ WIA replaced the Job Training Partnership Act (JTPA).
} 
Education provides approximately $\$ 22$ million annually to fund 125 national, State, and local projects.

PWI services generally include intake and evaluation, prevocational counseling, training to enhance job-seeking skills, vocational training, job development, and job placement. The program emphasizes job training in work settings, generally within commercial or industrial establishments. For example, some projects arrange for clients to participate in the same training programs businesses provide to their own employees.

In fiscal year 1993, PWI successfully placed 11,486 individuals with disabilities in jobs, at an average cost of $\$ 1,726$ (U.S. Department of Education, undated). According to the International Association of Business, Industry and Rehabilitation (I-NABIR), an advocacy organization for PWI projects, for every dollar spent on services, PWI clients return $\$ 3.00$ in the first year after placement in FICA (Social Security taxes), income tax, and reductions in public income supports (I-NABIR, undated). This might significantly overstate the returns to the program, however, because some clients might have successfully entered the workforce without participating in PWI.

\section{F. Tax Policies}

Two provisions in the U.S. tax code have the potential to affect the employment incentives faced by individuals with disabilities, although not developed specifically for that purpose. Two tax benefits that might affect the decision to work among those with disabilities are the income exemption of flexible healthcare spending accounts and the deduction for impairment-related work expenses.

Income Exemption of Flexible Healthcare Spending Accounts: Benefits from a flexible healthcare spending account must be received from a qualified, employer-based plan. This benefit allows individuals to exclude healthcare expenses from taxable income, up to a maximum benefit of $\$ 3,600$ per year. Flexible healthcare spending accounts may be used to pay for most healthcare expenditures, including prostheses, assistive devices, and other technologies of importance to persons with disabilities.

Flexible spending accounts might act as a work incentive for people with disabilities because the benefit is available only through employer-based plans, although people with disabilities might have indirect access to these plans through the employer of a spouse or other family member (if they are a dependent of that family member). The benefit is likely to have only a small effect on the employment decisions of persons with disabilities for two reasons. First, the benefit must be offered by the individual's employer, and not all employers offer it. Second, its value is likely to be small for most people with disabilities. On average, a male full-time worker age 21 to 64 with a severe disability earns $\$ 22,560$ a year (McNeill, 1997). A person earning this amount and taking advantage of the full benefit available under the flexible healthcare plan would reduce his tax burden by $\$ 540$ dollars. Thus, the tax savings is fairly small and represents a small percentage of the medical expenditure $(\$ 3,600)$ associated with the receipt of the deduction. Individuals in higher marginal tax brackets will receive a greater benefit (up to $\$ 1,188$ ), but the tax benefit is likely to have little impact on their employment because of their high income. 
Individuals who are self employed may deduct $60 \%$ of the costs of health insurance premiums. For those not covered by Medicare or Medicaid, this provision would serve as an incentive to work; however, the incentive is restricted to the relatively small proportion of people with disabilities who are self employed.

Itemized Deduction of Impairment-Related Work Expenses: An employee who has a physical or mental disability that functionally limits his or her employment may deduct the impairment-related work expenses from his or her taxable income. Impairment-related expenses that may be deducted include those necessary for the satisfactory completion of work, those for goods and services not required or used in personal activities, and those not specifically covered by other tax laws. These might include the expenses associated with the services of a personal assistant.

The IRWE deduction reduces the costs a person with a disability faces in returning to work. In theory, this will increase the net benefits from working and increase the likelihood that an individual with a disability will work. In actuality, however, the effect of this provision on the decision to work is likely to be small for two reasons. First, if the impairment-related work expenses of SSI recipients who participate in the SSA IRWE program are indicative of these expenses for people with disabilities in general, then the expenses are generally small (less than $\$ 200$ per month for more than $90 \%$ of individuals), thus, the tax benefit will generally be small. Second, the deduction is taken only when the individual has itemized deductions totaling a value that exceeds the amount of the standard deduction ( $\$ 4,300$ for a single individual and $\$ 6,350$ for a head of household in 1999). Individuals who do not itemize deductions will not benefit from the provision.

Earned Income Tax Credit: The Earned Income Tax Credit (EITC) supplements the earnings of low-income workers by providing them with a refundable income tax credit. The income limits that determine eligibility for this credit are more generous for persons with children. In addition, the EITC includes income from long-term disability benefits received before minimum retirement age in the computation of the credit. Generally, an individual qualifies for this credit if he or she works and earns income less than:

- $\$ 10,200$ with no qualifying child;

- $\$ 26,928$ with one qualifying child; or

- $\$ 30,580$ with more than one qualifying child (IRS, 1999).

The incentive effect of the EITC is likely to be substantial for some individuals, particularly those with one or more qualifying children. For example, on average, a male full-time worker age 21 to 64 with a severe disability earns \$22,560 a year (McNeill, 1997). Such an individual faces a tax burden of $\$ 3,386$. With one qualifying child, this individual would receive a $\$ 688$ tax credit. With two children, the value of the credit would rise to $\$ 1,675$. In the first case, the EITC reduces the recipient's tax burden by $20 \%$, and in the second case by $49 \%$.

Although the EITC serves as an incentive to work, it is targeted to low-wage earners, not lowwage earners with disabilities. A panel of experts convened by the National Academy of Social 
Insurance (NASI) has recommended supplementing the earnings of people with disabilities directly through a Disabled Worker Tax Credit (DWTC). The DWTC would not begin to pay benefits to those receiving DI until they had income above the SGA level. Beginning the DWTC at this level would reduce the cliff effect of lost DI benefits to some degree. The DWTC would also help reduce the implicit SSI tax for SSI beneficiaries (Burkhauser and Wittenburg, 1996).

\section{Factors Affecting Employer Demand and Use of Human Resources}

\section{A. Overview}

In deciding on the types and amounts of labor (and capital) to use for producing a given level of output, firms will consider the contribution, or productivity, of each input relative to its cost. The firm's objective is to minimize the cost of producing its chosen level of output. Thus, in making hiring decisions, employers will weigh the potential costs of hiring an individual (wages, nonwage compensation, and training or other investments) against the potential benefits (the value of their productivity) and compare this to the relative costs and benefits of hiring alternative candidates for a given position. If the presence of a disability affects the costs or productivity of labor, or the employer's perception of costs and productivity of labor, the demand for that labor will be affected.

In the case of job candidates with disabilities, employers might perceive persons with disabilities as less productive than equally qualified individuals without disabilities, making them less likely to hire people with disabilities relative to others. Employers might also perceive persons with disabilities to be more costly than others because accommodations or other investments might be necessary to achieve the desired level of productivity. As individuals with disabilities experience higher-than-average medical care expenditures and use, firms providing health benefits and whose insurance costs are sensitive to the healthcare costs of a few employees might believe the high costs of healthcare for workers with disabilities constitutes a reason not to employ them.

\section{B. Productivity and Availability of Substitute Labor}

Assessing the likely level of productivity of a potential employee is a critical process for an employer when making a hiring decision. Hiring an employee who under-performs can be expensive for an employer. For small firms, the consequences of making a poor hiring decision can be particularly severe because the workload is divided among a relatively small pool of workers.

When considering hiring an individual with a disability, an employer might face a great deal of uncertainty about assessing the candidate's potential productivity, thereby increasing the perceived risk associated with hiring the individual. Several factors can affect this level of perceived risk, which can subsequently affect the hiring decision.

First, the potential employer's level of knowledge regarding the impairment might play an important role in assessing potential productivity. For instance, an employer with reasonably good knowledge of the individual's functional limitations because of his or her impairment and how that is likely to affect work performance given the requirements of the job, might be able to 
make a more accurate assessment of an individual's potential productivity. Employers with less information are likely to make less accurate assessments.

Second, the degree to which the impairment is relevant to the work required can have a significant effect on perceived risk. For instance, an employer considering hiring as a telemarketer an individual who uses a wheelchair might expect the impairment to have no effect on job performance. However, the same employer looking to hire an individual suffering from chronic back pain might anticipate that the candidate will require frequent breaks and experience high absenteeism.

There are numerous studies that document the negative effect of poor health and disability on productivity, as measured via earnings, hours of work, and wage rates. ${ }^{34}$ The problem is that it is difficult to determine how much of the differentials observed are because of the health condition or disability and how much is because of a variety of other factors that affect the observed productivity (as measured by hours of work and wage levels). Wage rates, in theory, should be a strong indicator of productivity. As a rule, we do not expect employers to pay individuals more than the value of what they produce, and we do not expect individuals to work for a wage that is lower than their labor is valued by the market. The problem is that wages do not adjust quickly to changes in productivity, and individuals and employers do not always have good information about the value of labor's output.

Although clearly there exist concerns about productivity differentials between individuals with and without disabilities, there is little information on which employers can rely in assessing the potential consequences of a specific impairment for productivity. Even where evidence is available, measures of productivity differentials between individuals with and without disabilities lack precision because of the difficulty in separating productivity differences due to the impairment from productivity differences due to other unobserved factors. In addition, the managers making the hiring decisions might lack experience working with persons with particular disabilities and, thus, have no basis for determining the potential effect of the impairment on performance in the context of the job for which the individual is being considered.

Given the potential uncertainty that some employers might face in considering whether or not to hire persons with disabilities, the availability of substitute or alternative sources of labor will affect the demand for the labor of people with disabilities. Equally qualified persons without disabilities will be substitutes for those with disabilities, and all else being equal, when available, these individuals will be preferred to those with disabilities in hiring situations where employers perceive greater uncertainty about the productivity of individuals with disabilities. The implication is that the demand for the labor of people with disabilities will be greater when substitute labor is scarce (during an economic boom) and lower when substitute labor is in abundance (during a recession). Put another way, people with disabilities might be among the last hired and first fired over the ups and downs of the business cycle.

\footnotetext{
34 See, for example, Bartel and Taubman (1979), Chirikos and Nestel (1981), and Baldwin, Zeager, and Flacco, (1994).
} 
Studies of the labor force participation of people with disabilities over the business cycle provide some evidence of the "last hired, first fired" phenomenon. For example, Yelin and Katz (1994a) examined labor force trends among persons with and without disabilities using National Health Interview Survey (NHIS) data from 1970 to 1992 and CPS data from 1981 to 1992. They found that in periods of economic downturn, persons with disabilities suffer more pronounced losses in labor force participation than persons without disabilities; and in periods of economic growth, they experience less pronounced gains than persons without disabilities.

Another more recent study showed that, although there were large employment and earnings gains by people without disabilities from 1989 to 1997, employment and earnings of people with disabilities actually fell (Burkhauser, Daly, and Houtenville, 1999). From 1989 to 1997 (two periods of similar macroeconomic conditions), the employment rates and real median family income levels of men with disabilities fell by $15 \%$ and $8 \%$, respectively. Over the same period, the employment rates of men without disabilities remained unchanged, although their median family incomes increased by more than $40 \%$. The patterns are similar for women, though less negative for women with disabilities. These patterns suggest that people with disabilities actually lost ground during one of the most vigorous economic expansions in U.S. history.

There are certainly other factors contributing to the observed trends in the employment and earnings of people with disabilities over the business cycle. As discussed further in Section VI, the Social Security Disability Insurance (DI) and Supplemental Security Income (SSI) programs might contribute to the greater sensitivity of people with disabilities to economic downturns and slower recovery during economic expansions. Nonetheless, the actual and perceived productivity of people with disabilities, and the availability of substitute (non-disabled) labor will certainly affect the employment opportunities of those with disabilities.

Public policies that make the labor of people with disabilities more productive, reduce employer uncertainty about productivity, or reduce the costs of hiring people with disabilities will promote their employment relative to substitute labor (i.e., those without disabilities). The programs and policies that encourage human capital development of people with disabilities discussed previously might have an effect. Employment programs that provide wage subsidies to employers that hire people with disabilities, thereby reducing the cost of that labor, might also increase the employment of people with disabilities. Other policies, such as the Americans with Disabilities Act (ADA) and certain tax policies (discussed further below), also address these issues to some degree.

\section{Wage Discrimination}

Wage discrimination occurs when two individuals with equal productivity are offered unequal compensation. In the case of a worker with a disability, this discrimination could result from prejudice or from an incorrect perception about the productivity of workers with disabilities. Because people with disabilities do have impairments that can affect productivity, it can be difficult to differentiate between the wage effects that are because of health limitations and those that are because of discrimination. To the extent that wage discrimination does occur, it might discourage people with disabilities from participating in the labor market. 
A number of studies have attempted to measure wage differentials between persons with and without disabilities, separated by discriminatory and non-discriminatory components. As noted above, productivity is difficult, if not impossible, to measure accurately. Hence, wage differentials that are found to be because of discrimination might actually be because of unmeasured productivity differences, and it is important to interpret the results of these studies with caution.

A study of wage offer differentials in 1972 found that, after controlling for measured productivity differences, men with disabilities received wage offers that were approximately $84 \%$ of the offers to men without disabilities, and women with disabilities received offers that were $40 \%$ of the offers to women without disabilities (Baldwin and Johnson, 1992). The authors also examined how wage differentials are affected by issues such as intensity of prejudice or employer uncertainty, finding that individuals with disabilities subject to increasingly intense prejudice experienced greater wage differentials.

Baldwin, Flacco, and Zeager (1991) used data from the 1984 Survey of Income and Program Participation to investigate the effect of employer uncertainty on discriminatory wage differentials, positing that employer uncertainty could result in "statistical discrimination." This occurs when employers make assumptions about the productivity of an individual with a disability based on the average productivity of workers with disabilities. Most employers do not have the experience or the information necessary to judge the potential productivity of an individual with a disability. Baldwin, Flacco, and Zeager found that increased employer uncertainty about the capabilities of workers with disabilities does result in lower wages.

Acemoglu and Angrist (1998) looked at the potential effect of the ADA on hiring decisions. Their findings - that medium-size firms were less likely than other firms to hire people with disabilities following the implementation of the ADA - support the hypothesis that firms large enough to be subject to the ADA but small enough to be vulnerable to an increase in costs might reduce potential exposure by hiring fewer people with disabilities.

Although none of these findings are conclusive, they support the assertion that employers' perceptions of lower productivity of individuals with disabilities can create an incentive to pass over such individuals or to offer a lower wage than would be offered to a similarly qualified individual without a disability, to compensate for the increased risk. This assertion is supported by a 1987 study, which surveyed approximately 900 managers and executives from 900 firms regarding their employment practices with respect to workers with disabilities. A majority of managers interviewed believed that discrimination was an important barrier to the employment workers of with disabilities (Louis Harris, 1987).

\section{Employer Accommodation}

A potentially large cost for employers that hire people with disabilities are the accommodations that might need to be made for these workers. Such accommodations might include the purchase of special equipment (such as modified computers for persons with impaired eyesight), providing wheelchair access and instituting flexible hours to accommodate shift work, and allowing employees to work from home. 
Economic theory suggests that relatively high costs of accommodation would likely result in reduced demand for labor among individuals with disabilities. In an attempt to avoid having to make such accommodations, employers might avoid hiring individuals with disabilities or might shift the cost of those accommodations to their employees with disabilities, resulting in the payment of lower wages. Their ability to do this is limited, however, by the 1990 ADA. The act prohibits job-related discrimination against people with disabilities and requires that reasonable accommodation be provided for people with disabilities unless the difficulty or expense of accommodation would result in undue hardship for the firm. The effect of having to provide accommodations on a firm's hiring of individuals with disabilities will depend then on how costly such accommodations are.

The Job Accommodation Network (JAN), a service of the President's Committee on Employment of People with Disabilities, is a toll-free information and referral service that provides information on job accommodation, employers' responsibilities under the ADA, and on technical assistance, funding, education, and services related to the employment of people with disabilities. JAN also analyzes trends and statistical data related to the technical assistance it provides (PCEPD, undated).

The evidence on the costs of accommodations to individuals with disabilities is sparse; however, the data that are available suggest that, although some accommodations can be costly, the majority of accommodations can be made relatively inexpensively. Survey data collected by JAN for The President's Committee on Employment of People with Disabilities between October 1992 and June 1998 show that among employers making accommodations, 20\% of accommodations were made at no cost, $80 \%$ cost $\$ 1,000$ or less, $17 \%$ cost between $\$ 1,001$ and $\$ 5,000$, and 3\% cost more than $\$ 5,000$. Annual amortized costs of these accommodations over their useful lifetime might be substantially lower.

JAN also reports that, based on employers' responses to the survey, the average benefit gained from each dollar spent to make an accommodation was nearly $\$ 33$ (1998). The results of this survey suggest that the costs of accommodation might not pose a substantial obstacle to hiring individuals with disabilities; however, when interpreting these findings, we should note that low cost accommodations and those likely to yield the greatest net benefit are probably the most likely to be implemented. The costs associated with observed accommodation do not necessarily represent the costs that would be observed if the prevalence of accommodation were to increase. Put differently, the reason that more costly accommodations are not observed might be employer's successful avoidance of hiring or retaining workers who require such expensive accommodations.

In addition to the above data that show the actual cost of most accommodations to be modest, other survey data finds that employers perceive the costs of accommodations to be modest. Results from a 1987 Louis Harris and Associates study show that most of the managers interviewed believe that the average cost of employing a worker with a disability is about the same as the cost of employing a worker without a disability, and that making accommodations for employees with disabilities is not expensive. About half of the executives interviewed said that their company had made accommodations for employees with disabilities. In a survey on disability employment policies and practices in the Federal government, the authors found that $90 \%$ of agencies had made their existing facilities accessible to employees with disabilities, had 
been flexible in the application of human resource policies, or had acquired or modified equipment or devices (Bruyère and Horne, 1999).

The 1987 Louis Harris study also found that small firms were less likely to make work accommodations, to have formal disability management programs or hiring policies, or to keep employees after the onset of disability. This might be the case, as another study suggests, because small firms have no trained staff to manage work accommodations, they have limited opportunities for shifting workers with disabilities into other jobs in the company, and they often have no generous health or disability benefits to offer workers.

A recent survey consisting of 813 employers reveals many of the same employment practice patterns with respect to workers with disabilities as found by the 1987 study (Society for Human Resource Management, 1998). As in 1987, larger employers, especially those with 2,500 or more employees, were found to be more likely than smaller employers to proactively recruit people with disabilities, to have formal return to work or disability management programs, and to accommodate the needs of employees with disabilities. In contrast to the 1987 study, a large majority of employers, including some smaller employers, reported having made accommodations to meet the needs of employees with disabilities, including making schedules more flexible and modifying facilities.

The study also found, however, that approximately one-third of employers with 500 or more employees and roughly one-quarter of employers with fewer than 500 employees reported that changing co-worker and supervisor attitudes regarding people with disabilities made making changes to meet the needs of employees with disabilities difficult or difficult. This finding suggests that, despite efforts to eliminate negative stereotypes regarding the ability of people with disabilities to work, these stereotypes remain an important barrier to the employment of workers with disabilities.

Although the evidence regarding the cost of accommodations is mixed, it appears that costs of accommodations might be low and that employers generally perceive accommodation costs as such. If this is indeed the case, then such costs will not have a large effect on employers' decisions to hire people with disabilities, and requiring that employers make such accommodations under the ADA will also have only a small effect on the employment of people with disabilities. The issue might be more complex, however.

\section{E. Impact of the Americans with Disabilities Act}

As noted above, the 1990 ADA prohibits job-related discrimination against people with disabilities and requires that reasonable accommodation be provided for people with disabilities unless the difficulty or expense of accommodation would result in undue hardship for the firm.

On the face of it, the ADA's prohibition of discrimination based on physical or mental impairment and the mandate for employers to accommodate workers with disabilities would be expected to remove significant barriers to employment for people with disabilities. However, evaluation of the ADA from a theoretical economic perspective suggests that there might be difficulties in the implementation of such a mandate. 
Economic theory says that the demand for workers with disabilities will depend on the extent to which their productivity balances the costs of their accommodation, and, as described previously, available data suggest that employers can frequently make accommodations for relatively little cost. However, this will not necessarily be the case under the ADA. If the ADA leads to an increase in the supply of workers with disabilities, then the severity level of disabling impairments would be expected to rise, resulting in a rise in the costs of accommodation. In addition to higher accommodation costs, employers might realize a reduced ability to shift accommodation costs through wage discrimination, resulting in a decrease in the number of offers extended to people with disabilities (Chirikos, 1991). Alternatively, the ADA might increase the employment of people with disabilities through a variety of mechanisms. First, increased knowledge of potential employers regarding the actual costs of accommodations and capabilities of people with disabilities could result in an increase in hiring. As well, people with disabilities might be more willing to seek employment after the passage of ADA, in the anticipation of encountering a more receptive job market.

The empirical evidence regarding the effects of the ADA on the employment of people with disabilities is mixed. Two recent studies provide the first empirical analyses of the effects of the ADA on the employment of people with disabilities, and both studies argue that, in fact, the ADA has caused a reduction in the employment of people with disabilities (DeLeire, 1997; Acemoglu and Angrist, 1998). One of these notes that there has been an $8 \%$ decline in the relative employment rate of people with disabilities after 1990, which the study attributes to the ADA (DeLeire, 1997).

There is at least one reason to suspect that the ADA is not responsible for all, or any, of the $8 \%$ decline. People with disabilities appear to have a particularly difficult time finding and maintaining employment during recessions relative to people without disabilities. Hence, even in the absence of the ADA, it is likely that the relative employment of people with disabilities would have declined in the early 1990s because of the 1990-1992 recession (Bound and Burkhauser, forthcoming).

The Acemoglu and Angrist (1998) study found that the ADA has had a negative effect on the employment of men with disabilities of all working ages and a negative effect on the employment of women under age 40. The study controls for a person's receipt of DI and/or SSI disability benefits but fails to examine the contribution of the recession to the drop in the relative employment among people with disabilities, which makes the findings far less compelling. Another limitation of this study is that it considers the effect of the ADA only on hiring, not on job retention. Because one of the goals of the ADA is to increase the willingness of employers to accommodate people with disabilities, it might be that once hired, the ADA has the effect of increasing the length of job retention.

There is some evidence that this might be occurring. One study found that the ADA increases the mean duration between onset of disability and application for DI. In an analysis of Health and Retirement Study (HRS) data, Burkhauser, Butler and Weathers (1999) found that employer accommodation significantly slows a worker's application for DI benefits. They estimate that universal employer accommodation would increase the expected duration of men by 3.13 years (from 10.45 years) and for women by 2.62 years (from 10.99 years). In sum, the provisions of the ADA have, in theory, the potential to increase the cost of employer accommodations, which 
could serve as a disincentive to hiring persons with disabilities. The empirical evidence of this, however, is limited. It might also be the case that the ADA has increased both employee and employer knowledge and awareness of disability and employment issues in ways that have enhanced the employment opportunities of people with disabilities, although evidence of this, too, currently is unavailable.

\section{F. Tax Policies}

There are several provisions in the U.S. tax code for incentives to employers to hire persons with disabilities and workers with other disadvantages. The tax policies described below include both tax credits and tax deductions, which reduce the employer's tax burden and offset the potential or realized costs of hiring individuals with disabilities.

A tax credit differs from a deduction in that tax credits are calculated against the tax burden, while deductions are calculated against taxable income. In practice, this means that a tax credit results in a dollar-for-dollar reduction in a taxpayer's liability, while a deduction results in a smaller proportional reduction in a taxpayer's liability. ${ }^{35}$ The theoretical impact of each of the tax policies described below will be to increase a firm's incentive to employ people with disabilities.

Section 190 Deduction: Also called the Deduction of Costs of Removing Architectural or Transportation Barriers to the Disabled or Elderly, this plan allows businesses to deduct expenses incurred while removing barriers to persons with disabilities from the location of the business. The maximum deduction is $\$ 15,000$ (amounts over this limit may be added to the basis of the property and depreciated.) Section 190 deductions are available only for expenses incurred in the removal of impediments; expenses for installing new facilities are not deductible.

Section 44 Credit: Also known as the Disabled Access Credit, this is a non-refundable tax credit for small businesses (defined as those businesses with fewer than 30 employees and less that $\$ 1$ million in gross receipts) that pay or incur expenses to provide access to persons with disabilities. The deduction is intended to cover the expenses incurred by small businesses complying with the ADA, for whom the cost of compliance is likely to be particularly burdensome. The credit is $50 \%$ of all eligible access expenditures that exceed $\$ 250$ but do not exceed $\$ 10,250$. Small businesses eligible for this credit are not precluded from taking the Section 190 deduction.

The Work Opportunity Tax Credit: The Work Opportunity Tax Credit (WOTC), enacted in August 1996, grants employers a tax credit equal to $35 \%$ of the wages of certain targeted groups, including persons with physical and mental disabilities. For an employer to receive this credit, an eligible employee must have worked for the employer for at least 180 days or completed 400

\footnotetext{
${ }^{35}$ The following example clarifies this distinction. A business with a taxable income of $\$ 100,000$, eligible to take a tax deduction of $\$ 1,500$, is able to subtract the amount of the deduction $(\$ 1,500)$ from its taxable income $(\$ 100,000)$ for a resulting taxable income of $\$ 98,500$. Assuming an average tax rate of $30 \%$, the business will pay $\$ 29,550$ in taxes $(\$ 98,500 \times 30 \%)$. Without the deduction, the business's tax burden would have been $\$ 30,000(\$ 100,000 \mathrm{x}$ $30 \%)$, for a reduction in taxes of $\$ 450(\$ 30,000-\$ 29,550)$. The same business eligible for a tax credit of $\$ 1,500$ simply subtracts the $\$ 1,500$ from its calculated tax burden for a reduction in taxes of $\$ 1,500(\$ 30,000-\$ 1,500=$ $\$ 28,500)$. In this case, the value of the tax credit is nearly three times that of the tax deduction.
} 
hours of service and have given notice of his or her eligibility before being hired. Initially, the credit was limited to $35 \%$ of a maximum of $\$ 6,000$ in wages. The credit has subsequently become more generous with the passage of the Welfare-to-Work Credit (WtWC), covering $35 \%$ of the first $\$ 10,000$ in the first year to $50 \%$ of the first $\$ 10,000$ of eligible wages in the second year with a maximum credit of $\$ 8,500$ per qualified worker.

Section 190 and Section 44 might serve as weak incentives to hire individuals with disabilities because they leave the employer exposed to a substantial portion of the cost of construction or removal transportation or architectural barriers. This might be particularly true regarding more costly expenditures. The WOTC and the WtWc are likely to provide a more substantial incentive to employers to hire individuals with disabilities, particularly among low-wage employers since the relative value of the credit is higher at lower wage levels.

Evidence exists that tax credits designed to encourage employers to hire disadvantaged individuals might not perform as anticipated and might even discourage the hiring of such workers. In an experiment conducted for the Department of Labor on the effect of the Targeted Jobs Tax Credit (TJTC) - the precursor to the WtWc-researchers found that potential employees who revealed their eligibility for the TJTC subsidy were hired less frequently than similarly qualified individuals who did not reveal their eligibility for the subsidy (12.8\% of those disclosing eligibility status were hired versus $20.6 \%$ of those not disclosing eligibility status). It appears that employers used the eligibility for the subsidy as a basis to discriminate against hiring those eligible, rather than as an incentive to favor them in hiring. An interpretation of this finding is that employers perceived eligibility status as a signal that the candidates were "damaged goods" and, thus, were reluctant to extend offers (Burtless, 1985).

\section{Factors Affecting Job - Employee Matching}

\section{A. Overview}

Economic theory includes a framework for describing the process of matching individuals to jobs and factors that contribute to job search outcomes. As noted previously, individuals vary in their abilities, education, work experiences, and demographic characteristics, and jobs vary in their requirements for certain skills, knowledge, and other factors. Economists often describe the labor market as a matching process in which workers with varying characteristics are matched with appropriate jobs. Much of the theory of the matching process focuses on the individual's job search, but the framework also addresses issues relevant to employers and their behavior in the hiring of people with disabilities.

A person's decision to look for work and to accept a job offer is influenced by a number of factors, including access to and availability of work, preferences regarding employment, and alternatives to work, such as the availability of unemployment insurance or transitional assistance. Persons with disabilities seeking employment face these same constraints, but, in addition, face barriers entering the job market that individuals without disabilities do not encounter. Persons with disabilities also have additional options for income support unavailable to persons without disabilities. 
According to economic job search theory, a number of factors, including assets, profiles of offer possibilities, wage preferences, and tolerance for unemployment constrain job seekers. For people with disabilities, assets include their possible eligibility for income support programs, which, like other assets, can generate a stream of earnings. Assets are a critical limiting factor because the availability of assets determines the maximum length of the job search. As asset income expires, the job seeker is increasingly compelled to accept the best available offer of employment, regardless of other preferences. As long as an individual is able to continue the job search (that is, he or she has sufficient income to fund the search), the other components of the model-profiles of offer possibilities, wage preferences and tolerance for unemploymentinteract to determine the search outcome. ${ }^{36}$

Employers, on the labor demand side of the labor market equation, seek to hire an optimal employee, but are constrained in a number of ways, as well. Typically, firms continue to hire labor until the marginal cost of hiring an additional employee equals the marginal productivity that will be provided by that employee. Under ideal conditions, one in which potential employers and potential employees have complete information and choice, workers are optimally matched to jobs in the sense that alternative matches cannot be found that are better for either the firm or the worker. But conditions in the labor market are not always ideal. One of the biggest constraints faced by both sides is that each must make decisions based on imperfect information, which can lead to inefficient outcomes.

For instance, an employer hiring an employee is generally unable to measure worker productivity directly before making an offer of employment. Instead, the employer must make an educated guess about an employee's potential productivity based on information provided by the employee, among other sources. The employee has an incentive to overstate productivity to secure an offer, and the potential employer has an incentive to understate the demands of a position to secure an acceptance of work or to depress wages. Usually neither side can independently verify the representations of the other. It is only after an offer has been accepted that both sides are able to observe critical factors such as productivity and working conditions. Economists refer to this as "asymmetry of information." If productivity is lower than expected, the employer suffers. If employer demands are greater than anticipated, the employee realizes that working conditions are not as good as he or she had expected, given the level of compensation paid.

Note that persons with disabilities might face substantial challenges regarding information management and communication. For people whose disability onset occurs during adulthood, the information value of past experiences is destroyed. In such cases, there might be a learning curve associated with understanding, and communicating, present capabilities.

\footnotetext{
${ }^{36}$ An example illustrates how these factors interact. Consider a person who has recently become unemployed and has minimal savings. Unemployment insurance benefits (UI) won't cover his living expenses, and by combining his savings and UI, he calculates that he will be able to search for a job for three months. As his search begins, he defines for himself his "reservation wage," that is, the wage he must receive to willingly accept an offer of employment. As his job search progresses, he will reevaluate his reservation wage in light of the quality and frequency of offers received. If he nears the terminal date of his job search, he must weigh the risk of continuing his search for a job at his reservation wage with the risk that he might have to accept an offer with a lower wage as the terminal date of his search approaches and no better offers become available.
} 
One way employers and job candidates attempt to overcome asymmetric information is to observe certain indicators, or signals, that the employer or potential employee believes might correlate with certain outcomes. For an employer, a particularly important outcome is productivity. In looking for signals of productivity, employers might observe characteristics that cannot be changed, such as age, race, and gender as well as characteristics that can be changed, such as work experience and education level. ${ }^{37}$ Potential employees might observe signals such as the employer's reputation or the relative generosity of benefits.

A number of programs and policies have been implemented to help increase the efficiency and equity of the job and employee search process in the United States. Congress has passed antidiscrimination laws to make it illegal to base hiring decisions on characteristics unrelated to the ability to perform a particular job. Transitional income assistance programs exist to decrease the cost of the period of unemployment or underemployment and allow the recipient to initiate and/or extend the job search period. Finally, public employment programs with job search components can assist unemployed workers in finding employment and employers to find appropriately qualified workers.

\section{B. Asymmetric Information}

For markets to generate mutually beneficial transactions, both parties to a contract must have accurate information about the quality and price of the goods or services being purchased, such as labor. The presence of asymmetric information during an employment negotiation can pose substantial problems for both parties, but it can be a particular issue for people with disabilities.

In general, employers have an incentive to understate the amount of work required to perform a job, and employees have an incentive to overstate their willingness or qualifications to work. When employers misrepresent job requirements, employees might accept a position that they otherwise would not have accepted, or they might accept a lower wage than they would have otherwise. In either case, the employer benefits and the employee suffers. Such misrepresentations can be particularly disadvantageous to people with disabilities. People with disabilities are required not only to adapt to the circumstances of their employment, but also must adapt to the circumstances of their disability. An employee who discovers that his or her employer misrepresented both workload and willingness to provide needed accommodations might find the job incompatible and be forced to terminate employment. If this happens frequently, the person with a disability might become discouraged from seeking employment altogether. $^{38}$

It is also possible for the employee to overstate his or her willingness or ability to work as well as to understate the total cost of needed accommodations. When this occurs, employers might become discouraged from hiring workers with disabilities. Either because of such an experience

\footnotetext{
${ }^{37}$ It is important to note that basing a hiring decision on certain signals such as characteristics unrelated to the ability to perform a job (e.g., age, race, disability status, and gender) is illegal, while basing a hiring decision on characteristics relevant to job performance (e.g., education and experience) is legal. This issue is important for persons with disabilities who typically face both legal and illegal forms of employment discrimination.

${ }^{38}$ Employee turnover is costly to employers; this cost creates an incentive for employers to represent fairly job requirements.
} 
or out of fear that such an experience might occur, employers might inappropriately perceive a potential employee's disability as a signal that the individual is likely to be less productive or less qualified than an otherwise comparable individual without a disability would be. As with any job candidate, the employer has good reason to be skeptical of the employee's ability claims. Even as employers gain experience about the productivity of people with disabilities, accurately estimating the productivity of a particular person is difficult because of the variability among individuals. The presence of a disability adds another dimension of uncertainty to the hiring decision, which might discourage employers from hiring individuals with disabilities.

Other than the Job Accommodation Network (JAN) described above, we have not identified public programs or policies that explicitly address the issue of asymmetric information and its significance to the employment of people with disabilities. To some degree though, the Americans with Disabilities Act (ADA) addresses the issue by not allowing employers to discriminate on the basis of a disability, but making it illegal to use disability status as a signal does not provide employers with additional information about potential employee performance. From the potential employee's perspective, the ADA might reduce the importance of asymmetric information in the decision of whether or not to accept a job offer. If the ADA increases the likelihood that the necessary accommodations required to perform the job will be provided, it will reduce the ability of employers to misrepresent the requirements of the job and, thus, the likelihood that those with disabilities will take a job with which they are incompatible.

\section{Transitional Income Assistance and Income Support Programs}

People with disabilities can rely on both transitional income assistance and income support programs during the job search. Transitional income assistance programs are designed to provide temporary assistance to unemployed or otherwise disadvantaged individuals and families. Typically, these programs have restrictions on the receipt of such benefits, in terms of eligibility and the amount of time an individual can receive payments. There are two main public transitional income assistance programs available to the working-age population: Unemployment Insurance (UI) and Temporary Assistance to Needy Families (TANF). Transitional assistance programs differ from other public income support programs (e.g., Social Security Disability Insurance [DI], Supplemental Security Income [SSI], and workers' compensation [WC]) because they are time limited. DI, SSI and WC provide benefits indefinitely, as long as the beneficiary continues to meet eligibility requirements. UI provides temporary benefits (typically to a maximum of 26 weeks) for workers who have recently lost their jobs. Eligibility is determined by a number of factors, including prior work history (typically a person must have been engaged in eligible employment for a minimum of two quarters in the prior base year) and a demonstrated ability and willingness to work. The benefit amount is based on earnings prior to unemployment. TANF, as Section III describes, is provided to families, with at least one child under the age of 18, meeting state-determined income requirements. Receipt of TANF is contingent on meeting certain work requirements, and lifetime benefit receipt is limited to 60 months (fewer months in some states).

Although the objectives of the programs differ, both programs serve to increase the resources available to people who are unemployed, allowing these individuals to increase the time they have to search for employment before their resources run out. UI is designed explicitly to facilitate transition between jobs or temporary layoffs. TANF focuses on developing the 
capabilities of low-income parents (especially unmarried mothers), helping and encouraging them to obtain employment, and providing assistance in the interim. The time limits on both programs ensure that they do not function as long-term income replacement programs and that they are, indeed, transitional.

UI and TANF might be limited in their ability to serve people with disabilities, relative to those without disabilities, for several reasons. As noted previously, TANF and Aid to Families with Dependent Children (AFDC) employment and training strategies historically have been ill suited to the needs of people with disabilities. UI time limits, on average, might be too short for people with disabilities if, as discussed previously, the job search process generally takes longer for these individuals. In addition, to qualify for UI, an individual must have been engaged in UIcovered employment preceding the episode of unemployment. Because workers with disabilities are more likely to be self employed and part-time workers than those without disabilities, they also will less likely be working in UI-covered employment situations.

Unlike those without disabilities, persons with disabilities have access to SSI and DI as an income source during times of unemployment. Features of these programs, however, make them poor sources of transitional income assistance for people with disabilities. The long application process, the five-month waiting period for DI, and the fairly high risk of having the application denied make DI and SSI a poor transitional income option for those with a significant chance of becoming meaningfully employed. These same factors reduce individuals' incentives, once they are on the DI or SSI rolls, to seek employment because of the difficulty involved in re-qualifying for benefits if a work attempt fails.

Because receipt of SSI, DI, and WC benefits is not time limited, these programs might be expected to increase the time spent searching for employment among those seeking to return to work. When a person begins to receive DI, SSI or WC, all else being equal, such an individual can afford to be more selective in searching for employment than a comparable person receiving UI or TANF.

The "stickiness" of the DI and SSI programs (i.e., once on, there one stays) has been cited as a contributing factor to the sensitivity of workers with disabilities to economic downturns and the lack of sensitivity to subsequent economic recovery, noted previously in Section $\boldsymbol{I} \boldsymbol{V}$. Many studies have shown a relationship between DI and SSI applications and unemployment rates. ${ }^{39}$ One such study found a strong and statistically significant relationship between the State-level changes in the unemployment rate and the number of DI and SSI applications (Stapleton et al., 1995). The authors estimated that there were approximately 59,000 more DI applications filed in 1992 than there would have been if unemployment had remained at the 1988 level rather than increasing during the 1991 recession, representing a 7.3\% increase. For SSI, there were approximately 41,000 more applications filed in 1992 than would have been filed if unemployment had remained at the 1988 level, representing a 4.7\% increase.

\footnotetext{
${ }^{39}$ See Stapleton et al. (1995) for a review.
} 


\section{Job Search Services}

Job search services can serve individuals with disabilities in a number of ways. First, job search services provide critical information useful both to potential employers and potential employees. For the person with a disability seeking employment, job search services help link the individual with appropriate prospective employers. By doing so, job search services can raise the probability that a candidate will obtain a suitable offer of employment at the reservation wage. The services provide valuable information to the employers, as well. They help employers identify individuals with suitable skills, but even more importantly, they can help employers more accurately estimate accommodation costs and potential employee productivity. As discussed earlier, without such assistance, employers might overestimate costs and underestimate productivity, which will discourage employers from hiring people with disabilities.

Job search services can also lower the cost of seeking employment by linking individuals to potential employers more efficiently, reducing the cost of an otherwise prolonged job search. Finding early leads might be important for securing employment because the job seekers' assets typically are limited, and the probability of finding employment within a given timeframe is related to the degree of exposure the job seeker has to potential employers.

Finally, job search services might provide valuable links to human capital development services. Early connections to such services can be important; as time passes, investment in human capital becomes more expensive relative to employment. Early investment in human capital can result in higher future earnings and higher rates of average employment.

Job search service components are embedded in the Federal and State employment programs for people with disabilities, described previously in this paper, including the vocational rehabilitation (VR) system, State programs established under the 1998 Workforce Investment Act (WIA), and the 1999 Ticket to Work program established by the Work Initiatives Improvement Act (WIIA).

In addition, Project ABLE (Able Beneficiaries Link to Employers) is a service established specifically to match jobs to appropriately qualified people with disabilities. Project ABLE is a national resume bank that provides employers an easily accessible applicant pool of qualified job-ready individuals, who are interested in working. The resume bank operates through the joint efforts of the Office of Personnel Management (OPM), the Social Security Administration (SSA), the Rehabilitation Services Administration (RSA), the Department of Veterans Affairs (VA), and State VR agencies. The goal is to provide employers access to quality human resources while providing training and employment services to eligible people with disabilities (SSA, 1998b).

Social Security beneficiaries can enroll in Project ABLE by contacting their local VR or VA agency. State certified VR and VA counselors evaluate the potential candidates and make initial determinations about candidates' qualifications and job readiness (SSA, 1998b). After this initial screening, candidates' resumes and data are entered into the Project ABLE resume bank for review by potential employers. If a candidate is not ready for employment, the VR or VA agency might be able to offer training or other services that will help the individual prepare for work. 
Employers participating in Project ABLE send job announcements to project staff at OPM, who forward the resumes of qualified individuals to the employers.

\section{Recent Policies and Initiatives Designed to Promote the Employment of People with Disabilities}

A number of recent policies and initiatives have been passed with the intention of helping people with disabilities enter the workforce. In general, these can be characterized as increasing access to existing and new training and support programs; reducing the cost of employment by extending medical coverage and increasing the income available to persons with disabilities who work; and/or research efforts intended to improve our understanding of the factors affecting the employment of people with disabilities.

\section{A. Presidential Task Force on Employment of Adults with Disabilities}

Executive Order 13078 established the Presidential Task Force on Employment of Adults with Disabilities on March 13, $1998 .^{40}$ Its purpose is to create a coordinated and aggressive national policy to bring adults with disabilities into gainful employment at a rate that is as close as possible to that of the general adult population. The Task Force is to develop and recommend to the President, through the Chair of the Task Force, a coordinated Federal policy to reduce employment barriers for people with disabilities. Policy recommendations might cover areas ranging from discrimination to training services and job retention. ${ }^{41}$

In November 1999, the Task Force published its Second Annual Report to the President, in which it reviewed progress toward its recommendations from the First Annual Report and laid out new objectives and priorities. The Task Force's recommendations include:

- Further integrating the efforts of various Federal agencies, including the Departments of Labor, Education, Justice, and Health and Human Services, the Social Security Administration, and the Office of Personnel Management.

- Improving the enforcement and increased use of already-existing legislation. These recommendations include increased enforcement of and information dissemination about the Americans with Disabilities Act (ADA), particularly targeted at small businesses; efforts to encourage states to take advantage of the Medicaid Buy-in provision of the Balanced Budget

\footnotetext{
${ }^{40}$ Task Force members include the Secretaries of Labor, Education, Veterans Affairs, Health and Human Services, Treasury, Transportation, and Commerce; the Commissioner of Social Security; the Director of the Office of Personnel Management; the Administrator of the Small Business Administration; the Chair of the Equal Employment Opportunity Commission; the Chair of the National Council on Disability; the Chair of President's Committee on Employment of People with Disabilities; and other senior executive branch officials as determined by the Chair of the Task Force (Secretary of Labor).

41 Other recommendations should cover reasonable accommodations, inadequate access to healthcare, lack of consumer-driven long-term supports and services, AT, community services, childcare, education, vocational rehabilitation, on-the-job support, and economic incentives to work.
} 
Act; and efforts to increase understanding and use of various work incentives and training opportunities among people with disabilities.

- Further promoting the Federal government's role as a leader in the effort to increase employment among people with disabilities, including its implementation of ADA provisions and its recruitment efforts.

- Engaging in research to increase understanding of barriers to employment and to establish a reliable measure of the employment rate among people with disabilities. In this connection, the Task Force has funded a Cornell University survey of human resource employees in Federal agencies designed to capture information on the equal opportunity policies and practices of those agencies that was completed in 1999. (Bruyère and Horne, 1999).

- Developing and promoting the use of technology to make productive employment more feasible for people with disabilities.

- Promoting legislative efforts to make work more financially rewarding for people with disabilities, including looking into indexing the Supplemental Security Income (SSI) earned income exclusion and SGA for inflation and increasing the scope of tax deductions available for employment- and disability-related expenses. (Presidential Task Force, 1999).

\section{B. Department of Labor Office on Disability Policy, Evaluation, and Technical Assistance}

The U.S. Labor Department's proposed 2001 budget includes \$21 million in funding for a new Office on Disability Policy, Evaluation, and Technical Assistance, which will be charged with increasing the employment rate of people with disabilities. An assistant secretary will head the office, ensuring that people with disabilities get full consideration in all programs funded or managed by the department and that the laws enforced by the department are evaluated to identify and remove barriers that might exist for people with disabilities. The office will also ensure that all service of the new system of one-stop centers, established by the Workforce Investment Act (WIA), are accessible to people with disabilities.

The new office will absorb the President's Committee on the Employment of People with Disabilities.

\section{1997 Balanced Budget Act (P.L. 105-33)}

States under Section 4733 of the Balanced Budget Act (BBA) are able to provide Medicaid for working people with disabilities by creating a new optional eligibility group. Buy-in to Medicaid is designed to help people with disabilities who have relatively high earnings but do not qualify for Medicaid under one of the other provisions. Individuals are not required to have been on SSI to be eligible for this Medicaid Buy-in provision. However, the state must make a disability determination if an individual was not an SSI recipient. The legislation allowed states to provide the benefit to individuals with incomes up to $250 \%$ of the Federal poverty standard. The Health Care Financing Administration has ruled that states can deduct certain expenses from income before applying the income test. 
- States using buy-in: Oregon, Minnesota, Mississippi, South Carolina.

- States planning to implement buy-in: Wisconsin, Alaska.

- States seeking Medicaid waiver: Ohio, California, New Mexico, North Carolina, Oklahoma.

- States expanding healthcare insurance/services: Colorado, Arkansas, Utah.

It is also worth noting that Tennessee's Medicaid waiver, TennCare, in place since 1994, extends Medicaid to many individuals with disabilities, even beyond the $250 \%$ of Federal poverty standard. For some years, Massachusetts and Hawaii also have had programs aimed at providing health insurance to working people with disabilities.

The Medicaid Buy-in should allow low-income workers with disabilities to purchase affordable health insurance, reducing a major incentive to withdraw from the workforce and seek SSI. Because the buy-in does not depend on current or former SSI participation, it weakens the incentive for a person with a disability to withdraw from the workforce or restrict earnings to receive Medicaid benefits through SSI. There is still, however, an incentive to restrict earnings to remain within the Buy-in income limits (an incentive partially addressed by the WIIA), and the attractiveness of the Buy-in to potential participants will depend on the Buy-in premium levels. The national impact of this program will also depend heavily on whether it is eventually implemented in a large number of states. Some states might be reluctant to bear the risk of increasing their Medicaid expenditures, even though the Federal government will pay for at least half of additional expenditures.

\section{1998 Workforce Investment Act (P.L. 105-220)}

Title I of the WIA provides assistance to states interested in establishing statewide and local workforce investment systems to increase employment, retention and earnings of participants. The goals of the WIA include improving the quality of the workforce to sustain economic growth, improving productivity and competitiveness, and reducing dependency on welfare. Under the WIA, states are required to create workforce development plans that describe how the state will meet the needs of major customer groups, including individuals with disabilities and show how the plans will ensure nondiscrimination and equal opportunity.

Title IV of the WIA specifically highlights people with disabilities with amendments to the Rehabilitation Act. Under Title IV, State and local boards are required to 1) link the State vocational rehabilitation systems to the developing State workforce investment systems, 2) streamline the current State vocational rehabilitation systems, and 3) improve delivery of services by providing more consumer choice, facilitating self-employment for disabled individuals, ensuring certain core services are available to all eligible individuals, and improving the clients' dispute resolution process.

The WIA addresses the needs of people with disabilities in several respects. Each state's governor is required to: 
- Establish a State Workforce Investment Board to help design, implement, and provide oversight of the new workforce development system;

- Oversee the creation of local workforce investment boards to set policy for the local portions of the statewide workforce investment system;

- Designate local workforce investment areas;

- Develop one-stop delivery systems in all local areas.

The State Board is responsible for organizing the service system to most effectively serve customers with multiple barriers to employment, including individuals with disabilities. In doing so, the State Board helps create a strategic five-year plan for building the State workforce investment system, which must describe how the state will develop strategies to target and serve special populations, including those with disabilities. The local workforce investment boards perform many of the same function as the State boards, but on the local level. Both boards contribute to the creation of one-stop delivery systems, which provide job search, job training, and occupational education programs.

The WIA mandates that one-stop systems be readily accessible to all Americans. Some of the partners in this system include employment services, adult education, post-secondary vocational education, vocational rehabilitation (VR), Welfare-to-Work, and Community Services Block Grant. All adults are eligible for core services and youth enrolled in school are eligible for certain services if they meet certain State criteria for employment, income, and/or disability. In many states, these systems are directly linked to VR and/or Temporary Assistance for Needy Families (TANF) services. Core services include determinations of eligibility for assistance; intake and initial assessment services; job search, placement, and career counseling; provision of program performance information and program cost information; provision of vocational rehabilitation services; assistance in establishing eligibility for Welfare-to-Work activities and education and training; and follow-up services, including counseling.

Individuals who fail to find employment after the provision of core services are eligible to receive intensive services. Intensive services include comprehensive and specialized assessments of the skill levels and service needs of eligible individuals; development of an individual employment plan; counseling and career planning; case management for those seeking training; short-term prevocational services; literacy activities related to basic workforce readiness; and out-of-area job search services. Finally, following intensive services those who remain unemployed are eligible for vouchers under Title I to pay for job training. ${ }^{42}$

Nondiscrimination provisions of the WIA were implemented by regulations issued by the Department of Labor on November 12, 1999. Discriminatory actions that are prohibited include denying a qualified individual with a disability the opportunity to participate or benefit from WIA services or affording such individuals lesser, different, separate or segregated opportunities, or otherwise limiting a qualified individual with a disability in the enjoyment of a right,

\footnotetext{
${ }^{42}$ WIA replaced the Job Training Partnership Act (JTPA).
} 
privilege, advantage, or opportunity afforded others. States must also offer individuals with disabilities services in the most integrated environment possible.

Finally, individuals who receive Social Security Disability Insurance (DI) or SSI are automatically eligible under the WIA for vocational rehabilitation services. ${ }^{43}$

\section{E. 1999 Ticket to Work and Work Incentive Improvement Act (P.L. 106-170)}

Signed by President Clinton on December 17, 1999, the Ticket to Work and Work Incentive Improvement Act (WIIA) is intended to address a number of the work disincentives inherent in the DI and SSI programs. The bill includes several provisions designed to increase incentives for employment among SSI and DI beneficiaries.

\section{Ticket to Work and Self-Sufficiency Program}

This portion of the Act amends the Social Security Act to establish an SSA Ticket to Work and Self-Sufficiency Program. The program will provide disability beneficiaries who are appropriate candidates with a voucher, or ticket, to be used to obtain vocational rehabilitation or employment services. The voucher can be assigned to any enrolled public or private provider of these services. SSA is to develop regulations to ensure that beneficiaries have access to a wide array of services as well as to information to help them choose a service provider. The provider is paid based on a combination of the outcomes of the case, in the form of disability benefit savings and treatment plan milestones attained by the beneficiary. During the time when a beneficiary is using a Ticket-to-Work, SSA is prohibited from initiating a continuing disability review (CDR), the periodic review which determines whether a beneficiary is still medically eligible to receive disability benefits.

The motivation behind the Ticket-to-Work proposal is to expand the employment and training opportunities of beneficiaries by expanding their access to a wide variety of rehabilitation services. The plan aims to improve access by reducing the role of SSA in the VR process and allowing market forces to reward providers who successfully move people with disabilities into work, both through the use of a voucher system and a performance-based contract.

The provision of the Ticket-to-Work that suspends CDRs for individuals participating in the program aims to reduce the risk a person faces when he or she enters a vocational rehabilitation program. By prohibiting the initiation of a CDR for those engaged in VR, the provision ensures that people will not avoid rehabilitation services for fear that their participation will make them ineligible for disability benefits.

A number of concerns have been raised about the ability of the program to significantly improve long-term employment outcomes for people with disabilities. Several critics have pointed out

\footnotetext{
43 The description of the WIA relies heavily on Silverstein, J.D., Robert (2000). A Description of the Workforce Investment Act from a Disability Policy Perspective. Washington, DC: Center for the Study and Advancement of Disability Policy (CSADP) with support from the Rehabilitation Research and Training Center on Workforce Investment and Employment Policy for Persons with Disabilities, Rehabilitation Research and Training Center on State Systems and Employment.
} 
that although the program does have the potential to meaningfully change the availability of rehabilitation services, there are many important details to be resolved by SSA in implementing the program. The manner of its implementation will determine its effectiveness. For example, the duration of the ticket assignment, the number of allowable renewal periods, and the payment amounts and schedule, all items seen as crucial to the program's effectiveness, are yet to be specified. Other critics have suggested that the program lacks the potential to dramatically change the delivery of VR services, both because it fails to address the timing of referral to VR (which many believe often occurs far too long after an injury or debilitating illness to be effective) and because it is likely to work through many of the same organizations that are currently providing VR services.

Another important concern is that the Ticket to Work does not really create incentives that are likely to return people with disabilities to work. Although it might create economic incentives for providers to rehabilitate effectively, it does not dramatically affect the economic incentive structure facing the individual with a disability. Although the program might make VR easier and less risky to access, some have suggested that because it does not make rehabilitation and work significantly more attractive to the beneficiary, it is unlikely to dramatically increase the number of working people with disabilities.

One final concern regarding the Ticket to Work is that it might induce demand for DI or SSI; that is, if the Ticket-to-Work provision is attractive enough, individuals with disabilities who have not applied for DI or SSI might do so to become eligible.

\section{Expansion of Health Insurance Eligibility}

As discussed previously, the fear of losing eligibility for public health insurance is frequently cited as a major disincentive to work for people with disabilities. Because healthcare costs are often extremely high for people with disabilities, the cost of healthcare can often outweigh the financial benefits of a job that does not provide comprehensive health insurance coverage. For many individuals with disabilities, particularly those who are not capable of working a full-time job that would provide health benefits, employment has simply not been a financially viable option. The health insurance provisions of the WIIA are intended to improve this situation. These provisions aim to make public healthcare available to working people with disabilities on terms similar to those offered to people with disabilities receiving public assistance so that individuals with disabilities might leave the public assistance rolls without fear of being unable to meet their medical expenses.

The WIIA loosens restrictions on states regarding who is eligible to buy into the Medicaid program. Under the Act, states have the option to eliminate all income, assets, and resource limitations for workers with disabilities who buy into Medicaid. States will also be able to continue to offer the Medicaid Buy-in to workers with disabilities, even if they are no longer eligible for DI or SSI because of medical improvement. States are authorized to require individuals to pay premiums, or other cost-sharing charges, on a sliding scale.

State elimination of restrictions on the Medicaid Buy-in would allow individuals with disabilities to increase their earnings without a large lump-sum increase in healthcare costs when they lose their Medicaid eligibility. Healthcare costs, instead, will increase gradually with income, acting 
as a tax on earnings. Although this "tax" reduces the incentive for people with disabilities to work, it is a much smaller disincentive than what exists under current policy. It is likely, therefore, to increase the employment and earnings of individuals who previously bought into Medicaid and restricted their earnings to remain eligible for the program. Relatively few states, however, have implemented the Medicaid Buy-in made available through the 1997 BBA; the Federal change in income restrictions is unlikely to have a large impact on employment unless more states choose to implement such a program.

The WIIA also provides for the continuation of Medicare coverage for individuals formerly receiving DI benefits. Under current law, the extended period of eligibility allows DI beneficiaries to continue to receive premium-free Medicare Part A coverage for a total of four years after they return to work. With the enactment of the WIIA, former recipients will continue to receive Medicare Part A coverage for an additional four and one-half years beyond the original four years.

This extension of Medicare eligibility will, in theory, make work more attractive to DI beneficiaries because it allows them to maintain a longer period of healthcare coverage after they begin working. The evidence on the original extension of Medicare eligibility (described in

Section III) casts some doubt on whether this provision will have the desired effect on employment. One study found that most recipients were not aware of the extended period of Medicare eligibility at the time of their award. The publicity associated with the passage of the WIIA and the funding for outreach and information services provided by the Act (see below) might improve beneficiary knowledge and understanding of the DI work incentive provisions.

Finally, the WIIA allows workers with disabilities who have a "Medigap" policy - a commercial insurance policy which provides benefits supplemental to Medicare - to suspend the premiums and benefits of the Medigap policy if they have employer-sponsored coverage. This allows workers to take advantage of employer-sponsored benefits, an important incentive to work, while keeping their Medigap policies in case their employment attempt fails. Unlike the expansion of the Medicaid Buy-in, this policy actually increases the financial returns to work by allowing a worker with a disability to stop paying Medigap premiums. This is likely both to make work more attractive to those not currently working and to make withdrawing from the labor force less attractive for those taking advantage of the policy (who would then have to resume Medigap premium payments to obtain continued coverage).

\section{Elimination of Other Work Disincentives}

Under the current law, an individual with a disability choosing to return to work faces the risk of losing eligibility for benefits in the short run and the risk of not being able to return to the disability roles in the event that his or her employment is terminated. Although the health insurance provisions described above address a significant part of this risk, the threat of losing eligibility for cash benefits remains. Several provisions of the WIIA address these concerns.

In addition to the limitations on conducting CDRs for individuals using a Ticket to Work, the WIIA also prohibits the use of work activity as a basis for review of an individual's disability status. A person with a disability who is working is still subject to CDRs on a regularly scheduled basis, but the initiation of work might not trigger such a review, and work activity 
might not be used as evidence that an individual is no longer disabled. This makes work activity less risky and presumably more attractive.

Another provision allows for expedited eligibility determinations for applications of former longterm beneficiaries that have completed their extended period of eligibility. If an individual returns to work, earns enough to be ineligible for disability benefits for longer than the extended period of eligibility, and is later unable to work, he or she will be able to return to the DI roles without the lengthy eligibility process to which first-time applicants are subjected. Like the limitation of CDRs, this provision reduces the risk beneficiaries face when returning to work. Like all of the WIIA provisions, the impact of this incentive on work activity is highly dependent on its being well-publicized, well-understood, and consistently applied. If individuals with disabilities believe, for whatever reason, that their long-term benefits will be unavailable in the event that they can no longer work at some later date, their work activity is unlikely to be significantly altered.

\section{Demonstration Project on Change in DI Benefits Schedule}

Under the WIIA, SSA is granted demonstration authority to evaluate the effects of a \$1 for \$2 withholding of DI payments for earnings over a specified level. This "phase-out" of benefits will make the DI benefit and incentive structure more similar to that of SSI. It eliminates the earnings cliff currently faced by DI beneficiaries, where earnings beyond SGA result in a total loss of benefits reducing the strong disincentive to work above the SGA level. The demonstration projects will evaluate the effects of the change on program participation, work activity, and program costs. Program participation seems likely to increase because beneficiaries can stay on the rolls while increasing their earnings and because the phase-out will make the participation more attractive for workers with disabilities who would not participate under the current program. Impacts on program costs could be positive or negative, depending on the effect of the program on beneficiary earnings.

\section{Work Incentives Outreach Program}

The WIIA directs SSA to establish a community-based work incentive planning and assistance program, for the purpose of providing accurate information related to work incentives to beneficiaries with disabilities. Under the program, SSA will:

- Establish a competitive program of grants, cooperative agreements, or contracts to provide benefit planning and assistance, including information on the availability of protection and advocacy services, to DI and SSI beneficiaries;

- Conduct or fund ongoing outreach efforts; and

- Establish a corps of work incentive specialists within SSA who specialize in DI and SSI work incentives for the purpose of providing accurate information.

SSA will award grants for the outreach efforts based on a percentage of the population of disabled beneficiaries in the state. The total amount of all grants awarded will not exceed $\$ 23$ million in each fiscal year from 2000 through 2004. 


\section{F. SGA Increase to $\$ 700$}

On July 1, 1999, the definition of substantial gainful activity (SGA) was raised from $\$ 500$ to $\$ 700$ of earned income per month. As discussed previously, the SGA threshold, the amount of income that an individual with a disability may earn without losing disability benefits, provides a substantial incentive to work only up the income level of the threshold itself. The adjustment is the first of its kind since 1990 and reflects growth in average wages since that time.

There are several potential effects of this change, each depending on the employment status of an individual before the change went into effect:

- For beneficiaries earning below the former SGA level of $\$ 500$, the change represents an opportunity to increase earnings without loss of benefits. Those already working might increase the number of hours they work to take advantage of this opportunity, and those who did not perceive the effort of finding a job worthwhile under the old limit might decide to seek employment under the new limit.

- For non-beneficiaries earning more than the former $\$ 500$ threshold but at or near the $\$ 700$ level, there is now an incentive to restrict earnings to the new threshold to become eligible for disability benefits, which might result in induced demand and a decrease in employment among members of this group.

The presumption is that the first effect will dramatically outweigh the second- that is, there are far more individuals with disabilities working just below the threshold than there are working just above it. SSA anticipates that this change will facilitate meaningful work among beneficiaries by reducing the likelihood that their return-to-work efforts will result in the immediate loss of cash benefits.

\section{G. SSA and RSA State Partnership Initiatives}

SSA and RSA recently initiated several projects designed to improve services and programming for people with disabilities as they attempt to enter or reenter the workforce. Both agencies have awarded cooperative agreements to a combined total of 17 states for projects to increase the employment of primarily DI and/or SSI recipients (although other groups of people with disabilities are also included). State grantees are responsible for designing, planning, and implementing demonstrations that increase employment of individuals with disabilities receiving DI and/or SSI. The grants will continue for five years at a total funding level exceeding \$25 million. Most of these grants aim to make it easier for people with disabilities to use existing services, via service integration or counseling. Most also include some form of continued health insurance coverage, in some cases through implementation of the BBA Medicaid Buy-in provision.

\section{H. SSA Demonstration on the Treatment of Affective Disorders}

SSA is designing a demonstration project that will test the effectiveness of providing better access to quality treatments for affective disorders to DI beneficiaries whose primary reason for impairment is an affective disorder. Persons with affective disorders represent one of the fastest growing cohorts on the disability rolls, representing one in nine DI beneficiaries. The rationale 
behind the demonstration is that appropriate treatment for such disorders can be effective in anywhere from $60 \%$ to $80 \%$ of cases. This combined with the fact that many beneficiaries lack access to adequate treatment (because of lack of health insurance, and high copays and deductibles and no prescription drug coverage under Medicare), suggests that providing access to treatment will result in improved health status of DI beneficiaries with affective disorders, and, in turn, lead to increased labor force participation and self-sufficiency. The demonstration is scheduled to begin around the end of fiscal year 2000 and will last for five years.

\section{Research Initiatives}

Several recent efforts designed to further our understanding of the factors that promote employment and economic independence among people with severe disabilities through research and information dissemination have been established by SSA, the Department of Education, and the Department of Health and Human Services. These are described below.

\section{NIDRR Rehabilitation Research and Training Centers on Employment}

The National Institute on Disability and Rehabilitation Research (NIDDR) recently established several new Rehabilitation Research and Training Centers (RRTC) aimed at improving employment outcomes of people with disabilities. All centers will conduct research, training, technical assistance, and dissemination activities.

American Indian RRTC (Northern Arizona University): This RRTC was established to improve the quality of life, including employment and self-sufficiency, of American Indians and Alaska Natives with disabilities. This site's projects will include 1) investigating and analyzing existing disability and employment data along with recommending improvements for planning and evaluating employment services for American Indians and Alaska Natives with disabilities; 2) recommending strategies to improve employment outcomes including existing employment and Vocational Rehabilitation practices for American Indians and Alaska Natives with disabilities residing on and off reservations; 3) developing and evaluating innovative and culturally appropriate Vocational Rehabilitation Services for employment of American Indians and Alaska Natives; and 4) disseminating results of the data collection and evaluation of model employment services to a range of relevant audience using accessible formats.

Penn/Matrix Research Institute Training Center on Vocational Rehabilitation Services for Persons with Long-Term Mental Illness: This RRTC focuses on four research areas: 1) improving the work incentives of the Social Security system; 2) linking client characteristics and program design to client outcomes; 3) exploring employer/employee relationships; and 4) examining vocational rehabilitation's relationship to behavioral managed care systems. It also focuses on four training issues: 1) improving rehabilitation research skills; 2) developing mental health/vocational rehabilitation curricula for human services, social work, and nursing; 3) assessing training methodologies in the field; and 4) expanding online dissemination to the field.

RRTC on Community Rehabilitation Programs to Improve Employment Outcomes (University of Wisconsin at Stout): The RRTC will help community-based rehabilitation programs adopt and adapt demonstrated practices and methodologies that will enhance achievement, community integration and economic independence of people with disabilities. 
Research conducted at this site will examine 1) resources available through community-based rehabilitation programs nationally; 2) differentiation of services and outcomes; 3) informed choice in the selection of goals and services; 4) impact of Federal and State policies; and 5) employment outcomes.

RRTC for Economic Research on Employment Policy for People with Disabilities (Cornell University, The Lewin Group): This RRTC will conduct research examining 1) the current employment status of people with disabilities; 2) the effects of labor market change on the employment and earnings of people with disabilities; 3) return to work rates after the onset of a disability; 4) the impact of civil rights protections on the employment and earnings of people with disabilities; and 5) the determinants of successful transitions from school to work. This RRTC has produced this report.

RRTC on Educational Supports (University of Hawaii): The research this RRTC will conduct is designed to increase access to post-secondary education programs and improve employment outcomes for people with disabilities. The research includes 1) examining and evaluating the current status of educational supports; 2) identifying effective support practices and models of delivery that contribute to successful access, performance, and retention and completion of postsecondary programs; 3) identifying specific barriers to the provision of disability-related services; 4) assessing the effectiveness of promising educational practices and disability-related services that are important to career mobility and success in the workplace; 5) testing the effectiveness of specific models of delivery believed to increase the accessibility of educational supports and innovative technologies; 6) identifying the types of educational and transitional assistance that post-secondary programs provide to improve educational and subsequent labor market success; 7) providing training, technical assistance, and information to support personnel, public and private rehabilitation personnel, career placement specialists, and students with disabilities; and 8) implementing a consumer-driven empowerment evaluation plan for assessment of the Center's progress in achieving its goals.

RRTC on Maintaining the Employment Status and Addressing the Personal Adjustment Needs of Individuals Who Are Hard of Hearing or Late Deafened (California School of Professional Psychology-San Diego [CSPP-SD]): This Center implements a series of projects involving hearing loss and workplace issues through collaboration with business, professional, and consumer organizations. The primary target populations are accessed through a network of schools and State agencies. Project examples include the identification of factors that have a negative impact on the employment status of people with hearing impairments. Interventions include review of assistive technology, career planning, mental health, and "rights training" in relation to the ADA. The project provides workshops for families and employers, establishes support groups for people with cochlear implants, and creates a family life center project: a onestop "shopping facility" where individuals with hearing loss can obtain a variety of interventions, information, and guidance regarding services and devices. Dissemination includes information on the ADA and the Assistive Technology Act. Training targets employers, consumers, and human resource organizations.

RRTC on Personal Assistance Services (World Institute on Disability): This project furthers the understanding that Personal Assistance Service (PAS) systems design can better promote the economic self-sufficiency, independent living, and full integration of people of all ages and 
disabilities into society. The project explores the models, policies, access to, and outcomes of, personal assistance services, through 1) gathering perspectives of consumers, program administrators, policy makers, and personal assistants using a State of the States survey and database development; 2) a policy study on the impact of devolution; 3) a cost-effectiveness study; 4) a study of workplace PAS; and 5) a study on the supply of qualified PAS.

RRTC on State Systems and Employment Outcomes (Children's Hospital: Institute for Community Inclusion, Boston, Massachusetts): This site will identify effective practices in coordinated employment efforts and facilitate such developments at local, regional, and State levels. Project activities focus on 1) examining state service systems; 2) documenting, through the analysis of national, State, and local data collection systems, actual employment outcomes for people with disabilities; 3 ) documenting strategies State agencies use for overcoming barriers to employment at the State and local levels; 4) examining, documenting, and disseminating practices at the State level that respond to the employment and support needs of SSI and DI program participants; and 5) reviewing and evaluating strategies and approaches to develop a more integrated employment approach at the Federal and State levels.

RRTC on Workforce Investment and Employment Policy for People with Disabilities (Community Options Inc., of Washington, D.C., in partnership with George Washington University Center on the Study and Advancement of Disability Policy, Rutgers University Center for Employment Policy and Workforce Development, and the University of Iowa Law Health Policy and Disability Center): This RRTC's studies will include 1) analyzing the relationship between selected State and Federal policies on the employment of people with disabilities; 2) analyzing targeted State policies and practices regarding the implementation of TANF and the WIA consistent with ADA; 3) analyzing selected State efforts to implement work incentive systems change grants from the SSA; 4) analyzing policy-based implications of outcome-based reimbursement and customer direction and control on the delivery of employment and rehabilitation services; and 5) analyzing through case studies of small and large businesses the effect of civil rights protections and multiple environmental factors on promoting or depressing the employment status of people with disabilities.

RRTC on Workplace Supports (Virginia Commonwealth University): The RRTC will examine 1) workplace supports and employer profitability; 2 ) the effectiveness of disability management; 3) longitudinal impact of workplace supports; 4) structural changes in the American economy; 5) employer perspectives on obstacles to employment; and 6) how to eliminate disincentives to employment.

The National Study of Health and Activity: SSA is sponsoring the National Study of Health and Activity (NSHA), known previously as the Disability Evaluation Study (DES). NSHA is the most ambitious national disability study of the American working-age population (aged 18-69) undertaken in many years. Data collected during the study will enable SSA to estimate how many adults with disabilities live in the United States and to better understand the relationship between disability and other aspects of everyday life, including work, family, community, and access to healthcare. This research is needed for future planning and to address policy questions about the nature and extent of disability in the United States. 
A pilot study began early in 2000. The main study, which will start about a year later, will result in approximately 10,000 completed interviews for a nationally representative sample. Study participants will include people who receive disability benefits from SSA, people who are likely to be eligible for benefits but do not receive them, and people with impairments who might receive benefits in the near future. For comparison, a group of people with no, or only minor, disabilities will also be included.

The study will begin with screening interviews for 100,000 or so individuals age 18 to 69 , who have been randomly selected. The screen will identify those with disabilities, and about one in ten of these will be selected to continue with a more in-depth interview. About half of those who complete the second interview also will be asked to participate in some functional tests and a medical examination. A team of medical professionals will conduct the medical exams in a Mobile Examination Center designed especially for the NSHA. Information will also be obtained from respondents' medical providers. Finally, assessments will be made to determine whether the respondents meet SSA medical criteria for DI and SSI eligibility.

\section{SSA Disability Research Institute}

SSA is funding a cooperative agreement to create a Disability Research Institute (DRI). The DRI will address the need for more extensive research for policymakers in the disability area. Research will be conducted to improve understanding of the work, program and policy environment, and how that environment affects behavior; to improve understanding of how clinical conditions and medical care allow individuals with disabilities to participate in that environment; and to improve understanding of how disability determinations can be designed to better support SSA objectives.

The DRI will be a university-based, multi-disciplinary center that will use a network of scholars from a variety of institutions. The DRI will have an annual budget of $\$ 1.25$ million for the first year and $\$ 1$ million for subsequent years. SSA expects to fund the DRI for a five years, contingent on funding availability and continued relevance to SSA initiatives.

\section{Office of the Assistant Secretary for Planning and Evaluation Study of Employment Supports Used by Working People with Disabilities}

The Office of the Assistant Secretary for Planning and Evaluation (ASPE) in the Department of Health and Human Services is funding a project that will provide information that may be used by Federal agencies, states, social service agencies, advocates for people with disabilities, and consumers with disabilities to develop and inform policies that will promote the employment of people with significant disabilities. Much of the previous policy research on employment of people with disabilities has been conducted using data from national surveys or administrative data from SSA or RSA. Detailed information on the experiences of persons with disabilities, their knowledge of work incentive policies and provisions, the events and factors affecting their employment decisions, the relative importance of specific factors, and the reasons for successful and unsuccessful employment attempts cannot be obtained from these data sources. For these reasons, the primary purpose of this project will be to collect and analyze extensive qualitative data on the employment experiences of successfully employed people with disabilities. 
The qualitative data collection effort will involve conducting interviews and focus groups with persons from a variety of groups, including State and local policymakers, practitioners, and advocates; working DI and SSI beneficiaries; and other working persons with significant disabilities. The study will focus on identifying the supports and other factors that have been instrumental in allowing individuals with significant disabilities to become successfully employed. The findings from the project are intended to complement other research previously and currently being conducted by ASPE as well as research being conducted by SSA, RSA, and other agencies serving persons with disabilities.

\section{Summary and Conclusions}

At the most fundamental level, economic theory views employment of an individual by a firm as a mutually advantageous, voluntary agreement between the employee and the employer. Workers trade their time, effort, and skills for compensation, in the form of earnings and fringe benefits. In determining whether to accept a job offer, or to continue working at an existing job, a worker presumably weighs the compensation package plus other costs (e.g., transportation costs) and benefits (e.g., job satisfaction) against the next best alternative opportunity available.

Employers are willing to compensate workers for their time, effort, and skills because workers increase the value of the goods and services produced by the firm. In determining whether to make an offer to a job candidate and how much compensation to offer, the employer considers the value that the candidate would add to the firm's revenue against compensation and other costs (overhead) associated with hiring the candidate as well as the value and costs associated with hiring competing candidates.

Economists apply this fundamental framework to the employment of individuals with disabilities as well as to those without disabilities. Differences in employment between these two groups are assumed to reflect differences in individual capabilities; income and in-kind support from other sources; non-compensation benefits and costs of employment to the individual; the information that employers and potential workers have about each other; and job search and recruiting costs. We have described how these factors are specifically relevant to the employment behavior of people with disabilities and how a wide range of public programs and policies can influence that behavior.

The economic view of employment has important implications for how the employment of individuals with disabilities can be improved as well as how to increase compensation and job quality for those who already work:

1. Increased employment and better jobs for individuals with disabilities are not the ultimate objective, but rather a means to:

- improving the incomes and economic well-being of those individuals;

- improving the emotional and physical well-being of those individuals; and/or

- reducing their reliance on government and charitable support. 
2. Individuals with disabilities who are not employed believe they are better off in their current situation than under any job offer they could generate. There are essentially three approaches to encouraging them to change that judgment:

- improve the quality of job offers;

- improve their well-being under their best available offer relative to their well-being if not employed by some other means; and

- change their perception about their well-being if employed relative to their well-being if not employed, in favor of their well-being if employed.

3. Employers would hire more workers with disabilities if they believed that the contribution of an additional disabled worker's time, effort, and skills to their firm's revenue were less than the total cost of employing the worker. More hiring can be encouraged by:

- increasing the individual's potential contribution to firm revenue;

- reducing the cost of employing the individual;

- changing employer perceptions about the individual's potential contributions or the costs of employing the individual, in favor of higher contributions and/or lower costs.

All of the public programs and policies described in this report can be characterized as addressing one or more of the above means to improving the employment and well-being of people with disabilities. Our review has, however, identified several key issues and areas where more research is needed to inform policymakers in their efforts to promote the employment of people with disabilities.

\section{The myriad of public programs and policies that affect people with disabilities creates complex and often contradictory incentives for individuals with disabilities.}

The wide range of public and private resources that might assist people with disabilities in obtaining and sustaining employment are rarely integrated. The lack of integration can lead to underuse of useful resources because of a lack of awareness of their availability and/or because the fragmented system is too complicated or requires too much effort to successfully navigate. A lack of service integration can also undermine the effectiveness of supports designed to promote the employment of people with disabilities because the eligibility criteria for some programs or supports might counter the work incentives created by others or otherwise create tradeoffs that make work less attractive to the individual with a disability. A primary example, described in Section III, is the link between eligibility for DI and SSI and eligibility for health insurance. Some of those who would rather work than receive cash benefits from DI or SSI might be prevented from doing so by lack of health insurance coverage.

There have been important recent efforts by policymakers to address the patchwork system of support services available to people with disabilities. As described in Section VI, several primary purposes of the President's Task Force are to assess existing Federal programs and policies, promote greater coordination among these programs, and reduce their inherent work 
disincentives. An important objective of the SSA and RSA state partnership initiatives is to develop strategies for states to better integrate their programs and policies with the Federal programs. The WIIA has provisions that partially de-link DI and SSI eligibility from health insurance coverage as well as a provision that funds states to provide information about services available to people with disabilities. Although all of these efforts represent a step in the direction of viewing the support system for people with disabilities, and the incentives and disincentives to work created by that system, as a whole, there is still limited understanding of the interactions between programs and policies, of the importance of particular supports to persons with specific types of disabilities, and the effects of these factors on the employment of people with disabilities. The planned evaluations of the major new initiatives should provide important new information that will improve our understanding of these issues.

Currently, there is little understanding of how those with disabilities who are employed overcome the challenges of their disabilities, in and out of the workplace, and how the challenges and methods of overcoming them vary across individuals and jobs.

A better understanding of why some people with severe disabilities are successfully employed while others are not is critical to the development of effective programs and policies. To what extent can the methods used by those who have overcome their challenges be used by others? To what extent is employment success because of the individual's unique circumstances (e.g., family support, employer support, nature of the individual's job, work experience, etc.)? We found little information about the determinants of labor market success, the nature of supports and accommodations that are most critical to that success, and how these differ across persons with different types of disabilities and job requirements.

The importance of ongoing support services and accommodations deserves special attention. Examples include personal assistance services, services from AT, transportation and communication services, supported employment, and management of chronic illnesses - both physical and mental. There is a tendency for employment research to focus, instead, on one-time services that help the individual enter employment in the first place or return to work after disablement. There is, however, growing evidence that many individuals with disabilities, especially those with chronic illness, rely heavily on continuing support services to maintain employment. More emphasis is needed in understanding the importance of such services to employment.

Few public programs and policies focus on keeping workers who become disabled from leaving employment and assisting these individuals during their transition.

At the onset of a disability, a worker must make a number of decisions weighing the costs and benefits of: supports, rehabilitation, and training needed to continue working, expected long-run earnings, income and in-kind benefits that could be received from public and private income support programs, along with a host of other factors. Our review indicates that there are few public resources for such individuals that facilitate or create incentives to pursue employment. As noted above, the primary income support programs for people with disabilities are designed to provide long-term assistance. The five-month no-work requirement before becoming eligible and the long application process discourage individuals from seeking assistance from these programs on a temporary basis during the period that they are adapting to their disability. In 
addition, access to public VR and other employment programs might only become available after the individual has become eligible for DI or SSI.

Private disability insurance programs often have disability management components that seek to reduce the impact of the disabling, or potentially disabling, health condition on the employment and earnings of the individual following onset. No analogous resources exist in the public sector for individuals who do not have access to them through their employers. It is possible that public income and return-to-work assistance that is temporary in nature and focused on adaptations to work during and immediately following the onset of disability might be cost-effective in the long-run if they reduce the number of individuals who become long-term participants of the DI and SSI programs. Provisions within the WIIA that permit demonstration projects among presumptively-eligible applicants might allow SSA to test this hypothesis.

\section{Research and programs that help reduce employer uncertainty about the productivity and costs of potential employees with disabilities are needed.}

Most of the programs and policies affecting the employment of people with disabilities directly affect the individual's labor supply decision. Far fewer address the issues faced by employers when making hiring decisions with respect to people with disabilities. Those issues relate to the potential additional costs and reduced productivity of potential employees with disabilities and greater uncertainty regarding costs and productivity compared to job candidates without disabilities. Although the ADA mandates that employers ignore disability status if it is not relevant to the performance of the job, it does nothing to reduce the greater uncertainty associated with job candidates with disabilities. As long as equally-qualified candidates without disabilities are available, all else being equal, they will be preferred by employers over candidates with disabilities solely because of the greater perceived risk associated with those with disabilities.

There is a general lack of access to information on the effectiveness of existing programs and policies designed to improve the employment potential of persons with disabilities or prevent the loss of employment potential because of impairment.

In conducting our review of the public programs and policies that affect the employment of people with disabilities, we conducted an extensive search for evidence of the effects of these programs and policies on employment. In many cases, we were unable to find any rigorous evaluations of the effects on employment, let alone analyses of the costs and benefits. Rigorous evaluations often are not possible because of problems that are difficult to surmount, including:

- sample sizes that are not large enough or not large enough to focus on specific subgroups of interest;

- difficulties in establishing appropriate comparison or control groups, to establish outcomes under alternative policies;

- problems in measuring outcomes and baseline characteristics of critical importance to outcomes (e.g., motivation); and 
- the extended lengths of time required to analyze impacts (some interventions require several years).

Another reason for the lack of information is limited funding for the research. Many programs, particularly those at the State or local level, would rather spend their resources on serving individuals than on conducting studies to evaluate how effective their services actually are. In some situations, programs might have an incentive not to conduct evaluations if the findings are likely to demonstrate limited or no effectiveness.

In addition, the evaluations that are conducted often do not consider the effects of incentives on the success or failure of the particular intervention or the interaction of the intervention with other existing programs, policies, and incentive structures. Services that promote employment are likely to be much more successful if the client has a strong financial or other motivation to become employed and if the relevant labor market is strong. Many such services might be much more effective than past studies have indicated if clients had stronger incentives to become employed and/or if the labor market were stronger. The problem is that most studies do not provide information on how such factors are likely to influence the efficacy of the intervention.

A final issue relates to access to the information and studies that do exist. Although we have noted our inability to find evidence of effectiveness for a number of large programs and policies, in some cases the information might exist. As is apparent from this review, research on the employment of people with disabilities crosses a number of Federal and State agencies and many different academic and professional disciplines. As a result, relevant information on the effectiveness of particular programs and policies is unavailable in a centralized, easy to access format.

In sum, better information about the effectiveness of existing strategies and easy access to that information by program administrators and public policymakers are needed if existing programs and policies designed to promote employment are to be improved and better strategies developed in the future. 


\section{References}

Acemoglu, D. and Angrist, J. (1998). "Consequences of Employment Protection: The Case of the Americans with Disabilities Act” (MIT working paper). Cambridge, MA: Massachusetts Institute of Technology.

Adams, M. and Beatty, P. (1998). "Consumer-Directed Personal Assistance Services: Independent Living, Community Integration, and the Vocational Rehabilitation Process." Journal of Vocational Rehabilitation, 10, 93-101.

ADAPT (1998). "A Community-Based Alternative to Nursing Homes and Large Institutions for People with Disabilities” [online]. Access date: March 16, 2000. Available: http://www. adapt.org/casaintr.htm.

Administration for Children and Families (2000). "Low-Income Home Energy Assistance Program: Applying for Assistance.” Washington, D.C.: Department of Health and Human Services [online]. Access date: March 16, 2000. Available:http://www.acf.dhhs.gov/ programs/liheap/start.htm.

Baldwin, M. and Johnson, W. G. (1992). Labor Market Discrimination against People with Disabilities. Greenville, NC: East Carolina University.

Baldwin, M., Flacco, P., and Zeager, L. (1991). Disabilities, Uncertainty, and Wages: Evidence from the SIPP. Greenville, NC: East Carolina University.

Baldwin, M. L., Zeager, L. A., and Flacco, P. R. (1994). “Gender Differences in Wage Losses from Impairments: Estimates from the Survey of Income and Program Participation." Journal of Human Resources, 29(3), 865-887.

Bartel, A. and Taubman, P. (1979). Health and Labor Market Success: The Role of Various Diseases. The Review of Economics and Statistics, Vol. 61(1), 1-8.

Bound, J. (1989). "The Health and Earnings of Rejected Disability Insurance Applicants." American Economic Review, 79, 482-503.

Bound, J. and Burkhauser, R. V. (Forthcoming). "Economic Analysis of Transfer Programs Targeted on People with Disabilities." Handbook of Labor Economics. Amsterdam: Elsevier Science.

Brady, H. E., Meyers, M., and Luks, S. (1998). "The Impact of Child and Adult Disabilities on the Duration of Welfare Spells" (working paper). University of California, Berkley.

Bruyère, S. and Horne, R. (1999). Disability Employment Policies and Practices in U.S. Federal Government Agencies, Executive Summary. Report by the Presidential Task Force on Employment of Adults with Disabilities. Ithaca, NY: Cornell University, School of Industrial Relations-Extension Division, Program on Employment and Disability. 
Bureau of Labor Statistics, Employee Benefits Survey (1996). Employee Benefits in Small Private Industry Establishments [online]. Access date: March 16, 2000. Available: http://www.bls.gov/ebshome.htm.

(1997). Employee Benefits in Medium and Large Private Industry Establishments [online]. Access date: March 16, 2000. Available: http://www.bls.gov/ebshome.htm.

Burkhauser, R. V. and Daly, M. (1995). "Employing People with Disabilities: What to Expect from the Americans with Disabilities Act," Cross-National Studies in Aging Program Project Paper No. 21. Syracuse, NY: Syracuse University.

Burkhauser, R. V. and Wittenburg, D. C. (1996). "How Current Disability Transfer Policies Discourage Work: Analysis from the 1990 SIPP." Journal of Vocational Rehabilitation, 7, 9-27.

Burkhauser, R. V., Butler, J. S., and Weathers II, Robert R. (1999). How Policy Variables Influence the Timing of Social Security Disability Insurance Applications. Ithaca, NY: Cornell University.

Burkhauser, R. V., Daly, M. C., and Houtenville, A. J. (1999). How Working Age People with Disabilities Fared over the 1990s Business Cycle, Draft. Ithaca, NY: Cornell University and San Francisco, CA: Federal Reserve Bank of San Francisco.

Burtless, G. (1985). "Are Targeted Wage Subsidies Harmful? Evidence from a Wage Voucher Experiment." Industrial and Labor Relations Review, 39(1).

Butler, R. J., and Worrall, J. D. (1985). "Work Injury Compensation and the Duration of Nonwork Spells.” The Economic Journal, 95, 714-724.

Chirikos, T. and Nestel, G. (1981). Impairment and Labor Market Outcomes: A Cross-Sectional and Longitudinal Analysis. In H. Parnes (Ed[s].), Work and Retirement. Cambridge, MA: MIT Press.

Chirikos, T. N. (1991). “The Economics of Employment.” The Milbank Quarterly, 69 (Supplements 1/2), 150-179.

Committee on Ways and Means, and House of Representatives, U.S. (1998). 1998 Green Book. Washington, D.C.: U.S. Government Printing Office.

Curington, W. P. (1993). "Compensation for Permanent Impairment and the Duration of Work Absence: Evidence from Four Natural Experiments." Journal of Human Resources, 29(3), 888-910.

Degener, T. (1992). Personal Assistant Service Programs in Germany, Sweden, and the USA. The World Institute on Disability.

DeLeire, T. (1997). "The Wage and Employment Effects of the Americans with Disabilities Act" (working paper). University of Chicago. 
DeWitt, J. (1991). “The Role of Technology in Removing Barriers." Milbank Memorial Fund Quarterly, 313-332.

Dykacz, J. (1998). "Return of Disabled-Worker Beneficiaries to the DI Program: Some Insights from the New Beneficiary Follow-up." Social Security Bulletin, 61, 3-11.

Egley, L. (1994). New Federal PC Option PAS Funding Rules: Summary. World Institute on Disability.

Federal Register (1999). Notices, 64, (205), 57506-57512 (October 25). From the Federal Register Online via GPO Access [http://www.access.gpo.gov/su_docs/] [DOCID: fr25oc99-115].

Friedland, R. B. and Evans, A. (1996). "People with Disabilities: Access to Health Care and Related Benefits." In Mashaw et al. (Eds.), Disability Work and Case Benefits. Kalamazoo, MI: Upjohn Institute.

General Accounting Office (1993). Vocational Rehabilitation: Evidence for Federal Program's Effectiveness is Mixed (GAO/PEMD-93-19). Washington, D.C.: Program Evaluation and Methodology Division.

(1996a). SSA Disability: Program Redesign Necessary to Encourage Return to Work, (GAO/HEHS-96-62). Washington, D.C.: Health, Education, and Human Services Division.

(1996b). Vocational Rehabilitation: VA Continues to Place Few Disabled Veterans in Jobs (GAO-HEHS-96-155). Washington, D.C.: Health, Education, and Human Services Division.

(1996c). PASS Program: SSA Work Incentive for Disabled Beneficiaries Poorly Managed (GAO/HEHS-96-51). [online] Access date: February 7, 2000. Available: http://www.access.gpo.gov.

(1997). Social Security: Disability Programs Lag in Promoting Return to Work (GAO/HEHS-97-46). Washington, D.C.: Health, Education, and Human Services Division.

(1998). Social Security Disability Insurance: Factors Affecting Beneficiaries' Return to Work (GAO/T-HEHS-98-230). Washington, D.C: Health, Education, and Human Services Division.

Gruber, Jonathan (1999). Disability Insurance Benefits and Labor Supply. Cambridge, MA: Massachusetts Institute of Technology and National Bureau of Economic Research.

Hanushek, E. A., Kain, J. F., and Rivkin, S. G. (1998). “Does Special Education Raise Academic Achievement for Students with Disabilities?” (working paper). 
Haveman, R. and Wolfe, B. (1995). Succeeding Generations: On the Effects of Investments in Children. NY: Russell Sage Foundation.

Haveman, R., Wolfe, B., and Warlick, J. (1987). Behavioral Responses to Social Security Retrenchment: Estimate from a Trichotomous Choice Model (Reprinted from the Conference on Economic Development and Social Welfare, 1987, 343-367). Madison, WI: University of Wisconsin Madison, Institute for Research on Poverty.

Haveman, R. H. and Wolfe, B. L. (1984). "Disability Transfers and Early Retirement: A Causal Relationship." Journal of Public Economics, 24, 47-66.

Hayward, B. (1998). "Longitudinal Study of the Vocational Rehabilitation Service Program Third Interim Report: Characteristics and Outcomes of Former VR Consumers with an Employment Outcome." [online]. Access date: March 15, 2000. Available: http://www.rti.org/publications/pubabs.cfm?PUB_ID=245.

Hayward, B. J. and Tashjian, M. D. (1996). "Longitudinal Study of the Vocational Rehabilitation Service Program Second Interim Report: Characteristics and Perspectives of Vocational Rehabilitation Consumers." [online]. Access date: March 15, 2000. Available: http://www.rti. org/publications/pubabs.cfm?PUB_ID=246.

Health Care Financing Administration (1998). A Profile of Medicare. Washington, D.C.: Department of Health and Human Services.

Henessey, J. C., and Muller, L. S. (1994). Work Efforts of Disabled-Worker Beneficiaries: Preliminary Findings from the New Beneficiary Followup Survey. Social Security Bulletin, 57(3), 42-51.

(1995). "The Effect of Vocational Rehabilitation and Work Incentives on Helping the Disabled-Worker Beneficiary Back to Work.” Social Security Bulletin, 58(1) Spring 1995.

Horn, L. (1999). Students with Disabilities in Postsecondary Education: A Profile of Preparation, Participation, and Outcomes (June, NCES 1999-187). Report prepared for the U.S. Department of Education.

Howton-Ford, L. (1995). Providing Employment Support for People with Long-Term Mental Illness. Baltimore, MD: Paul Brookes Publishing.

Illinois Industrial Commission (2000). History of Illinois Law. [on-line]. Access date: March 16, 2000. Available: http://www.state.il.us/agency/iic/history.htm.

Internal Revenue Service (1999). Earned Income Credit (Publication 596). Washington, D.C.: U.S. Department of the Treasury.

Job Accommodation Network (1998). Accommodation Benefit/Cost Data Tabulated through June 30, 1998. URL: http://janweb.icdi.wvu.edu/english/pubs/Statistics/ BenCosts698.html. 
Johnson, A. and Meckstroth, A. (1998). Ancillary Services to Support Welfare to Work. Report prepared for the Office of the Assistance Secretary for Planning and Evaluation, U.S. Department of Health and Human Services. Princeton, NJ: Mathematica Policy Research, Inc.

Johnson, W. G. and Lambrinos, J. (1985). "Wage Discrimination Against Handicapped Men and Women." Journal of Human Resources, 20, 264-277.

Johnson, W. G. and Ondrich, J. I. (1990). "The Duration of Post-injury Absences from Work." The Review of Economics and Statistics, 72(4), 578-586.

Kaye, H. S. (1998). Vocational Rehabilitation in the United States. Disability Statistics Abstract (20). Washington, D.C.: U.S. Department of Education, National Institute on Disability and Rehabilitation Research.

(2000). Computer and Internet Use Among People with Disabilities. Disability Statistics Report (13). Washington, D.C.: U.S. Department of Education, National Institute on Disability and Rehabilitation Research.

Kennedy, J. (1991). "Policy and Program Issues in Providing Personal Assistance Services." In R-P.a. WID (Ed[s].), Personal Assistance Services: A Guide to Policy and Action. Oakland, CA: World Institute on Disability, InfoUse, Western Consortium for Public Health.

(1993). "Policy and Program Issues in Providing Personal Assistance Services." Journal of Rehabilitation, 3, 17-23.

(1998). "Estimating the Size of the Adult Population Needing Personal Assistance Services: Implications for National Disability Policy.” Journal of Disability Policy Studies, 9(1), 7-30.

Kennedy, J., LaPlante, M. P., and Kaye, H. S. (1997). Need for Assistance in the Activities of Daily Living. Disability Statistics Abstract (18). Washington, D.C.: U.S. Department of Education, National Institute on Disability and Rehabilitation Research.

Kimmich, M. H. and Godfrey, T. (1991). New Models for the Provision of Personnel Assistance Services: Final Report (Grant No. G008720129-89). Human Services Research Institute.

Krause, J. S. and Anson, C. A. (1996). "Self-Perceived Reasons for Unemployment Cited by People with Spinal Cord Injury: Relationship to Gender, Race, Age, and Level of Injury." Rehabilitation Counseling Bulletin, 39(3), 217-227. 
Kreider, B. (1994). "Labor Force Responsiveness to Social Security Disability Insurance: A Joint Model of Applications to DI, Income, and Income Growth" (working paper). University of Wisconsin-Madison.

Kreuger, A. and Kruse, D. (1995). "Labor Market Effects of Spinal Cord Injuries in the Dawn of the Computer Age" (working paper). Cambridge, MA: National Bureau of Economics.

Kreuger, A. B. (1990). "Workers' Compensation Insurance and the Duration of Workplace Injuries" (NBER Working Paper 3253).

Lando, M., Coate, M., and Kraus, R. (1979). "Disability Benefit Applications and the Economy.” Social Security Bulletin, 42, 3-10.

LaPlante, M., Kennedy, J., and Trupin, L. (1996). Income and Program Participation of People with Work Disabilities. Disability Statistics Report (9). Washington D.C.: U.S. Department of Education, National Institute on Disability and Rehabilitation Research.

LaPlante, M. P., Hendershot, G. E., and Moss, A. J. (1997). "The Prevalence of Need for Assistive Technology Devices and Home Accessibility Features." Technology and Disability, 6, 17-28.

Litvak, S. (1991a). "Size and Characteristics of the PAS User Population.” In R.-P.a. WID (Eds.), Personal Assistance Services: A Guide to Policy and Action. Oakland, CA: World Institute on Disability, InfoUse, Western Consortium for Public Health.

(1991b). "Examples of Programs Designed to Maximize Recipient Management of Their Own Service." In R.-P.a. WID (Eds.), Personal Assistance Services: A Guide to Policy and Action. Oakland, CA: World Institute on Disability, InfoUse, Western Consortium for Public Health.

(1991c). "State and Federal Funding Sources for PAS.” In R.-P.a. WID (Eds.), Personal Assistance Services: A Guide to Policy and Action . Oakland, CA: World Institute on Disability, InfoUse, Western Consortium for Public Health.

(1994). Personal Assistance Services. Unpublished manuscript.

(Undated). "Financing Personal Assistance Services: Federal and State Legislation and Revenue Enhancing Options." In R.-P.a. WID (Ed[s].), Personal Assistance Services: A Guide to Policy and Action. Oakland, CA: World Institute on Disability, InfoUse, Western Consortium for Public Health.

Litvak, S. and Kennedy, J. (1991). Policy Issues Affecting the Medicaid Personal Care Services Optional Benefit (HHS-100-89-0025). U.S. Department of Health and Human Services (HHS), Assistant Secretary for Planning and Evaluation (ASPE): Research and Training Center on Public Policy in Independent Living, World Institute on Disability (NIDRR grant \#H133B00006-91). 
Louis Harris and Associates Inc. (1987). The ICD Survey II: Employing Disabled Americans. Washington, D.C. International Center for the Disabled with the National Council on the Handicapped and the President's Committee on Employment of the Handicapped.

(1994). 1994 National Organization on Disability/Harris Survey of Americans with Disabilities. New York: National Organization on Disability.

(1998). 1998 National Organization on Disability/Harris Survey of Americans with Disabilities. New York: National Organization on Disability.

Luft, H. (1975). The Impact of Poor Health on Earnings. The Review of Economics and Statistics, 57(1), 43-57.

Mank, D., Cioffi, A. and Yovanoff, P. (1998). "Employment Outcomes for People with Severe Disabilities: Opportunities for Improvement.” Mental Retardation, 36(3), 205-216.

McNeil, J. M. (1993). Americans with Disabilities: 1994-95. (Current Population Reports, Household Economic Studies). Washington, D.C.: U.S. Department of Commerce, Economics and Statistics Administration.

(1997). Americans with Disabilities: 1994-1995 (Current Population Reports, Household Economic Studies.) Washington, D.C.: U.S. Department of Commerce, Economics and Statistics Administration.

Mendelsohn, S. and Goodman, S. (1999). "U.S. Department of Education Tells Assistive Technology Funding and Systems Change Project: Assistive Technology Purchased for Students Receiving Special Education Services Can Be Used To Facilitate Transition into Adult Services and Productive Adult Life" [online]. Access Date: December 14, 1999. Available: http://www.ucpa.org/html/innovative/atfsc/students.html.

Meyer, B. D., Viscusi, W. K., and Durbin, D. L. (1991). "Workers' Compensation and Injury Duration: Evidence from a Natural Experiment" (working paper). Northwestern University.

Moffitt, R. and Wolfe, B. (1992). "The Effect of the Medicaid Program on Welfare Participation and Labor Supply." Review of Economics and Statistics, 124(4), 615-626.

Muller, S. (1992). "Beneficiaries Who Work and Their Experience under Program Work Initiatives." Social Security Bulletin, 55(2). Summer 1992, 2-19.

Muller, S., Scott, C., and Bye, B. (1996). "Labor Force Participation and Earnings of SSI Disability Recipients: A Pooled Cross-Sectional Time Series Approach to the Behavior of Individuals." Social Security Bulletin, 59(1), 22-42.

National Academy of Social Insurance (1994). "Rethinking Disability Policy: The Role of Income, Health Care, Rehabilitation and Related Services in Fostering Independence." 
(1996a). Balancing Security and Opportunity: The Challenge of Income Disability Policy. Report of the Disability Policy Panel. Washington, D.C.

(1996b). The Environment of Disability Income Policy: Programs, People, History and Context. Disability Policy Panel Interim Report. Washington, D.C.

National Council on Disability (1993). Study on the Financing of Assistive Technology Devices and Services for Individuals with Disabilities (A Report to the President and Congress). Washington, D.C.: National Council on Disability.

(1997). National Disability Policy: A Progress Report (A Report to the President and Congress). Washington, D.C.: National Council on Disability.

National Institute on Disability and Rehabilitation Research (1994). "Supported Employment for People with Severe Mental Retardation.” Rehab Brief. Washington D.C.: U.S.

Department of Education, National Institute on Disability and Rehabilitation Research.

National Underwriter Company, The (1994). Social Security Manual: 1994 Edition. Cincinnati, $\mathrm{OH}$.

Noble, J. H., Honberg, R. S., Hall, L. L., and Flynn, L. M. A Legacy of Failure: The Inability of the Federal-State Vocational Rehabilitation System to Serve People with Severe Mental Illness [online]. Access date: March 16, 2000. Available: http://www.nami.org/update/ legacy.htm.

O'Shaughnessy, C. and Butler, A. D. (1998). Rehabilitation Act: Major Programs, $105^{\text {th }}$ Congress Legislation, and Funding. Washington, D.C.: Congressional Research Service, Library of Congress.

Oi, W. Y. (1991). "Disability and a Workfare-Welfare Dilemma." In C. Weaver (Ed[s].), Disability and Work. Washington, D.C.: AEI Press.

Parsons, D. O. (1980). “The Decline of Male Labor Force Participation.” Journal of Political Economy, 88, 117-134.

Pellar, J. and Shaner, H. (1998). "Medicaid Eligibility Standards for Low-Income Families and Children: State Implementation of the Personal Responsibility and Work Opportunity Reconciliation Act of 1996." Prepared for the Health Care Financing Administration, Department Health and Human Services. Washington, D.C.: American Public Welfare Association.

President's Committee on Mental Retardation (1998). A Better Place: The Contribution of Americans with Mental Retardation to Our Nation's Workforce, 1998 Report to the President. Washington, D.C.: U.S. Department of Health and Human Services, Administration for Children and Families.

Presidential Task Force on the Employment of Adults with Disabilities (1999). Re-Charting the Course: If Not Now, When? The Second Report of the Presidential Task Force on 
Employment of Adults with Disabilities. [online]. Access date: March 16, 2000.

Available: http://www.dol.gov/dol/_sec/public/programs/ptfead/rechart.htm.

President's Committee on Employment of People with Disabilities. [online] Access date: March 16, 2000. Available: http://www50.pcepd.gov/pcepd/business/worksite.htm.

Richmond, G. W., Beatty, P., Tepper, S., and DeJong, G. (1997). “The Effect of ConsumerDirected Personal Assistance Services on the Productivity Outcomes of People with Disabilities.” Journal of Rehabilitation Outcomes Measures, 1(4), 48-51.

Rossi, R., Herting, J., and Wolman, J. (1997). Profiles of Students with Disabilities as Identified in NELS: 88. Washington, D.C.: U.S. Department of Education, National Center for Educational Statistics.

Rupp, K. and Scott, C. (1998). "Determinants of Duration on the Disability Rolls and Program Trends." In K. Rupp and D. Stapleton (Eds.) Growth in Income Entitlement Benefits for Disability: Explanations and Policy Implications. Kalamazoo, MI: The Upjohn Institute.

Sale, P., Revell, W. G., West, M., and Kregel, J. (1992). "Achievements and Challenges II: An Analysis of 1990 Supported Employment Expenditures," JASH, 17(4), 236-246.

Scheid, T. L. (1998). “The Americans with Disabilities Act, Mental Disability, and Employment Practices." The Journal of Behavioral Health Services and Research, 25(3), 312-324.

Seelman, K. D. (1998). "Blueprint for the Millennium: An Analysis of Regional Hearings on Assistive Technology for People with Disabilities" United Cerebral Palsy Associations. Report prepared for The National Institute on Disability and Rehabilitation Research. [online]. Access date: December 6, 1999. Available: http://www.ucpa.org/html/ innovative/atfsc/bluemil.html.

Social Security Administration (1998c). Social Security Bulletin: Annual Statistical Supplement Washington, D.C.: Office of Research, Evaluation, and Statistics.

(1998d). Workers' Compensation [online]. Available: http://www.ssa.gov.

(1999a). Current Operating Statistics [online]. Access Date: November 29, 1999. Available: http://www.ssa.gov/statistics/cos/t1b7.pdf, http:/www.ssa.gov/statistics/cos/ t1b2.pdf (DI statistics), and http://www.ssa.gov/statistics/cos/t2a1.pdf (SSI statistics).

(1999b). Quarterly Report on SSI Disabled Workers and Work Incentive Provisions. Baltimore, MD: Office of Research, Evaluation, and Statistics.

(1999d). Disability Notes, Spring 1999. [online]. Access Date: December 1, 1999. Available: http://www.ssa.gov/odhome/dinote21.htm.

(1999e). Redbook on Work Incentive Provisions. [online] Access Date: December 8, 1999. Available: http://www.ssa.gov/work/redbook99.html. 
(1998a). Supplemental Security Income Annual Report. Baltimore, MD: Office of Research, Evaluation, and Statistics.

Social Security Administration. (1998b). Employment and Rehabilitation Programs [online]. Available: http://www.ssa.gov.

(1999c). Supplemental Security Income Annual Statistical Report. Baltimore, MD: Office of Research, Evaluation, and Statistics.

Society for Human Resource Management (1998). The ADA at Work: Implementation of the Employment Provisions of the Americans with Disabilities Act. Alexandria, VA.

SRI International (1997). The National Longitudinal Transition Study: A Summary of Findings [online]. Access date: March 16, 2000. Available: http://www.sri.com/policy/cehs/nlts/ nltssum.html.

Stapleton, D. et al. (1995). Labor Market Conditions, Socioeconomic Factors and the Growth of Applications and Awards for SSDI and SSI Disability Benefits (Final Report) (HHS Contract No. 100-0012). Washington, D.C.: DHHS Office of the Assistant Secretary for Planning and Evaluation and The Social Security Administration.

Stapleton, D., Livermore, G., Allen, V., and Tucker, A. (1999). Research on Employment Supports for People with Disabilities. Final Report prepared for U.S. Department of Health and Human Services, Assistant Secretary for Planning and Evaluation. Washington, D.C.: The Lewin Group.

Stapleton, D., Livermore, G., Scrivner, S., Tucker, A., and Wittenburg, D. (1998). Exploratory Study of Health Care Coverage and Employment of People with Disabilities: Final Report. Final Report to the Office of the Assistant Secretary for Planning and Evaluation, U.S. Department of Health and Human Services. Washington, D.C.: The Lewin Group.

Stapleton, D. C. and Livermore, G. A. (1996). Impairment Trends in Applications and Awards for SSA's Disability Programs, Journal of Vocational Rehabilitation. Vol. 7, 93-115.

Stapleton, D. C., Wittenburg, D, Fishman, F., and Livermore G. (2000). Transitions from AFDC to SSI Prior to Welfare Reform. Final report prepared for the Social Security Administration. Washington, D.C.: The Lewin Group.

Stoddard, S., Jans, L., Ripple, J., and Kraus, L. (1998). Chartbook on Work and Disability in the United States, 1998. An InfoUse Report. Washington, D.C.: U.S. Department of Education, National Institute on Disability and Rehabilitation Research.

Strong, M. F. (1994). Optimum Models of Supported Employment for People with Psychiatric Disabilities: Final Administrative Report. Oakland, CA: Berkeley Planning Associates.

Study Group, Inc., The (1998). Meeting the Needs of Youth with Disabilities: Handbook on Supplemental Security Income Work Incentives and Transition Students. Minneapolis, MN: National Transition Network, Institute on Community Integration. 
Study of End-Stage-Renal-Disease (ESRD) Dialysis Patients. Madison, WI: Medical Education Institute, University Research Park, and Department of Pediatric Nephrology, University of Wisconsin.

Thompson, T., Holcomb, P., Loprest, P., and Brennan, K. (1998). State Welfare-to-Work Policies for People with Disabilities. Report prepared for the U.S. Department of Health and Human Services, Office of the Assistant Secretary for Planning and Evaluation. Washington, D.C.: Urban Institute.

Urban Institute (1996a). Personal and Family Challenges to Successful Transition from Welfare to Work. Washington, D.C.

(1996b). Designing Welfare-to-Work Programs for Families Facing Personal or Family Challenges: Lessons from the Field. Washington, D.C.

Urban Institute (1996c). Welfare-to-Work Options for Families Facing Personal and Family Challenges: Rationale and Program Strategies. Washington, D.C.

U.S. Department of Education. Secondary Education and Transitional Services for Youth with Disabilities. Catalog of Federal Domestic Assistance. No. 84, 158. (2000). Individuals with Disabilities Education Act of 1997. Access date: March 16, 2000. Available: http://www.ed.gov/offices/OSERS/IDEA/ IDEA. (1996b). Rehabilitation Services Administration (RSA) Programs: Basic Vocational Rehabilitation Services [on-line]. Available: http://www.ed.gov/offices/OSERS/RSA/ PGMS/cil.html.

U.S. Department of Education OSEP (1998). To Assure the Free Appropriate Public Education of All Children with Disabilities, Twentieth Annual Report to Congress on the Implementation of the Individuals with Disabilities Education Act. [online]. Access date: March 16, 2000. Available: http://www.ed.gov/ offices/OSERS/OSEP/OSEP98AnlRpt/.

U.S. Department of Veterans Affairs. (1998). Federal Benefits for Veterans and Dependents. Washington, D.C.

Wagner, M. and Blackorby, J. (1996). “Transition from High School to Work or College: How Special Education Students Fare.” Special Education for Students with Disabilities, 6(1), $103-120$.

Ward, C. (1992). Listening to the Experts: The Views of Working-Age Consumers with Disabilities (Results of the Fourth Year of a Five Year Study). Electronic Industry Foundation.

Wehman, P., Hill, J., and Koehler, F. (1979). Helping Severely Handicapped People Enter Competitive Employment. AAESPH Review, 4, 274-290. 
Wehman, P., Revell, W. G., Kregel, J. et al. (1991). "Supported Employment: An Alternative Model for Vocational Rehabilitation of People with Severe Neurological, Psychiatric, or Physical Disability," Archives of Physical Medicine and Rehabilitation, 72, 101-105.

West, M., Revell, W. G., and Wehman, P. (1992). “Achievements and Challenges I: A Five-Year Report on Consumer and System Outcomes from the Supported Employment Initiative." JASH, 17(24), 227-235.

Wittenburg, D., Fishman, M., Golden, T., and Allen, V. (2000) School-to-Work Transitions by Youths with Disabilities: Background and Policy Research Issues, Draft Report for the Cornell University and Lewin Group Rehabilitation Research and Training Center.

Wolfe, B. L. and Hill, S.C. (1995). "The Effect of Health on the Work Effort of Single Mothers." Journal of Human Resources, 30(1), 42-62.

World Institute on Disability and Rutgers University (Undated). The Need for Personal Assistance (G008720134 (NIDRR)). Rutgers University Bureau of Economic Research, Faculty of Arts and Sciences.

Yelin, E. H. and Katz, P. P. (1994a). Labor Force Trends among Persons with and without Disabilities. Monthly Labor Review, Vol. 117(10), 36-42.

(1994b). "Making Work More Central to Work Disability Policy." The Milbank Quarterly, 72(4), 593-619.

Yelowitz, A. (1995). "The Medicaid Notch, Labor Supply and Welfare Participation: Evidence from Eligibility Expansions.” Quarterly Journal of Economics, 110(4), 909-939.

(1996). "Using the Medicare Buy-in Program to Estimate the Effect of Medicaid on SSI Participation" (working paper). University of California - Los Angeles.

(1998). "Why Did the SSI-Disabled Program Grow So Much? Disentangling the Effect of Medicaid," in K. Rupp and D. Stapleton (Eds.), Growth in Income Entitlement Benefits for Disability: Explanations and Policy Implications. Kalamazoo, MI: The Upjohn Institute. 

For more information about the Cornell RRTC contact:

Susanne Bruyère, Ph.D.

Project Director

Cornell University

106 ILR Extension Building

Ithaca, NY 14853-3901 tel (607) 255-7727

fax (607) 255-2763

TDD (607) 255-2891

e-mailsmb23@cornell.edu

web www.ilr.cornell.edu/rrtc 